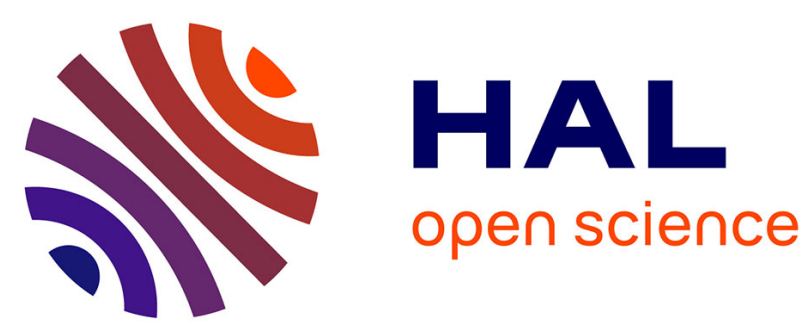

\title{
Inorganic Niobium and Tantalum Octahedral Cluster Halide Compounds with Three-dimensional Frameworks: A Review on their Crystallographic and Electronic Structures
}

Pierric Lemoine, Jean-François Halet, Stéphane Cordier

\section{To cite this version:}

Pierric Lemoine, Jean-François Halet, Stéphane Cordier. Inorganic Niobium and Tantalum Octahedral Cluster Halide Compounds with Three-dimensional Frameworks: A Review on their Crystallographic and Electronic Structures. Structure and Bonding, Springer, 2019. hal-02176884

\section{HAL Id: hal-02176884 \\ https://hal-univ-rennes1.archives-ouvertes.fr/hal-02176884}

Submitted on 8 Jul 2019

HAL is a multi-disciplinary open access archive for the deposit and dissemination of scientific research documents, whether they are published or not. The documents may come from teaching and research institutions in France or abroad, or from public or private research centers.
L'archive ouverte pluridisciplinaire HAL, est destinée au dépôt et à la diffusion de documents scientifiques de niveau recherche, publiés ou non, émanant des établissements d'enseignement et de recherche français ou étrangers, des laboratoires publics ou privés. 


\title{
Inorganic Niobium and Tantalum Octahedral Cluster Halide Compounds with Three-dimensional Frameworks: A Review on their Crystallographic and Electronic Structures
}

\author{
Pierric Lemoine*, Jean-François Halet, and Stéphane Cordier \\ Univ Rennes, CNRS, ISCR - UMR 6226, F-35000 Rennes, France \\ *Email: pierric.lemoine@univ-rennes1.fr
}

\begin{abstract}
This review summarizes the development of the rich crystal and bonding chemistry of facecapped and edge-bridged inorganic niobium and tantalum octahedral cluster halide compounds, with a particular emphasis on those showing three-dimensional cluster frameworks. Discussion is made on varied structures and bonding which are intimately linked to the valence electron concentration, i.e., the number of electrons that held the octahedral metal cluster architecture. Exploration of the literature indicates that apart from $\mathrm{Nb}_{6} \mathrm{l}_{11}$ and derivatives, which show electron-deficient face-capped $\mathrm{M}_{6} \mathrm{X}_{8} \mathrm{X}_{6}^{\mathrm{a}}{ }_{6}$ units, compounds containing edge-bridged $\mathrm{M}_{6} \mathrm{X}_{12}^{\mathrm{i}} \mathrm{X}_{6}^{\mathrm{a}}{ }_{6}$ motifs are the most largely encountered. Closed-shell compounds with a valence electron concentration of 16 are predominant, although a few 15-electron open-shell magnetic compounds or even 14-electron closed-shell species have also been reported. Particularly interesting from a structural point of view is the fashion in which these facecapped and edge-bridged clusters "pack" in crystals. The astonishing diversity of structural types, which are observed, is mainly due to the flexibility of the halogen ligands to coordinate in various manners to metal atoms. However, a rigorous structural analysis of these compounds reveals no close relationship between the valence electron concentration and the variability of the intercluster connections and/or the nature of the counter-ions. Indeed, the main bonding features of these compounds can be understood from the delocalized bonding picture of isolated 'molecular-like' $\mathrm{M}_{6} \mathrm{X}_{8} \mathrm{X}_{6}{ }_{6}$ or $\mathrm{M}_{6} \mathrm{X}_{12}^{\mathrm{i}} \mathrm{X}_{6}{ }_{6}$ clusters.
\end{abstract}

\section{Keywords}

Crystal structure - Electronic effect - Electronic structure · Halide · Inorganic compound · Interatomic distance - Intercluster distance - Ligand - Matrix effect - Metal-metal bond · Niobium - Octahedral cluster - Structure type · Tantalum · Three-dimensional framework - Valence electron concentration

\section{Contents}

1 Introduction

2 Cluster Frameworks of Structural Formula $\left[\mathrm{M}_{6} \mathrm{X}_{8} \mathrm{X}^{\mathrm{a}-\mathrm{a}}{ }_{6 / 2}\right]$

$2.1 \quad \mathrm{Nb}_{6} \mathrm{l}_{11}$-Type (HT and LT forms)

$2.2 \mathrm{CsNb}_{6} \mathrm{l}_{11}$-Type

2.3 Structural Comparison of $\mathrm{Nb}_{6} \mathrm{I}_{11}$ and $\mathrm{CsNb}_{6} \mathrm{I}_{11}$

4 Cluster Frameworks of Structural Formula $\left[\mathrm{M}_{6} \mathrm{X}_{12}^{\mathrm{i}} \mathrm{X}^{\mathrm{a}-\mathrm{a}-\mathrm{a}}{ }_{6 / 3}\right]$ 
Cluster Frameworks of Structural Formula $\left[\mathrm{M}_{6} \mathrm{X}_{12}^{\mathrm{i}} \mathrm{X}^{\mathrm{a}-\mathrm{a}}{ }_{6 / 2}\right]$

5.1 Cluster Compounds with Linear $M-X^{a-a}-M$ Bridges

5.2 Cluster Compounds with Bent $M-X^{-a-a}-M$ Bridges in Cubic Structure

5.3 Cluster Compounds with Bent $M-X^{a-a}-M$ Bridges in Trigonal Structure

5.4 Cluster Compounds with Both Linear and Bent $\mathrm{M}-\mathrm{X}^{\mathrm{a}-\mathrm{a}}-\mathrm{M}$ Bridges

6 Interatomic Distances in Inorganic $\mathrm{Nb}_{6}$ and $\mathrm{Ta}_{6}$ Cluster Halide Compounds with Threedimensional Frameworks

6.1 Cluster Units Based on Face-capped $\mathrm{M}_{6} \mathrm{X}_{8} \mathrm{X}_{6}{ }_{6}$ Building Blocks

6.2 Cluster Units Based on Edge-bridged $\mathrm{M}_{6} \mathrm{X}_{12}{ }_{12} \mathrm{X}_{6}{ }_{6}$ Building Blocks

7 Structural Relationships Between Crystal Structures Based on Hexagonal, Cubic and Trigonal Symmetry

8 Electronic Structure of Niobium and Tantalum Octahedral Cluster Halide Compounds

8.1 Variable VEC of $\mathrm{Nb}_{6} \mathrm{l}_{11}$ and Derivatives

8.2 Electronic Structure of Edge-bridged $\mathrm{M}_{6} \mathrm{X}_{12}^{\mathrm{i}} \mathrm{X}_{6}{ }_{6}$ Clusters

9

Summary

References

\section{Introduction}

Between niobium metal and niobium oxides and halides in their highest oxidation state (i.e., $\mathrm{Nb}_{2} \mathrm{O}_{5}$ and $\mathrm{NbX}_{5}$ ), metal atom cluster-based compounds form a particular class of compounds wherein metal atoms are associated and held together by metal-metal bonds. Such an association leads to welldefined aggregates of low nuclearities such as dimers, trimers, tetramers and octahedra [1-5]. They are separated one from another by a matrix of ligands (i.e., oxygen, halogen or chalcogen) that are bonded to the cluster in terminal $\left(X^{\mathrm{a}}\right)$, edge-bridging or face-capping positions $\left(\mathrm{X}^{\mathrm{i}}\right)$. Locally the metal is in a square pyramidal $\mathrm{NbX}_{4}{ }_{4} \mathrm{X}^{\mathrm{a}}$ arrangement of ligands wherein $\mathrm{Nb}-\mathrm{X}^{\mathrm{i}}$ bonds exhibit a stronger covalent character than the $\mathrm{Nb}-\mathrm{X}^{\mathrm{a}}$ one. Similar clusters are also formed with tantalum and despite a same number of valence electrons, it turns out that less cluster compounds are reported for this element than for its niobium congener. In the present study, we will focus on octahedral cluster halide compounds prepared by solid-state synthesis at high temperature. Resulting compounds are made of niobium or tantalum and are associated with halogen ligands forming predominantly edge-bridged $\mathrm{M}_{6} \mathrm{X}_{12} \mathrm{X}_{6}{ }_{6}$ building blocks, with $\mathrm{M}=\mathrm{Nb}, \mathrm{Ta} ; \mathrm{X}=\mathrm{F}, \mathrm{Cl}, \mathrm{Br}$, and I (Fig. 1, left), except in the case of niobium iodides and some derivative compounds based on face-capped $\mathrm{M}_{6} \mathrm{X}_{8}^{\mathrm{i}} \mathrm{X}_{6}{ }_{6}$ building blocks (Fig. 1, right) which are largely encountered with transition elements from groups 6 and 7 . Within the solid, the building blocks can be either discrete or they can share ligands to form different types of bridges, namely apical-apical, apical-apical-apical, apical-inner, inner-apical that are noted $X^{a-a}, X^{a-a-a}, X^{a-i}, X^{i-a}$ (Fig. 2), respectively, according to the notation developed by Schäfer and Schnering [6]. The cluster building blocks can be viewed as monomers [7] forming polymeric frameworks through the association of ligands. Thanks to the orthogonal disposition of ligands around the clusters, the connectivity can be developed in one-dimensional (1D), bi-dimensional (2D), or three-dimensional (3D) directions. When alkali metals, alkali-earth metals, $p$-block metals and rare-earth metals are used during the synthesis of clusters, they act as counter-cations and the cluster unit building block is negatively charged [8-23]. The size and the charge of the counter-ions as well as the total charge, the nature of halogen and metal atoms of the units are the keystones that govern crystal packing. The average oxidation state of $\mathrm{M}$ in the $\mathrm{M}_{6}$ clusters ranges from +2.67 in $\mathrm{Ta}_{6} \mathrm{Br}_{15}\left(\mathrm{TaBr}_{6}\right)$ to +1.67 in $\mathrm{CsNb}_{6} \mathrm{l}_{11}$. However, the metal atoms cannot be considered independently since overlapping occurs between them leading to metal-metal bonds. Consequently, for a better description of the bonds within the cluster units, one must consider the number of valence electrons that are available to form metal-metal bonds, the so-called valence electron concentration (VEC). It can be simply calculated considering an ionic Zintl-Klemm model with 
a total transfer of electrons from the counter-ions to the cluster and from the cluster to the ligands. The VEC value ranges between 14 as in $\operatorname{Ta}_{6} \mathrm{Br}_{15}\left(\mathrm{TaBr}_{6}\right)$ and 20 as in $\mathrm{CsNb}_{6} \mathrm{l}_{11}$. The VEC value drives the physical properties such as magnetism and absorption in the UV-visible region. Beyond fascinating structures and unusual specific physical properties, some of these cluster-based solid-state compounds are soluble. Solution chemistry not only revealed interesting redox properties enabling to stabilize species with lower VEC values, it also enabled the use of metal clusters as redox active or UVIR blocking building blocks for the design of composites and electrochromic cells [24, 25], nanoparticles [26] or modified electrodes [27], for instance.
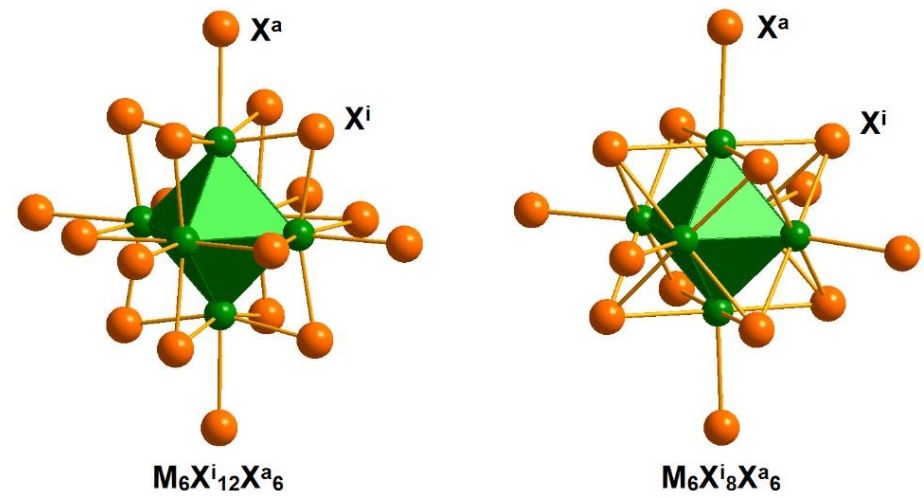

Fig. 1 Representation of the edge-bridged $M_{6} X_{12}^{i} X_{6}^{a}$ (left) and face-capped $M_{6} X_{8}^{i} X_{6}{ }_{6}$ (right) building blocks
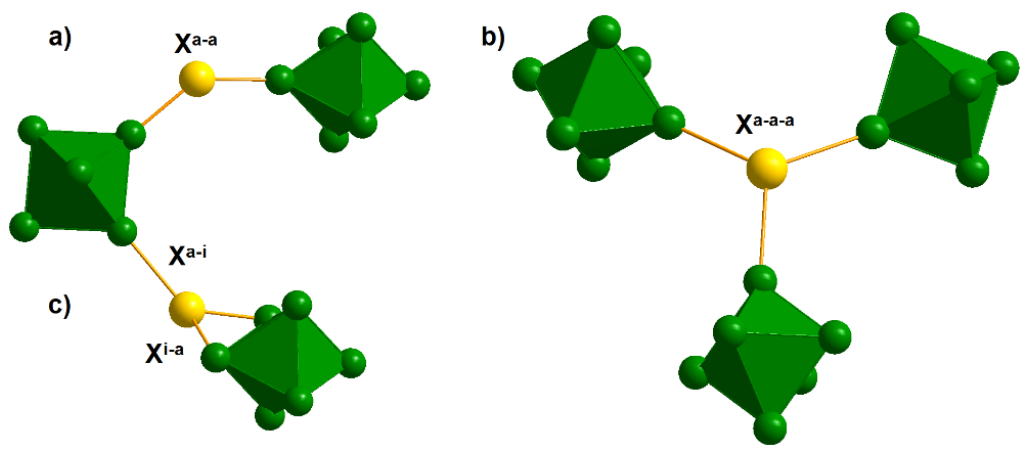

Fig. 2 Representation of the different types of building block bridges encountered in inorganic niobium and tantalum octahedral cluster halide compounds: (a) apical-apical $X^{a-a}$, (b) apical-apical-apical $X^{a-a-a}$, and (c) apical-inner $\mathrm{X}^{\mathrm{a}-\mathrm{i}}$ and inner-apical $\mathrm{X}^{\mathrm{i}-\mathrm{a}}$

Herein, we review the crystal chemistry and electronic structure of inorganic solid-state compounds based on $\mathrm{Nb}_{6}$ and $\mathrm{Ta}_{6}$ cluster halides actively studied earlier in the group of Marcel Sergent enlarged to more contemporary work reported in the literature. The structural richness encountered in this class of compounds is illustrated in Table 1 where a classification with respect to structural network dimensionality, as well as main information of the different structure types, are given. Due to the limited allotted space, solid-state oxy-halides, which constitute an important class of cluster species (see, e.g., [36] and references therein), are excluded, as well as the halide compounds for which the structure is discretely molecular (see, e.g., [37] and references therein). Thus, the following discussion will focus on inorganic solid-state halide compounds containing three-dimensional niobium and tantalum octahedral cluster frameworks through description and analysis of the electronic and steric factors that drive their crystal chemistry and bonding. Unit cell parameters and main interatomic distances of three-dimensional cluster frameworks compounds with complete crystal structure data available in literature are gathered in Tables 2 and 3, respectively. 
Table 1 Main information about structure types reported for inorganic niobium and tantalum octahedral cluster halide compounds

\begin{tabular}{|c|c|c|c|c|c|c|c|c|c|c|}
\hline Structure type & Network & SG stand. ${ }^{a}$ & SG publ. ${ }^{b}$ & Symm. $^{c}$ & SG No. & Centro. $^{d}$ & $\mathrm{VEC}^{\mathrm{e}}$ & Oxi. State $^{f}$ & Published chemical formula & Reference \\
\hline \multicolumn{11}{|l|}{$\left[M_{6} X_{8}{ }_{8} X^{a-a}{ }_{6 / 2}\right]$} \\
\hline $\mathrm{Nb}_{6} \mathrm{l}_{11}(\mathrm{HT})$ & $3 D$ & Pccn & & $\mathrm{O}$ & 56 & Yes & 19 & +1.83 & $\mathrm{Nb}_{6} \mathrm{l}_{11}$ & {$[28]$} \\
\hline $\mathrm{Nb}_{6} \mathrm{l}_{11}(\mathrm{LT})$ & $3 D$ & $\operatorname{Pna}_{1}$ & $P 2_{1} c n$ & $\mathrm{O}$ & 33 & No & 19 & +1.83 & $\mathrm{Nb}_{6} \mathrm{l}_{11}$ & [29] \\
\hline $\mathrm{CsNb}_{6} \mathrm{l}_{11}$ & $3 \mathrm{D}$ & $P 6_{3} 22$ & & $\mathrm{H}$ & 182 & No & 20 & +1.67 & $\mathrm{CsNb}_{611}$ & [9] \\
\hline \multicolumn{11}{|c|}{$\left[\mathrm{M}_{6} \mathrm{X}^{\mathrm{i}}{ }_{10} \mathrm{X}^{\mathrm{i}-\mathrm{a}} 2 / 2 \mathrm{X}^{\mathrm{a}-\mathrm{i}}{ }_{2 / 2} \mathrm{X}^{\mathrm{a}-\mathrm{a}}{ }_{4 / 2}\right]$} \\
\hline $\mathrm{Nb}_{6} \mathrm{Cl}_{14}$ & $3 \mathrm{D}$ & Cmca & $\mathrm{Bbcm}$ & $\mathrm{O}$ & 64 & Yes & 16 & +2.33 & $\mathrm{Nb}_{6} \mathrm{Cl}_{14}$ & {$[30]$} \\
\hline \multicolumn{11}{|l|}{$\left[M_{6} X_{12}^{i} X^{a-a-a}{ }_{6 / 3}\right]$} \\
\hline $\mathrm{Nb}_{6} \mathrm{Cl}_{12} \mathrm{I}_{2}$ & 3D & $P a \overline{3}$ & & $\mathrm{C}$ & 205 & Yes & 16 & +2.33 & $\mathrm{Nb}_{6} \mathrm{Cl}_{12} \mathrm{I}_{2}$ & [31] \\
\hline \multicolumn{11}{|l|}{$\left[M_{6} X^{i}{ }_{12} X^{a-a}{ }_{6 / 2}\right]$} \\
\hline $\mathrm{Nb}_{6} \mathrm{~F}_{15}$ & $3 \mathrm{D}$ & $\operatorname{Im} \overline{3} m$ & & $\mathrm{C}$ & 229 & Yes & 15 & +2.50 & $\mathrm{Nb}_{6} \mathrm{~F}_{15}$ & [32] \\
\hline $\mathrm{CsNb}_{6} \mathrm{Cl}_{8} \mathrm{~F}_{7}$ & $3 D$ & $P m \overline{3} m$ & & C & 221 & Yes & 16 & +2.33 & $\mathrm{Cs}_{1.3} \mathrm{Nb}_{6} \mathrm{Cl}_{8} \mathrm{~F}_{7}$ & [20] \\
\hline $\mathrm{Na}_{2} \mathrm{Nb}_{6} \mathrm{Cl}_{8} \mathrm{~F}_{7}\left(\mathrm{NbF}_{6}\right)$ & $3 D$ & $P m \overline{3} m$ & & C & 221 & Yes & 16 & +2.33 & $\mathrm{Na}_{1.9} \mathrm{Nb}_{6} \mathrm{Cl}_{8} \mathrm{~F}_{7}\left(\mathrm{NbF}_{6}\right)$ & [19] \\
\hline $\mathrm{Ta}_{6} \mathrm{Cl}_{15}$ & $3 D$ & $\operatorname{Ia} \overline{3} d$ & & C & 230 & Yes & 15 & +2.50 & $\mathrm{Ta}_{6} \mathrm{Cl}_{15}$ & [33] \\
\hline $\mathrm{NaNb}_{6} \mathrm{Cl}_{15}$ & $3 D$ & $\operatorname{Ia} \overline{3} d$ & & C & 230 & Yes & 16 & +2.33 & $\mathrm{NaNb}_{6} \mathrm{Cl}_{15}$ & [16] \\
\hline $\mathrm{KNb}_{6} \mathrm{Cl}_{10} \mathrm{~F}_{5}$ & $3 D$ & $\operatorname{Ia} \overline{3} d$ & & $C$ & 230 & Yes & 16 & +2.33 & $\mathrm{~K}_{1.2} \mathrm{Nb}_{6} \mathrm{Cl}_{10} \mathrm{~F}_{5}$ & {$[20]$} \\
\hline $\mathrm{Nb}_{6} \mathrm{Br}_{8} \mathrm{~F}_{7}$ & $3 D$ & $R \overline{3} c$ & & $\mathrm{Tg}$ & 167 & Yes & 15 & +2.50 & $\mathrm{Nb}_{6} \mathrm{Br}_{8.32} \mathrm{~F}_{6.68}$ & [34] \\
\hline $\mathrm{Ta}_{6} \mathrm{Br}_{15}\left(\mathrm{TaBr}_{6}\right)$ & $3 D$ & $R \overline{3} c$ & & $\operatorname{Tg}$ & 167 & Yes & 14 & +2.67 & $\mathrm{Ta}_{6} \mathrm{Br}_{15}\left(\mathrm{TaBr}_{6}\right)_{0.86}$ & [35] \\
\hline $\operatorname{lnNb}_{6} \mathrm{Cl}_{15}$ & $3 D$ & Pmma & & 0 & 51 & Yes & 16 & +2.33 & $\operatorname{lnNb}_{6} \mathrm{Cl}_{15}$ & {$[18]$} \\
\hline \multicolumn{11}{|l|}{$\left[\mathrm{M}_{6} \mathrm{X}^{\mathrm{i}}{ }_{12} \mathrm{X}^{\mathrm{a}}{ }_{2} \mathrm{X}^{\mathrm{a}-\mathrm{a}}{ }_{4 / 2}\right]$} \\
\hline $\mathrm{Li}_{2} \mathrm{Nb}_{6} \mathrm{Cl}_{16}$ & $2 \mathrm{D}$ & Cmca & & 0 & 64 & Yes & 16 & +2.33 & $\mathrm{Li}_{2} \mathrm{Nb}_{6} \mathrm{Cl}_{16}$ & [17] \\
\hline \multicolumn{11}{|l|}{$\left[\mathrm{M}_{6} \mathrm{X}^{\mathrm{i}}{ }_{12} \mathrm{X}^{\mathrm{a}}{ }_{4} \mathrm{X}^{\mathrm{a}-\mathrm{a}}{ }_{2 / 2}\right]$} \\
\hline $\mathrm{Cs}_{2} \mathrm{Nb}_{6} \mathrm{Br}_{5} \mathrm{~F}_{12}$ & $1 \mathrm{D}$ & $\mathrm{Cccm}$ & & 0 & 66 & Yes & 15 & +2.50 & $\mathrm{Cs}_{2.1} \mathrm{Nb}_{6} \mathrm{Br}_{4.73} \mathrm{~F}_{12.27}$ & [21] \\
\hline \multicolumn{11}{|l|}{$\left[M_{6} X^{i}{ }_{12} X^{a}{ }_{6}\right]$} \\
\hline $\mathrm{K}_{4} \mathrm{Nb}_{6} \mathrm{Cl}_{18}$ & OD & $C 2 / m$ & & $M$ & 12 & Yes & 16 & +2.33 & $\mathrm{~K}_{4} \mathrm{Nb}_{6} \mathrm{Cl}_{18}$ & [8] \\
\hline $\mathrm{Cs}_{4} \mathrm{Nb}_{6} \mathrm{l}_{9.5} \mathrm{~F}_{8.5}$ & OD & $\mathrm{C} 2 / \mathrm{m}$ & & M & 12 & Yes & 16 & +2.33 & $\mathrm{Cs}_{4.03} \mathrm{Nb}_{6} \mathrm{l}_{9.42} \mathrm{~F}_{8.58}$ & {$[22]$} \\
\hline $\mathrm{LuNb}_{6} \mathrm{Cl}_{18}$ & OD & $R \overline{3}$ & & $\mathrm{Tg}$ & 148 & Yes & 15 & +2.50 & $\mathrm{LuNb}_{6} \mathrm{Cl}_{18}$ & {$[12]$} \\
\hline $\mathrm{Cs}_{2} \mathrm{EuNb}_{6} \mathrm{Br}_{18}$ & OD & $R \overline{3}$ & & $\mathrm{Tg}$ & 148 & Yes & 16 & +2.33 & $\mathrm{Cs}_{2} \mathrm{EuNb}_{6} \mathrm{Br}_{18}$ & [14] \\
\hline $\mathrm{KGdNb}_{6} \mathrm{Cl}_{18}$ & OD & $R \overline{3}$ & & $\mathrm{Tg}$ & 148 & Yes & 16 & +2.33 & $\mathrm{KGdNb}_{6} \mathrm{Cl}_{18}$ & {$[11]$} \\
\hline $\mathrm{CsLuNb}_{6} \mathrm{Cl}_{18}$ & OD & $P \overline{3} 1 c$ & & $\mathrm{Tg}$ & 163 & Yes & 16 & +2.33 & $\mathrm{CsLuNb}_{6} \mathrm{Cl}_{18}$ & [13] \\
\hline $\mathrm{Li}_{2} \mathrm{In}_{2} \mathrm{Nb}_{6} \mathrm{Cl}_{18}$ & $O D$ & $P \overline{1}$ & & Tc & 2 & Yes & 16 & +2.33 & $\mathrm{Li}_{2} \mathrm{In}_{2} \mathrm{Nb}_{6} \mathrm{Cl}_{18}$ & [15] \\
\hline
\end{tabular}

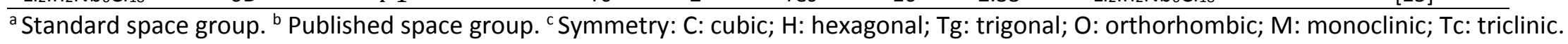

${ }^{d}$ Centrosymmetric. ${ }^{e}$ Valence electron concentration. ${ }^{f}$ Average oxidation state of $\mathrm{M}$ in the $\mathrm{M}_{6}$ clusters. 
Table 2 Compilation of the crystallographic data of inorganic niobium and tantalum octahedral cluster halide compounds with three-dimensional cluster frameworks

\begin{tabular}{|c|c|c|c|c|c|c|c|c|c|c|c|}
\hline Compound & Structure type & SG stand. & VEC & $\mathrm{T}(\mathrm{K})$ & $a(\AA)$ & $b(\AA)$ & $c(\AA)$ & $V\left(\AA^{3}\right)$ & $Z$ & $V / Z\left(\AA^{3}\right)$ & Ref. \\
\hline $\mathrm{Nb}_{6} \mathrm{I}_{11}$ & $\mathrm{Nb}_{6} \mathrm{l}_{11}(\mathrm{HT})$ & Pccn & 19 & - & $11.299(5)$ & $15.309(5)$ & $13.558(5)$ & 2345.21 & 4 & 586.3 & [28] \\
\hline $\mathrm{Nb}_{6} \mathrm{l}_{11}$ & $\mathrm{Nb}_{6} \mathrm{l}_{11}(\mathrm{HT})$ & Pccn & 19 & 298 & $11.319(2)$ & $15.310(4)$ & $13.552(3)$ & 2348.48 & 4 & 587.1 & [29] \\
\hline $\mathrm{Nb}_{6} \mathrm{l}_{10.5} \mathrm{Br}_{0.5}$ & $\ldots \mathrm{Nb}_{6} \mathrm{l}_{11}(\mathrm{HT})$ & Pccn & 19 & 298 & $11.280(1)$ & $15.302(1)$ & $13.524(1)$ & 2334.33 & 4 & 583.6 & [38] \\
\hline $\mathrm{Nb}_{6} \mathrm{l}_{8.7} \mathrm{Br}_{2.3}$ & $\mathrm{Nb}_{6} \mathrm{l}_{11}(\mathrm{HT})$ & Pccn & 19 & 298 & $11.167(2)$ & $15.091(3)$ & $13.431(3)$ & 2263.41 & 4 & 565.9 & [38] \\
\hline $\mathrm{D}_{0.45} \mathrm{Nb}_{6}{ }_{11} *$ & $\mathrm{Nb}_{6} \mathrm{l}_{11}(\mathrm{HT})$ & Pccn & $19 / 20$ & 350 & 11.334 & 15.421 & 13.579 & 2373.36 & 4 & 593.3 & [39] \\
\hline $\mathrm{HNb}_{6} \mathrm{I}_{11}$ & $\mathrm{Nb}_{6} \mathrm{l}_{11}(\mathrm{HT})$ & Pccn & 20 & - & $11.299(5)$ & $15.454(5)$ & $13.470(5)$ & 2352.06 & 4 & 588.0 & [40] \\
\hline $\mathrm{HNb}_{6} \mathrm{l}_{11}$ & $\mathrm{Nb}_{6} \mathrm{l}_{11}(\mathrm{HT})$ & Pccn & 20 & 347 & $11.344(2)$ & $15.502(4)$ & $13.530(2)$ & 2379.31 & 4 & 594.8 & [29] \\
\hline $\mathrm{Mo}_{4.7} \mathrm{Nb}_{1.3} \mathrm{I}_{11}$ & $\mathrm{Nb}_{6} \mathrm{l}_{11}(\mathrm{HT})$ & Pccn & $23 / 24$ & 295 & $11.0950(2)$ & $15.3216(4)$ & $13.1567(3)$ & 2236.54 & 4 & 559.1 & [41] \\
\hline$\left.\mathrm{Mo}_{5} \mathrm{Nb}_{1}\right|_{11}$ & $\mathrm{Nb}_{6} \mathrm{l}_{11}(\mathrm{HT})$ & Pccn & 24 & 110 & $11.0364(9)$ & $15.2588(10)$ & $13.0874(10)$ & 2203.94 & 4 & 551.0 & [41] \\
\hline $\mathrm{Mo}_{5} \mathrm{Nb}_{1} \mathrm{I}_{11}$ & $\mathrm{Nb}_{6} \mathrm{l}_{11}(\mathrm{HT})$ & Pccn & 24 & 220 & $11.0571(10)$ & $15.2873(14)$ & $13.1289(9)$ & 2219.22 & 4 & 554.8 & [41] \\
\hline $\mathrm{Nb}_{6} \mathrm{I}_{11}$ & $\mathrm{Nb}_{6} \mathrm{l}_{11}(\mathrm{LT})$ & $P n a 2_{1}$ & 19 & 110 & $13.429(4)$ & $15.317(6)$ & $11.286(3)$ & 2321.44 & 4 & 580.4 & [29] \\
\hline $\mathrm{Nb}_{6} \mathrm{l}_{11}$ & $\mathrm{Nb}_{6} \mathrm{l}_{11}$ (LT) & $\operatorname{Pna2}_{1}$ & 19 & 258 & $13.489(3)$ & $15.324(4)$ & $11.311(2)$ & 2338.05 & 4 & 584.5 & [29] \\
\hline$\left.\mathrm{Nb}_{6}\right|_{10.5} \mathrm{Br}_{0.5}$ & $\mathrm{Nb}_{6} \mathrm{l}_{11}$ (LT) & $\operatorname{Pna2}_{1}$ & 19 & 110 & $13.404(1)$ & $15.287(1)$ & $11.249(1)$ & 2305.00 & 4 & 576.3 & [38] \\
\hline$\left.\mathrm{Nb}_{6}\right|_{8.7} \mathrm{Br}_{2.3}$ & $\mathrm{Nb}_{6} \mathrm{l}_{11}(\mathrm{LT})$ & $\operatorname{Pna2}_{1}$ & 19 & 110 & $13.346(1)$ & $15.064(2)$ & $11.136(1)$ & 2238.83 & 4 & 559.7 & [38] \\
\hline $\mathrm{D}_{0.45} \mathrm{Nb}_{6} \mathrm{l}_{11} *$ & $\mathrm{Nb}_{6} \mathrm{l}_{11}$ (LT) & $P_{n a 2}$ & $19 / 20$ & 120 & 13.479 & 15.387 & 11.294 & 2342.39 & 4 & 585.6 & [39] \\
\hline $\mathrm{DNb}_{6} \mathrm{I}_{11}$ & $\mathrm{Nb}_{6} \mathrm{l}_{11}(\mathrm{LT})$ & $P_{n a 2}$ & 20 & 295 & $13.465(7)$ & $15.495(8)$ & $11.328(5)$ & 2363.48 & 4 & 590.9 & [42] \\
\hline $\mathrm{HNb}_{6} \mathrm{I}_{11}$ & $\mathrm{Nb}_{6} \mathrm{l}_{11}(\mathrm{LT})$ & $P_{n a 2}$ & 20 & 216 & $13.437(2)$ & $15.474(4)$ & $11.303(3)$ & 2350.17 & 4 & 587.5 & [29] \\
\hline $\mathrm{CsNb}_{61}$ & CsNb6l11 & $P 6_{3} 22$ & 20 & $\mathrm{RT}$ & $11.007(2)$ & - & $11.894(2)$ & 1247.95 & 2 & 624.0 & [9] \\
\hline $\mathrm{Nb}_{6} \mathrm{Cl}_{14}$ & $\mathrm{Nb}_{6} \mathrm{Cl}_{14}$ & Cmca & 16 & - & $13.494(5)$ & $12.252(5)$ & $11.019(5)$ & 1821.75 & 4 & 455.4 & [30] \\
\hline $\mathrm{Ta}_{6} \mathrm{Br}_{14}$ & $\mathrm{Nb}_{6} \mathrm{Cl}_{14}$ & Cmca & 16 & 293 & $14.063(4)$ & $13.177(4)$ & $11.570(16)$ & 2144.02 & 4 & 536.0 & [43] \\
\hline $\mathrm{Ta}_{6} \mathrm{l}_{14}$ & $\mathrm{Nb}_{6} \mathrm{Cl}_{14}$ & Cmca & 16 & - & $15.000(5)$ & $14.445(5)$ & $12.505(5)$ & 2709.52 & 4 & 677.4 & [44] \\
\hline Ta6li4 & $\mathrm{Nb}_{6} \mathrm{Cl}_{14}$ & Cmca & 16 & 293 & $15.032(4)$ & $14.487(3)$ & $12.518(6)$ & 2726.02 & 4 & 681.5 & [45] \\
\hline $\mathrm{Nb}_{6} \mathrm{Cl}_{12} \mathrm{I}_{2}$ & $\mathrm{Nb}_{6} \mathrm{Cl}_{12} \mathrm{I}_{2}$ & $P a \overline{3}$ & 16 & 296 & $12.578(1)$ & - & - & 1989.92 & 4 & 497.5 & [31] \\
\hline $\mathrm{Nb}_{6} \mathrm{Cl}_{10.8} \mathrm{I}_{3.2}$ & $\mathrm{Nb}_{6} \mathrm{Cl}_{12} \mathrm{I}_{2}$ & $P a \overline{3}$ & 16 & 296 & $12.720(17)$ & - & - & 2058.08 & 4 & 514.5 & [31] \\
\hline $\mathrm{Nb}_{6} \mathrm{~F}_{15}$ & $\mathrm{Nb}_{6} \mathrm{~F}_{15}$ & $\operatorname{Im} \overline{3} m$ & 15 & - & 8.19 & - & - & 549.35 & 2 & 274.7 & [32] \\
\hline $\mathrm{Nb}_{6} \mathrm{~F}_{15}$ & $\mathrm{Nb}_{6} \mathrm{~F}_{15}$ & $\operatorname{Im} \overline{3} m$ & 15 & RT & $8.1878(2)$ & - & - & 548.91 & 2 & 274.5 & [46] \\
\hline $\mathrm{CsNb}_{6} \mathrm{Cl}_{8} \mathrm{~F}_{7}$ & $\mathrm{CsNb}_{6} \mathrm{Cl}_{8} \mathrm{~F}_{7}$ & $P m \overline{3}$ & 16 & 293 & $8.2743(3)$ & - & - & 566.49 & 1 & 566.5 & [20] \\
\hline $\mathrm{Na}_{2} \mathrm{Nb}_{6} \mathrm{Cl}_{8} \mathrm{~F}_{7}\left(\mathrm{NbF}_{6}\right)$ & $\mathrm{Na}_{2} \mathrm{Nb}_{6} \mathrm{Cl}_{8} \mathrm{~F}_{7}\left(\mathrm{NbF}_{6}\right)$ & $P m \overline{3} m$ & 16 & 298 & $8.2005(9)$ & - & - & 551.47 & 1 & 551.5 & [19] \\
\hline $\mathrm{Na}_{2} \mathrm{Nb}_{6} \mathrm{Br}_{4} \mathrm{~F}_{11}\left(\mathrm{NbF}_{6}\right)$ & $\mathrm{Na}_{2} \mathrm{Nb}_{6} \mathrm{Cl}_{8} \mathrm{~F}_{7}\left(\mathrm{NbF}_{6}\right)$ & $P m \overline{3} m$ & 16 & 293 & $8.1765(6)$ & - & - & 546.64 & 1 & 546.6 & [34] \\
\hline $\mathrm{Ta}_{6} \mathrm{Cl}_{15}$ & $\mathrm{Ta}_{6} \mathrm{Cl}_{15}$ & $I a \overline{3} d$ & 15 & - & $20.286(1)$ & - & - & 8348.13 & 16 & 521.8 & [33] \\
\hline $\mathrm{Ta}_{6} \mathrm{Cl}_{15}$ & $\mathrm{Ta}_{6} \mathrm{Cl}_{15}$ & $\operatorname{Ia} \overline{3} d$ & 15 & 293 & $20.326(1)$ & - & - & 8397.61 & 16 & 524.9 & [47] \\
\hline $\mathrm{Ta}_{6} \mathrm{Br}_{15}$ & $\mathrm{Ta}_{6} \mathrm{Cl}_{15}$ & $\operatorname{Ia} \overline{3} d$ & 15 & 293 & $21.309(2)$ & - & - & 9675.85 & 16 & 604.7 & [47] \\
\hline $\mathrm{Nb}_{6} \mathrm{Cl}_{12.8} \mathrm{~F}_{2.2}$ & $\mathrm{Ta}_{6} \mathrm{Cl}_{15}$ & $\operatorname{Ia} \overline{3} d$ & 15 & RT & $20.099(1)$ & - & - & 8119.39 & 16 & 507.5 & [48] \\
\hline $\mathrm{Nb}_{6} \mathrm{Cl}_{10.6} \mathrm{~F}_{4.4}$ & $\mathrm{Ta}_{6} \mathrm{Cl}_{15}$ & $\operatorname{Ia} \overline{3} d$ & 15 & RT & $19.9700(20)$ & - & - & 7964.05 & 16 & 497.8 & [48] \\
\hline $\mathrm{NaNb}_{6} \mathrm{Cl}_{15}$ & $\mathrm{NaNb}_{6} \mathrm{Cl}_{15}$ & $\operatorname{Ia} \overline{3} d$ & 16 & 293 & $20.417(2)$ & - & - & 8510.91 & 16 & 531.9 & [16] \\
\hline $\mathrm{LiNb}_{6} \mathrm{Cl}_{15}$ & $\mathrm{NaNb}_{6} \mathrm{Cl}_{15}$ & $\operatorname{Ia} \overline{3} d$ & 16 & 100 & $20.5550(20)$ & - & - & 8684.65 & 16 & 542.8 & [49] \\
\hline $\mathrm{KNb}_{6} \mathrm{Cl}_{10} \mathrm{~F}_{5}$ & $\mathrm{KNb}_{6} \mathrm{Cl}_{10} \mathrm{~F}_{5}$ & $\operatorname{Ia} \overline{3} d$ & 16 & 293 & $19.589(1)$ & - & - & 7516.87 & 16 & 469.8 & [20] \\
\hline
\end{tabular}




\begin{tabular}{|c|c|c|c|c|c|c|c|c|c|c|c|}
\hline $\mathrm{Nb}_{6} \mathrm{Br}_{8} \mathrm{~F}_{7}$ & $\mathrm{Nb}_{6} \mathrm{Br}_{8} \mathrm{~F}_{7}$ & $R \overline{3} c$ & 15 & 293 & $9.6373(6)$ & - & $35.415(2)$ & 2848.58 & 6 & 474.8 & [34] \\
\hline $\mathrm{Ta}_{6} \mathrm{Br}_{15}\left(\mathrm{TaBr}_{6}\right)_{0.86}$ & $\mathrm{Ta}_{6} \mathrm{Br}_{15}\left(\mathrm{TaBr}_{6}\right)_{0.86}$ & $R \overline{3} c$ & 14 & 293 & $12.9860(11)$ & - & $33.285(4)$ & 4861.05 & 6 & 810.2 & [35] \\
\hline $\ln \mathrm{Nb}_{6} \mathrm{Cl}_{15}$ & $\mathrm{InNb}_{6} \mathrm{Cl}_{15}$ & Pmma & 16 & 296 & $17.866(1)$ & $13.4552(8)$ & $9.2934(8)$ & 2234.05 & 4 & 558.5 & [18] \\
\hline $\mathrm{K}_{0.77} \mathrm{Nb}_{6} \mathrm{Cl}_{15}$ & $\ln \mathrm{Nb}_{6} \mathrm{Cl}_{15}$ & Pmma & 16 & 293 & $17.8010(20)$ & $13.4143(11)$ & $9.2551(10)$ & 2210.01 & 4 & 552.5 & [50] \\
\hline $\mathrm{RbNb}_{6} \mathrm{Cl}_{15}$ & $\operatorname{lnNb}_{6} \mathrm{Cl}_{15}$ & Pmma & 16 & 293 & $17.8348(14)$ & $13.4135(9)$ & $9.2142(6)$ & 2204.29 & 4 & 551.1 & [50] \\
\hline $\mathrm{CsNb}_{6} \mathrm{Cl}_{15}$ & $\ln \mathrm{Nb}_{6} \mathrm{Cl}_{15}$ & Pmma & 16 & 293 & $17.8948(15)$ & 13.4397(10) & $9.2437(11)$ & 2223.12 & 4 & 555.8 & [50] \\
\hline
\end{tabular}

* Deuterium deficiency is due to the absence of deuteriation of the inner part of the single-crystal specimen in approximatively equal weight [39].

Table 3 Main interatomic distances (Å) encountered in inorganic niobium and tantalum octahedral cluster halide compounds with three-dimensional cluster frameworks

\begin{tabular}{|c|c|c|c|c|c|c|c|c|c|c|c|}
\hline Compound & VEC & $\mathrm{T}(\mathrm{K})$ & $\left\langle d_{M-M}\right\rangle$ & $\overline{d_{M-M}}$ & $\left\langle d_{M-X^{i}}\right\rangle$ & $\overline{d_{M-X^{\imath}}}$ & $\overline{d_{M-X^{l-a}}}$ & $\overline{d_{M-X^{a-l}}}$ & $\overline{d_{M-X^{a-a}}}$ & $\overline{d_{M-X^{a-a-a}}}$ & Ref. \\
\hline $\mathrm{Nb}_{6} \mathrm{l}_{11}$ & 19 & - & $2.712-2.936$ & 2.834 & 2.774-2.939 & 2.863 & - & - & 2.942 & - & [28] \\
\hline $\mathrm{Nb}_{6} \mathrm{l}_{11}$ & 19 & 298 & $2.743-2.918$ & 2.851 & $2.834-2.903$ & 2.867 & - & - & 2.926 & - & [29] \\
\hline $\mathrm{Nb}_{6} \mathrm{l}_{10.5} \mathrm{Br}_{0.5}$ & 19 & 298 & 2.751-2.912 & 2.852 & $2.829-2.897$ & 2.861 & - & - & 2.888 & - & [38] \\
\hline$\left.\mathrm{Nb}_{6}\right|_{8.7} \mathrm{Br}_{2.3}$ & 19 & 298 & $2.734-2.899$ & 2.829 & $2.809-2.879$ & 2.841 & - & - & 2.852 & - & [38] \\
\hline $\mathrm{D}_{0.45} \mathrm{Nb}_{6} \mathrm{l}_{11}$ & $19 / 20$ & 350 & $2.773-2.930$ & 2.866 & $2.838-2.903$ & 2.870 & - & - & 2.926 & - & [39] \\
\hline $\mathrm{HNb}_{6} \mathrm{I}_{11}$ & 20 & - & $2.727-2.936$ & 2.836 & $2.775-2.945$ & 2.865 & - & - & 2.945 & - & [40] \\
\hline $\mathrm{HNb}_{6} \mathrm{l}_{11}$ & 20 & 347 & $2.806-2.950$ & 2.886 & $2.839-2.910$ & 2.870 & - & - & 2.918 & - & [29] \\
\hline $\mathrm{Mo}_{4.7} \mathrm{Nb}_{1.3} \mathrm{l}_{11}$ & $23 / 24$ & 295 & $2.667-2.716$ & 2.698 & $2.760-2.820$ & 2.790 & - & - & 2.932 & - & [41] \\
\hline$\left.\mathrm{Mo}_{5} \mathrm{Nb}_{1}\right|_{11}$ & 24 & 110 & $2.661-2.714$ & 2.693 & $2.752-2.810$ & 2.785 & - & - & 2.919 & - & [41] \\
\hline $\mathrm{Mo}_{5} \mathrm{Nb}_{1} \mathrm{I}_{11}$ & 24 & 220 & $2.664-2.712$ & 2.693 & $2.755-2.815$ & 2.780 & - & - & 2.926 & - & [41] \\
\hline $\mathrm{Nb}_{6} \mathrm{l}_{11}$ & 19 & 110 & $2.676-2.982$ & 2.852 & $2.807-2.901$ & 2.863 & - & - & 2.921 & - & [29] \\
\hline $\mathrm{Nb}_{6} \mathrm{l}_{11}$ & 19 & 258 & $2.698-2.955$ & 2.842 & $2.814-2.895$ & 2.863 & - & - & 2.927 & - & [29] \\
\hline $\mathrm{Nb}_{6} \mathrm{l}_{10.5} \mathrm{Br}_{0.5}$ & 19 & 110 & $2.683-2.973$ & 2.857 & $2.816-2.892$ & 2.857 & - & - & 2.911 & - & [38] \\
\hline $\mathrm{Nb}_{6} \mathrm{I}_{8.7} \mathrm{Br}_{2.3}$ & 19 & 110 & $2.688-2.922$ & 2.832 & $2.799-2.870$ & 2.833 & - & - & $\mathrm{NC}^{\mathrm{a}}$ & - & [38] \\
\hline $\mathrm{D}_{0.45} \mathrm{Nb}_{6} \mathrm{l}_{11}$ & $19 / 20$ & 120 & $2.707-2.976$ & 2.871 & $2.830-2.906$ & 2.869 & - & - & 2.922 & - & [39] \\
\hline $\mathrm{DNb}_{6} \mathrm{I}_{11}$ & 20 & 295 & $2.742-2.991$ & 2.855 & $2.537-2.968$ & 2.805 & - & - & 2.882 & - & [42] \\
\hline $\mathrm{HNb}_{6} \mathrm{l}_{11}$ & 20 & 216 & $2.722-2.987$ & 2.882 & $2.823-2.930$ & 2.869 & - & - & 2.916 & - & [29] \\
\hline $\mathrm{CsNb}_{6} \mathrm{I}_{11}$ & 20 & RT & 2.771-2.941 & 2.826 & $2.862-2.918$ & 2.882 & - & - & 2.981 & - & [9] \\
\hline $\mathrm{Nb}_{6} \mathrm{Cl}_{14}$ & 16 & - & $2.889-2.963$ & 2.915 & $2.351-2.458$ & 2.408 & 2.471 & 3.014 & 2.582 & - & [30] \\
\hline $\mathrm{Ta}_{6} \mathrm{Br}_{14}$ & 16 & 293 & $2.864-2.959$ & 2.897 & $2.569-2.609$ & 2.585 & 2.625 & 3.440 & 2.839 & - & [43] \\
\hline Ta6l $_{14}$ & 16 & - & $2.790-3.112$ & 2.899 & $2.711-2.826$ & 2.764 & 2.694 & 4.349 & 3.110 & - & [44] \\
\hline $\mathrm{Ta}_{6} \mathrm{l}_{14}$ & 16 & 293 & $2.838-3.115$ & 2.927 & $2.787-2.803$ & 2.795 & 2.803 & 4.231 & 3.105 & - & [45] \\
\hline $\mathrm{Nb}_{6} \mathrm{Cl}_{12} \mathrm{I}_{2}$ & 16 & 296 & $2.906-2.928$ & 2.917 & $2.434-2.486$ & 2.458 & - & - & - & 3.148 & [31] \\
\hline $\mathrm{Nb}_{6} \mathrm{Cl}_{10.8} \mathrm{l}_{3.2}$ & 16 & 296 & 2.907-2.933 & 2.920 & $2.449-2.760$ & 2.505 & - & - & - & 3.189 & [31] \\
\hline $\mathrm{Nb}_{6} \mathrm{~F}_{15}$ & 15 & - & 2.803 & 2.803 & 2.049 & 2.049 & - & - & 2.113 & - & [32] \\
\hline $\mathrm{Nb}_{6} \mathrm{~F}_{15}$ & 15 & RT & 2.794 & 2.794 & 2.059 & 2.059 & - & - & 2.118 & - & [46] \\
\hline $\mathrm{CsNb}_{6} \mathrm{Cl}_{8} \mathrm{~F}_{7}$ & 16 & 293 & 2.861 & 2.861 & $2.095-2.461^{b}$ & 2.340 & - & - & 2.114 & - & [20] \\
\hline
\end{tabular}




\begin{tabular}{|c|c|c|c|c|c|c|c|c|c|c|c|}
\hline $\mathrm{Na}_{2} \mathrm{Nb}_{6} \mathrm{Cl}_{8} \mathrm{~F}_{7}\left(\mathrm{NbF}_{6}\right)$ & 16 & 298 & 2.831 & 2.831 & 2.361 & 2.361 & - & - & 2.099 & - & [19] \\
\hline $\mathrm{Na}_{2} \mathrm{Nb}_{6} \mathrm{Br}_{4} \mathrm{~F}_{11}\left(\mathrm{NbF}_{6}\right)$ & 16 & 293 & 2.815 & 2.815 & $2.070-2.572^{b}$ & 2.223 & - & - & 2.098 & - & [34] \\
\hline $\mathrm{Ta}_{6} \mathrm{Cl}_{15}$ & 15 & - & $2.921-2.928$ & 2.925 & $2.413-2.462$ & 2.434 & - & - & 2.564 & - & [33] \\
\hline $\mathrm{Ta}_{6} \mathrm{Cl}_{15}$ & 15 & 293 & 2.918-2.919 & 2.918 & $2.424-2.447$ & 2.436 & - & - & 2.599 & - & [47] \\
\hline $\mathrm{Ta}_{6} \mathrm{Br}_{15}$ & 15 & 293 & $2.956-2.959$ & 2.957 & $2.568-2.586$ & 2.576 & - & - & 2.804 & - & [47] \\
\hline $\mathrm{Nb}_{6} \mathrm{Cl}_{12.77} \mathrm{~F}_{2.23}$ & 15 & $\mathrm{RT}$ & $2.924-2.938$ & 2.931 & $2.362-2.427$ & 2.404 & - & - & 2.542 & - & [48] \\
\hline $\mathrm{Nb}_{6} \mathrm{Cl}_{10.61} \mathrm{~F}_{4.39}$ & 15 & RT & $2.907-2.930$ & 2.918 & $2.333-2.428$ & 2.387 & - & - & 2.520 & - & [48] \\
\hline $\mathrm{NaNb}_{6} \mathrm{Cl}_{15}$ & 16 & 293 & $2.926-2.936$ & 2.931 & $2.445-2.459$ & 2.451 & - & - & 2.609 & - & [16] \\
\hline $\mathrm{LiNb}_{6} \mathrm{Cl}_{15}$ & 16 & 100 & $2.908-2.916$ & 2.912 & $2.433-2.470$ & 2.451 & - & - & 2.643 & - & [49] \\
\hline $\mathrm{KNb}_{6} \mathrm{Cl}_{10} \mathrm{~F}_{5}$ & 16 & 293 & $2.830-2.863$ & 2.846 & $2.029-2.460$ & 2.309 & - & - & 2.443 & - & [20] \\
\hline $\mathrm{Nb}_{6} \mathrm{Br}_{8} \mathrm{~F}_{7}$ & 15 & 293 & $2.853-2.917$ & 2.885 & $1.952-2.586^{\mathrm{b}}$ & 2.288 & - & - & 2.711 & - & [34] \\
\hline $\mathrm{Ta}_{6} \mathrm{Br}_{15}\left(\mathrm{TaBr}_{6}\right)_{0.86}$ & 14 & 293 & $2.960-2.964$ & 2.962 & $2.570-2.589$ & 2.579 & - & - & 2.808 & - & [35] \\
\hline \multirow[t]{2}{*}{$\operatorname{lnNb}_{6} \mathrm{Cl}_{15}{ }^{\mathrm{c}}$} & 16 & 296 & $2.914-2.951$ & 2.936 & $2.437-2.472$ & 2.454 & - & - & 2.688 & - & [18] \\
\hline & & & $2.907-2.963$ & 2.936 & $2.444-2.476$ & 2.456 & - & - & 2.628 & - & \\
\hline \multirow[t]{2}{*}{$\mathrm{K}_{0.77} \mathrm{Nb}_{6} \mathrm{Cl}_{15}{ }^{\mathrm{c}}$} & 16 & 293 & $2.918-2.952$ & 2.940 & $2.433-2.466$ & 2.449 & - & - & 2.674 & - & [50] \\
\hline & & & $2.915-2.964$ & 2.935 & $2.436-2.472$ & 2.450 & - & - & 2.605 & - & \\
\hline \multirow[t]{2}{*}{$\mathrm{RbNb}_{6} \mathrm{Cl}_{15}{ }^{\mathrm{c}}$} & 16 & 293 & $2.919-2.946$ & 2.934 & $2.434-2.468$ & 2.451 & - & - & 2.678 & - & [50] \\
\hline & & & $2.907-2.952$ & 2.933 & $2.438-2.465$ & 2.451 & - & - & 2.598 & - & \\
\hline \multirow[t]{2}{*}{$\mathrm{CsNb}_{6} \mathrm{Cl}_{15}{ }^{\mathrm{c}}$} & 16 & 293 & $2.924-2.951$ & 2.937 & $2.435-2.461$ & 2.449 & - & - & 2.679 & - & [50] \\
\hline & & & 2.913-2.960 & 2.939 & $2.436-2.467$ & 2.449 & - & - & 2.605 & - & \\
\hline
\end{tabular}

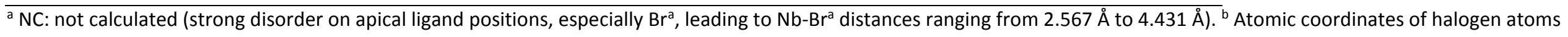
corresponding to the same inner ligands were refined independently. ${ }^{\mathrm{C}}$ Calculation done independently for cluster $\mathrm{A}$ and cluster $\mathrm{B}$. 


\section{Cluster Frameworks of Structural Formula $\left[\mathrm{M}_{6} \mathrm{X}_{8}^{\mathrm{i}} \mathrm{X}^{\mathrm{a}-\mathrm{a}}{ }_{6 / 2}\right]$}

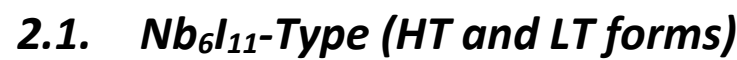

The existence of the binary compound $\mathrm{Nb}_{6} \mathrm{l}_{11}$ (i.e., $\mathrm{Nbl}_{1.83}$ ) was first reported in $1965[30,44]$ and interpreted as a cluster compound with $\left[\left.\mathrm{Nb}_{6}\right|_{8} ^{1}{ }_{8}^{\mid a^{a-a}}{ }_{6 / 2}\right]$ structural formula $[44,51]$. This hypothesis was confirmed independently by Bateman et al. in 1966 [52] and Simon et al. in 1967 [28] with the resolution of its crystal structure. $\left.\mathrm{Nb}_{6}\right|_{11}$ crystallizes in the orthorhombic symmetry space group Pccn (No. 56) with normalized lattice parameters $a \approx 11.30 \AA, b \approx 15.31 \AA$ and $c=13.56 \AA$ [28, 52]. Niobium atoms are located on three independent crystallographic sites of general position $8 e$ and iodine atoms are located on five independent $8 e$ and one $4 c$ crystallographic sites [28]. The structure is built up on four face-capped $\left[\mathrm{Nb}_{6} \mathrm{I}^{\mathrm{i}} 8\right]^{3+}$ cluster cores per unit cell, which are three-dimensionally bridged two by two by the apical ligands (Fig. 3) leading to the structural formula $\left[\left.\left.\mathrm{Nb}_{6}\right|^{i} 8\right|^{a-a}{ }_{6 / 2}\right]$. Such face-capped cluster units are generally found with molybdenum, tungsten (group 6) and rhenium (group 7), $\mathrm{Nb}_{6} \mathrm{l}_{11}$ representing the first compound containing unusual $\left[\mathrm{M}_{6} \mathrm{X}_{8}^{\mathrm{i}}\right]^{\mathrm{n}}$ cluster core for the group 5 of transition elements [52].

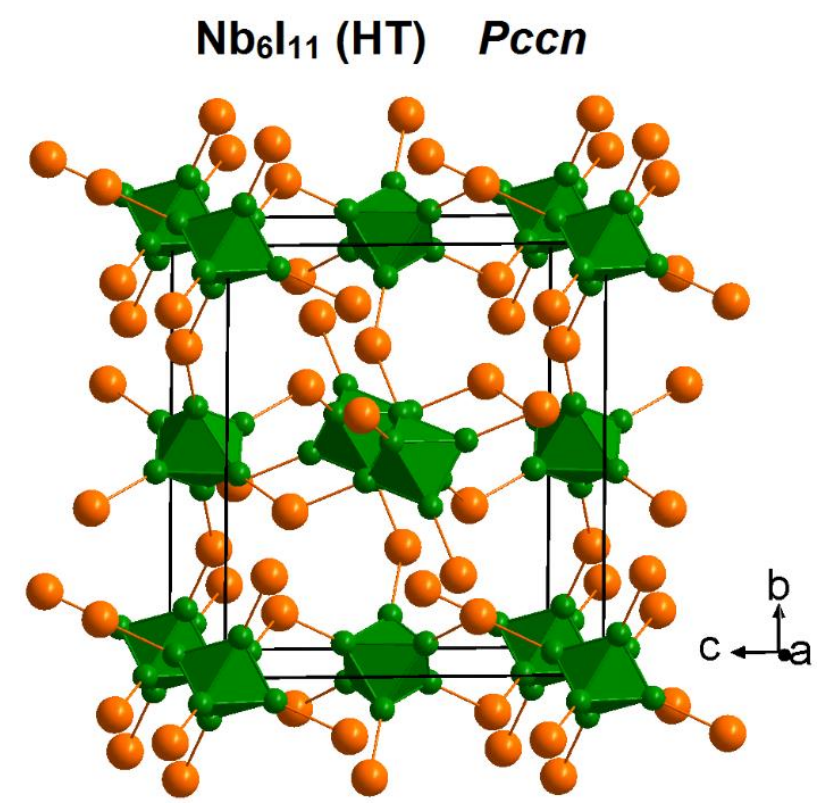

Fig. 3 Crystal structure representation of the high-temperature form of $\mathrm{Nb}_{6} \mathrm{l}_{11}$ (space group Pccn) highlighting the three-dimensional cluster framework. Inner ligands are omitted for clarity

$\mathrm{Nb}_{6} \mathrm{l}_{11}$ is characterized by a second order structural phase transition at $274 \mathrm{~K}$ from the centrosymmetric space group Pccn (high-temperature $(\mathrm{HT})$ form) to the non-centrosymmetric one $P n a 2_{1}$ (low-temperature (LT) form) [29]. As the space group $P n a 2_{1}$ is a subgroup of $P c c n$ and differs only by the lack of the inversion center, the LT form can be viewed as a continuous deformation of the HT form. Hence, each crystallographic site of general position $8 e$ (according to Pccn space group) occupied by either niobium or iodine atoms in the HT form splits into two different crystallographic sites of general position $4 a$ (according to $P n a 2_{1}$ space group) in the LT form (Fig. 4). It leads for the LT form to the distribution of niobium and iodine atoms on six and eleven different $4 a$ crystallographic sites, respectively [29]. It should be noted that for the sake of comparison, the published space group was $P 2_{1} C n$ [29] instead of the standardized one $P n a 2_{1}$ (No. 33), allowing keeping equivalent unit cell parameters and orientation of the cluster units for both HT and LT forms. This structural phase transition was firstly suggested by large bump in the inverse magnetic susceptibility measurements 
[28] and then confirmed by specific heat measurements $[53,54]$ and single-crystal X-ray diffraction [29]. From single-crystal X-ray diffraction, it was shown than both forms evidence a distortion of the $\mathrm{Nb}_{6}$ clusters (Fig. 4). For the $\mathrm{HT}$ form, this distortion is due to the interconnection of the clusters leading to a shift of two opposite metals of the octahedral $\mathrm{Nb}_{6}$ cluster. It induces that only the inversion center is kept as symmetry element, and consequently, leads to strongly distorted octahedral $\mathrm{Nb}_{6}$ cluster with $\mathrm{Nb}-\mathrm{Nb}$ distances ranging between $2.743 \AA$ and $2.918 \AA$ at $298 \mathrm{~K}$ (Fig. 4). For the LT form, a distortion component is added which is essentially a twist of $5^{\circ}$ at $258 \mathrm{~K}$ and $7^{\circ}$ at $110 \mathrm{~K}$ between the two opposite triangular faces of the $\mathrm{Nb}_{6}$ octahedron accompanied by a compression along the twist axis [29]. This twist removes the inversion center leading to a non-centrosymmetric structural arrangement and induces a strong distortion of the octahedral $\mathrm{Nb}_{6}$ cluster with $\mathrm{Nb}-\mathrm{Nb}$ distances ranging between 2.698 $\AA$ and $2.955 \AA$ at $258 \mathrm{~K}$ and between $2.676 \AA$ and $2.982 \AA$ at $110 \mathrm{~K}$ (Fig. 4).
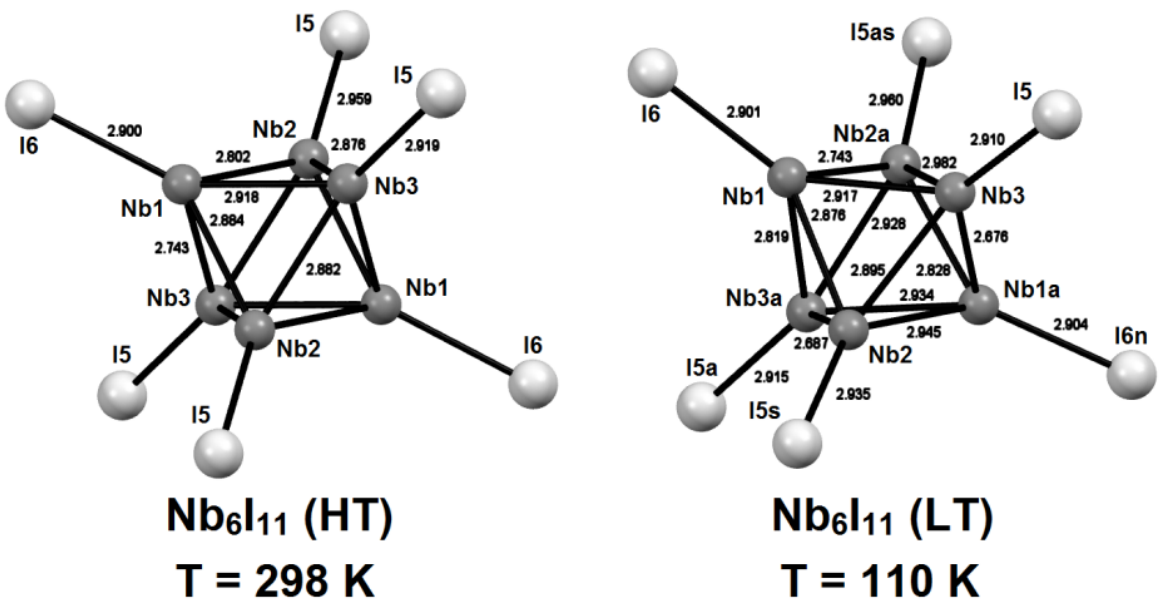

Fig. 4 Representation of the structural transition effect on the distortion of the $\mathrm{Nb}_{6}$ clusters in the $\mathrm{HT}$ form (left) and in the $\mathrm{LT}$ form (right) of $\mathrm{Nb}_{6} \mathrm{l}_{11}$. Inner ligands are omitted for clarity. Data are from reference [29]

The $\left[\mathrm{Nb}_{6} \mathrm{I}_{8}\right]^{3+}$ cluster core shows remarkable magnetic properties in relation with its electron deficiency, only 19 electrons available for 12 cluster metal-metal bonding $d$ orbitals (see Section 8), and its second order structural phase transition [28, 53,54]. Indeed, $\mathrm{Nb}_{6} \mathrm{l}_{11}$ exhibits a paramagnetic behavior in agreement with the VEC of 19 with a thermal dependence of the inverse magnetic susceptibility characterized by four different regions (named regions I to IV according to reference [54]). Above $274 \mathrm{~K}$ (i.e., region IV), $\mathrm{Nb}_{6} \mathrm{l}_{11}$ evidences a Curie-Weiss behavior with a quartet ground state $(S=3 / 2)$ which changes into a doublet ground state $(S=1 / 2)$ supplemented by a van Vleck paramagnetism contribution between $40 \mathrm{~K}$ and $170 \mathrm{~K}$ (i.e., region II) [54]. Between these two regions (i.e., region III), the susceptibility of $\mathrm{Nb}_{6} \mathrm{l}_{11}$ is unusual and related to a second order structural phase transition through a spin crossover transition: the $S=3 / 2$ level gradually depopulated due to an increase in the separation between the two states at the expense of the $S=1 / 2$ level [54]. From polarized neutron diffraction measurements, it was shown (i) that each $\mathrm{Nb}_{6} \mathrm{l}_{11}$ cluster carries three unpaired spins in region IV and only one in region II and (ii) that the spin density is predominantly distributed on one of the three pairs of equivalent niobium atoms (centrosymmetrically related) in region IV, while in region II the spin density is not delocalized over the cluster but rather mainly associated to a niobium site and in a lesser extent to its partner involved in the so-called polarized bond [55]. Finally, the magnetic behavior below $40 \mathrm{~K}$ (i.e., region I) is still not well understood as no magnetic ordering is detected down to $2.5 \mathrm{~K}$ [54]. For more information see references [53-55].

In parallel to the study of the binary $\mathrm{Nb}_{6} \mathrm{I}_{11}$ compound, the $\mathrm{H}$-filled and $\mathrm{D}$-filled analogues were also reported (Table 2). As for its parent compound, a structural phase transition at $\mathrm{T}=324 \mathrm{~K}$ from the 
centrosymmetric space group Pccn to the non-centrosymmetric one $P n a 2_{1}$, as well as similar level crossing mechanism, is observed for $\mathrm{HNb}_{6} \mathrm{I}_{11}[29,53,54]$. The $\mathrm{HT}$ and LT crystal structures are similar to those of $\mathrm{Nb}_{6} \mathrm{l}_{11}$ with the exception that hydrogen atoms are located into the $\mathrm{Nb}_{6}$ octahedra making these compounds the first examples of centered $M_{6}$ octahedral clusters reported in the literature. From neutron powder diffraction results, it was shown that hydrogen/deuterium atoms are located at the center of the $\mathrm{Nb}_{6}$ octahedra on the $4 a$ crystallographic site (according to Pccn space group) in the HT form [40], while in the LT form, these interstitial atoms are probably slightly displaced from the center of gravity of the $\mathrm{Nb}_{6}$ cluster [42]. However, from a single-crystal neutron diffraction study it was shown that interstitial atoms are located at the centroid of the $\mathrm{Nb}_{6}$ octahedra in both $\mathrm{HT}$ and LT forms [39]. Due to the additional electron coming from hydrogen atom insertion, the $\left[\mathrm{HNb}_{6} \mathrm{I}_{8}^{\mathrm{i}}\right]^{3+}$ cluster core in $\mathrm{HNb}_{6} \mathrm{I}_{11}$ presents a VEC of 20 explaining the diamagnetic behavior observed at low temperature [40]. Photoelectron spectroscopy data indicated that insertion of hydrogen into $\mathrm{Nb}_{6} \mathrm{l}_{11}$ induces an increase of the oxidation state of niobium from $\approx 1.8$ to $\approx 2.0$ [56]. This result could be related with the weak polarization of hydrogen atom by neighboring niobium atoms highlighted by theoretical calculations performed with the self-consistent-field-X $\alpha$-scattered-wave (SCF-X $\alpha-S W$ ) method [57]. Structural data and magnetic measurements for both $\mathrm{Nb}_{6} \mathrm{I}_{11}$ and $\mathrm{HNb}_{6} \mathrm{I}_{11}$ are well explained by a coupled structural and electronic phase transition where degeneracy is reduced through the crossing of electronic levels $[29,53]$. On the crystal chemistry point of view, insertion of hydrogen in $\mathrm{Nb}_{6} \mathrm{l}_{11}$ leads to a weak increase of the unit cell volume (Table 2) and the Nb-Nb distances (Table 3) whatever the structure [29]. Imoto and Simon indicated that this experimental result is in apparent contradiction with the theoretical increase in the number of bonding electrons expected by the electron transfer from hydrogen atom to metal cluster [29]. However, the distribution of the $\mathrm{Nb}-\mathrm{Nb}$ distances is narrower in both forms of $\mathrm{HNb}_{6} \mathrm{I}_{11}$ compared to those of $\mathrm{Nb}_{6} \mathrm{I}_{11}[29]$.

The crystal structure and magnetic influence of a bromine for iodine substitution was evidenced with the study of the $\mathrm{Nb}_{6} \mathrm{l}_{11-\mathrm{x}} \mathrm{Br}_{\mathrm{x}}(0 \leq x \leq 2.7)$ series [38]. The authors showed from X-ray diffraction analysis, that the unit cell parameters decrease with the increase of bromine content (Table 2 ), in agreement with the size difference of bromine and iodine atoms. From single-crystal X-ray diffraction data obtained on $x=0.5$ and $x=2.3$ samples at both $298 \mathrm{~K}$ and $110 \mathrm{~K}$ (Table 2), they established that a preferential substitution of one bridging apical ligand position (i.e., the $4 c$ crystallographic site according to Pccn space group for the HT form) by bromine atoms first occurs for lower bromine content (i.e., $x=0.5$ ), and then for higher bromine content (i.e., $x=2.3$ ), with bromine atoms equally distributed on all of the apical ligand positions. Finally, they also showed that the structural phase transition from Pccn space group (HT form) to Pna $2_{1}$ space group (LT form) occurs for all substituted compounds but with a (non-linear) decrease of the transition temperature with increasing bromine content from $274 \mathrm{~K}$ for $\mathrm{Nb}_{6} \mathrm{l}_{11}$ to $170 \mathrm{~K}$ for $\mathrm{Nb}_{6} \mathrm{I}_{8.3} \mathrm{Br}_{2.7}$. Concomitantly, a broadening of the transition interval arises from the disorder on apical ligand positions. This influence is also observed through the inverse magnetic susceptibility measurements, where the bump induced by phase transition is less and less pronounced upon the increase of bromine content.

More recently, the crystal structure of two heterometallic iodide compounds $\left(\mathrm{Mo}_{4.7} \mathrm{Nb}_{1.3} \mathrm{l}_{11}\right.$ and $\mathrm{Mo}_{5} \mathrm{Nb}_{1} 1_{11}$, Table 2) was solved by single crystal X-ray diffraction technique at different temperatures [41]. These compounds crystallize in the $\mathrm{Nb}_{6} \mathrm{l}_{11}-\mathrm{HT}$ type of structure even at $110 \mathrm{~K}$. Due to very close scattering factors between molybdenum and niobium, the three independent metal atom positions were assumed by the authors to have the same statistical distribution. The ratios were fixed by the chemical composition determined from EDX data for $\mathrm{Mo}_{4.7} \mathrm{Nb}_{1.3} \mathrm{l}_{11}$ and estimated on the basis of the chemical data and similarity of the unit cell parameters for $\mathrm{Mo}_{5} \mathrm{Nb}_{1} \mathrm{I}_{11}$ [41]. The authors interpreted the surprising crystal structure modification from $\mathrm{Mo}_{6} \mathrm{I}_{12}$ to $\mathrm{Nb}_{6} \mathrm{l}_{11}-\mathrm{HT}$ for only one niobium to molybdenum atom substitution, by considering the VEC values in $\mathrm{Mo}_{6} \mathrm{I}_{12}, \mathrm{Nb}_{6} \mathrm{I}_{11}$, and $\mathrm{Mo}_{6-\mathrm{x}} \mathrm{Nb}_{\mathrm{x}} \mathrm{I}_{11}$. Indeed, $\mathrm{Nb}_{6} \mathrm{I}_{11}$ is 
characterized with an electron deficient character of the cluster core (VEC $=19$ ) while $\mathrm{Mo}_{6} \mathrm{l}_{12}$ contains the optimal VEC number of 24. The niobium for molybdenum substitution should decrease the VEC number, however, the crystal structure transition from Mo6 $\mathrm{M}_{12}$-type to $\mathrm{Nb}_{6} \mathrm{l}_{11}-\mathrm{HT}$ implies a transformation of the terminal iodine ligands into bridging atoms resulting to optimal VEC number of 24 for the $\left[\mathrm{Mo}_{5} \mathrm{Nb}_{1} \mathrm{I}_{8}^{\mathrm{i}}\right]^{3+}$ cluster core [41]. Nevertheless, electron spin resonance spectrum revealed a broad signal corresponding to one unpaired electron, suggesting also the existence of the $\left[\mathrm{Mo}_{4} \mathrm{Nb}_{2} \mathrm{I}_{8}\right]^{3+}$ cluster core with VEC number of 23 in the solid solution $\mathrm{Mo}_{6-x} \mathrm{Nb}_{x} \mathrm{I}_{11}(x=1-1.5)$. Finally, the authors showed that in $\mathrm{Mo}_{6-\mathrm{x}} \mathrm{Nb}_{\mathrm{x}} \mathrm{I}_{11}$ (i) the average $\mathrm{M}-\mathrm{M}$ bond lengths are intermediate between those of the $\mathrm{HT}$ form of $\mathrm{Nb}_{6} \mathrm{l}_{11}$ and of $\mathrm{Mo}_{6} \mathrm{I}_{12}$ and (ii) the $\mathrm{M}-\mathrm{X}^{\mathrm{i}}$ and $\mathrm{M}-\mathrm{X}^{\mathrm{a}}$ bond lengths are quite similar to those found in $\mathrm{Mo}_{6} \mathrm{l}_{12}$ and $\mathrm{Nb}_{6} \mathrm{l}_{11}$, respectively (Table 3) [41].

\section{$2.2 \mathrm{CsNb}_{6} \mathrm{l}_{11}$-Type}

The crystal structure of $\mathrm{CsNb}_{6} \mathrm{I}_{11}$ was reported in 1980 by Imoto and Corbett [9]. This compound crystallizes in the non-centrosymmetric hexagonal symmetry space group $P 6_{3} 22$ (No. 182) with refined cell parameters $a=11.007$ (2) $\AA$ and $c=11.894$ (2) $\AA$ from a Guinier film at room temperature, and $a=$ $11.007(3) \AA$ and $c=11.899$ (4) $\AA$ from single-crystal X-ray measurements at the same temperature. Niobium atoms are located on one crystallographic site of general position $12 i$, iodine atoms on three independent crystallographic sites $12 i, 4 f$ and $6 g$, and cesium atoms on the $2 b$ site. The crystal structure consists of a pseudo hexagonal close-packed arrangement along the $c$-axis of distorted facecapped octahedral $\left[\mathrm{Nb}_{6} \mathrm{I}_{8}{ }^{2}\right]^{2+}$ cluster cores $\left(D_{3 d}\right.$ symmetry, VEC $\left.=20\right)$ three-dimensionally interconnected by sharing their apical ligands (Fig. 5). This leads, as in $\mathrm{Nb}_{6} \mathrm{l}_{11}$, to a cluster framework of structural formula $\left[\left.\mathrm{Nb}_{6}{ }_{8}{ }_{8}\right|^{a-a}{ }_{6 / 2}\right]$. Cesium atoms lie in the triangular interstices of the hexagonal cluster layers. The coordination polyhedron of cesium atoms is then formed by six inner iodine ligands at a distance of 4.110(2) ^ forming a flattened and twisted trigonal antiprism oriented perpendicularly to the $c$-axis and six apical iodine ligands at a distance of 4.293(1) $\AA$ forming an elongated trigonal antiprism along the $c$-axis (Fig. 6).

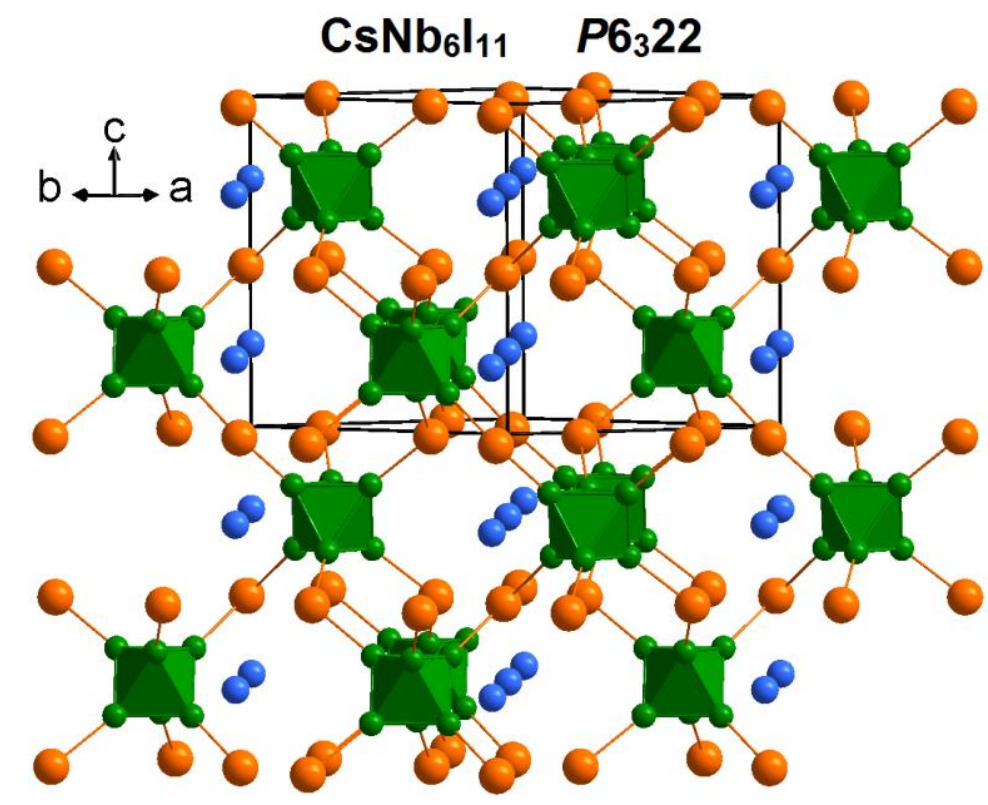

Fig. 5 Crystal structure representation of $\mathrm{CsNb}_{6} \mathrm{l}_{11}$ highlighting the three-dimensional cluster framework and the hexagonal close-packed arrangement of the cluster units. Inner ligands are omitted for clarity 


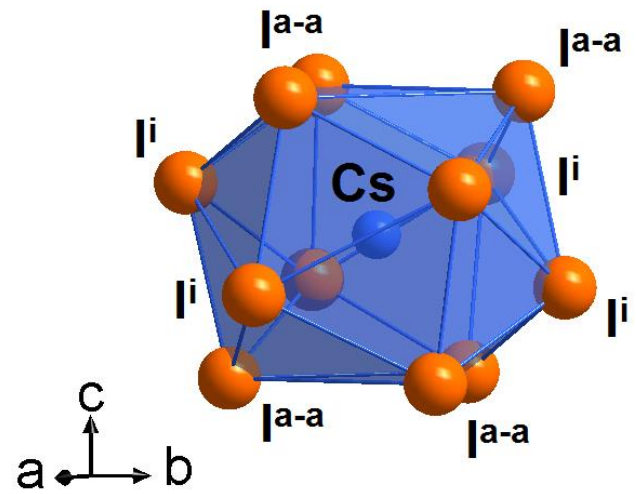

Fig. 6 Representation of the cesium environment in $\mathrm{CsNb}_{6} \mathrm{I}_{11}$

In $\mathrm{CsNb}_{6} \mathrm{l}_{11}, \mathrm{Nb}-\mathrm{Nb}$ distances range from $2.771 \AA$ to $2.941 \AA$ for an average of $2.826 \AA$, Nb-li range between $2.862 \AA$ and $2.918 \AA$ for an average of $2.882 \AA$ and $\mathrm{Nb}$ - $\mathrm{l}^{\mathrm{a}-\mathrm{a}}$ distances are equal to 2.981 $\AA$ (Table 3). Existence of short and long $\mathrm{Nb}-\mathrm{Nb}$ distances arises from the rotation of one metal triangle by $6.1^{\circ}$ about the $C_{3}$ axis relative to the other [9]. The $\mathrm{Nb}-\mathrm{Nb}$ and $\mathrm{Nb}-\mathrm{I}^{i}$ distances in $\mathrm{CsNb}_{6} \mathrm{I}_{11}$ are comparable with those reported for the high-temperature form of $\mathrm{Nb}_{6} \mathrm{l}_{11}$ (Pccn) (Table 3), indicating that the VEC increase of the cluster core from $19\left(\left[\left.\mathrm{Nb}_{6}\right|_{8} ^{\mathrm{I}_{8}}\right]^{3+}\right)$ to $20\left(\left[\mathrm{Nb}_{6} \mathrm{I}_{8}^{\mathrm{i}}\right]^{2+}\right)$ does not influence the interatomic distances [9]. On the contrary, the $\mathrm{Nb}-\mathrm{l}^{\mathrm{a}}$ distances are longer in $\mathrm{CsNb}_{6} \mathrm{l}_{11}$ than those reported for the high-temperature form of $\mathrm{Nb}_{6} \mathrm{l}_{11}$ (Table 3), suggesting that the longer $\mathrm{Nb}-\mathrm{I}^{\mathrm{a}}$ distances encountered in $\mathrm{CsNb}_{6} \mathrm{I}_{11}$ in comparison to those found in $\mathrm{Nb}_{6} \mathrm{l}_{11}$ are related to the different cluster unit arrangements as well as ionic interactions between cesium cations and iodine apical ligands in $\mathrm{CsNb}_{6} \mathrm{I}_{11}$.

The hydride $\mathrm{CsNb}_{6} \mathrm{l}_{11} \mathrm{H}_{0.93}$ was reported to be isostructural with its parent compound with unit cell parameters determined from a Guinier film at room temperature $(a=11.021(1) \AA$ and $c=11.899(2)$ A) [9]. As for $\left.\mathrm{Nb}_{6}\right|_{11}$, insertion of hydrogen into $\mathrm{CsNb}_{6} \mathrm{l}_{11}$ leads to a very similar weak increase of the unit cell volume. Consequently, even if the localization of the hydrogen atoms was not determined, it can be assumed that hydrogen atoms are located at the center of the $\mathrm{Nb}_{6}$ octahedra as shown for $\mathrm{Nb}_{6} \mathrm{l}_{11}$ compounds. Finally, the existence of $\left.\mathrm{CsNb}_{6}\right|_{11} \mathrm{H}$, for which the VEC is equal to 21 , indicates that hydrogen insertion into $\mathrm{Nb}_{6} \mathrm{I}_{11}$ is not simply a result of the presence of an odd number of electrons binding the cluster cage [9].

\subsection{Structural Comparison of $\mathrm{Nb}_{6} \mathrm{l}_{11}$ and $\mathrm{CsNb}_{6} \mathrm{I}_{11}$}

As previously mentioned, $\mathrm{Nb}_{6} \mathrm{l}_{11}$ and $\mathrm{CsNb}_{6} \mathrm{l}_{11}$ compounds are characterized by clusters sharing apical ligands leading to the same structural formula $\left[\left.\left.\mathrm{Nb}_{6}\right|_{8}{ }_{8}\right|^{\mathrm{a}-\mathrm{a}} 6 / 2\right]$. However, these compounds evidence different cluster unit arrangements. Indeed, the structure of $\mathrm{Nb}_{6} \mathrm{l}_{11}$ may be described as an orthorhombic distortion of a face-centered cube defined by $\left[\left.\mathrm{Nb}_{6}\right|^{i}{ }_{8}{ }^{a}{ }_{3}\right]$ cluster units (Fig. 3), while that of $\left.\mathrm{CsNb}_{6}\right|_{11}$ consists of a pseudo hexagonal close-packed arrangement of $\left[\left.\mathrm{Nb}_{6}\right|_{8} ^{i}{ }_{8}{ }^{a}{ }_{3}\right]^{-}$cluster units (Fig. 5). The cluster units packing is the result of a compromise between the repulsion between adjacent clusters (electronic effect) and the attraction between cluster units and counter-cations (halogen matrix effect). In $\mathrm{CsNb}_{6} \mathrm{l}_{11}$, these two effects coexist, while only the former governs the structure of $\mathrm{Nb}_{6} \mathrm{l}_{11}$. Ionic interactions between cesium cations and iodine apical ligands of the cluster units in $\mathrm{CsNb}_{6} \mathrm{l}_{11}$ explain the weak $\mathrm{Nb}-\mathrm{l}^{\mathrm{a}-\mathrm{a}}$ - $\mathrm{Nb}$ bond angle of $118.41^{\circ}$, leading to short $\mathrm{Nb} \cdots \mathrm{Nb}$ distances of 5.122 $\AA$ (Table 4). On the opposite, the absence of this halogen matrix effect in $\mathrm{Nb}_{6} \mathrm{l}_{11}$ induces larger $\mathrm{Nb}-\mathrm{l}^{\mathrm{a}-\mathrm{a}}$ $\mathrm{Nb}$ bond angles, especially that at $\approx 152^{\circ}$, leading to longer $\mathrm{Nb} \cdots \mathrm{Nb}$ distances (Table 4 ) even if the $\mathrm{Nb}-\mathrm{I}^{\mathrm{a}}$ distances are shorter in comparison to those encountered in $\mathrm{CsNb}_{6} \mathrm{l}_{11}$ (Table 3). 
Table $4 \mathrm{Nb} \cdots \mathrm{Nb}$ distances $(\AA)$ and $\mathrm{Nb}--^{\mathrm{a}-\mathrm{a}}-\mathrm{Nb}$ bond angles $\left({ }^{\circ}\right)$ in $\mathrm{CsNb}_{6} \mathrm{I}_{11}$ and $\mathrm{Nb}_{6} \mathrm{I}_{11}$

\begin{tabular}{|c|c|c|c|}
\hline \multicolumn{4}{|c|}{$\mathrm{CsNb}_{6} \mathrm{I}_{11}(\mathrm{RT})^{\mathrm{a}}$} \\
\hline $\mathrm{Nb} 1 \cdots \mathrm{Nb} 1$ & 5.122 & Nb1-I3-Nb1 & 118.41 \\
\hline \multicolumn{4}{|c|}{$\mathrm{Nb}_{6} \mathrm{l}_{11}-\mathrm{HT}(\mathrm{T}=298 \mathrm{~K})^{\mathrm{b}}$} \\
\hline $\mathrm{Nb1} \cdots \mathrm{Nb} 1$ & 5.629 & Nb1-I6-Nb1 & 152.15 \\
\hline $\mathrm{Nb} 2 \cdots \mathrm{Nb} 3$ & 5.204 & $\mathrm{Nb2}-15-\mathrm{Nb3}$ & 124.59 \\
\hline \multicolumn{4}{|c|}{$\mathrm{Nb}_{6} \mathrm{I}_{11}-\mathrm{LT}(\mathrm{T}=258 \mathrm{~K})^{\mathrm{b}}$} \\
\hline $\mathrm{Nb} 1 \cdots \mathrm{Nb} 2$ & 5.635 & Nb1-I11-Nb2 & 151.98 \\
\hline Nb3 $\cdots$ Nb5 & 5.185 & Nb3-19-Nb5 & 124.18 \\
\hline $\mathrm{Nb} 4 \cdots \mathrm{Nb} 6$ & 5.200 & Nb4-I10-Nb6 & 124.25 \\
\hline \multicolumn{4}{|c|}{$\mathrm{Nb}_{6} \mathrm{l}_{11}-\mathrm{LT}(\mathrm{T}=110 \mathrm{~K})^{\mathrm{b}}$} \\
\hline $\mathrm{Nb} 1 \cdots \mathrm{Nb} 2$ & 5.618 & Nb1-I11-Nb2 & 150.78 \\
\hline Nb3 ‥Nb5 & 5.157 & Nb3-19-Nb5 & 123.87 \\
\hline $\mathrm{Nb} 4 \cdots \mathrm{Nb} 6$ & 5.178 & Nb4-I10-Nb6 & 123.58 \\
\hline
\end{tabular}

${ }^{a}$ Ref. [9]. ${ }^{\text {b }}$ Ref. [29]

These structural features are also observed through the intercluster distances (i.e., distance between centroids of two adjacent $\mathrm{Nb}_{6}$ clusters). In $\left.\mathrm{CsNb}_{6}\right|_{11}$, each $\mathrm{Nb}_{6}$ cluster is surrounded by six clusters at 11.007(2) $\AA$ and by six clusters (three above and three below the hexagonal layer) at 8.704(2) $\AA$ (Fig. 7). In $\mathrm{Nb}_{6} \mathrm{l}_{11}-\mathrm{HT}$, each $\mathrm{Nb}_{6}$ cluster is surrounded by four and two clusters in the $(a, c)$ plane at $8.829(2) \AA$ and $11.319(2) \AA$, respectively, and by two and two clusters at 9.520(2) $\AA$ and $10.223(2) \AA$, respectively, both above and below the pseudo hexagonal layer (Fig. 7). The shorter intercluster distances (8.704(2) $\AA$ for $\mathrm{CsNb}_{6} \mathrm{l}_{11}, 8.829(2) \AA$ and 9.520(2) $\AA$ for $\mathrm{Nb}_{6} \mathrm{l}_{11}-\mathrm{HT}$ ) are observed between $\mathrm{Nb}_{6}$ clusters bridged by the iodine atoms in apical position. On the opposite, the longer intercluster distances (11.007(2) for $\mathrm{CsNb}_{6} \mathrm{l}_{11}, 10.223(2) \AA$ and 11.319(2) $\AA$ for $\mathrm{Nb}_{6} \mathrm{l}_{11}-\mathrm{HT}$ ) are observed between clusters which are not bridged by apical ligands. The longer intercluster distances in $\mathrm{CsNb}_{6} \mathrm{I}_{11}$, observed in the layers where the cesium cations are lying, are intermediate between those measured in $\left.\mathrm{Nb}_{6}\right|_{11}-\mathrm{HT}$ in relation with both steric and electrostatic effects. This observation is coherent with the shorter $\mathrm{Nb} \cdots \mathrm{Nb}$ distances of adjacent cluster units in $\mathrm{CsNb}_{6} \mathrm{l}_{11}$ compared to those in $\left.\mathrm{Nb}_{6}\right|_{11}-\mathrm{HT}$ and confirms the important role of cesium cations to the cluster framework compactness through halogen matrix effect in $\mathrm{CsNb}_{6} \mathrm{I}_{11}$.
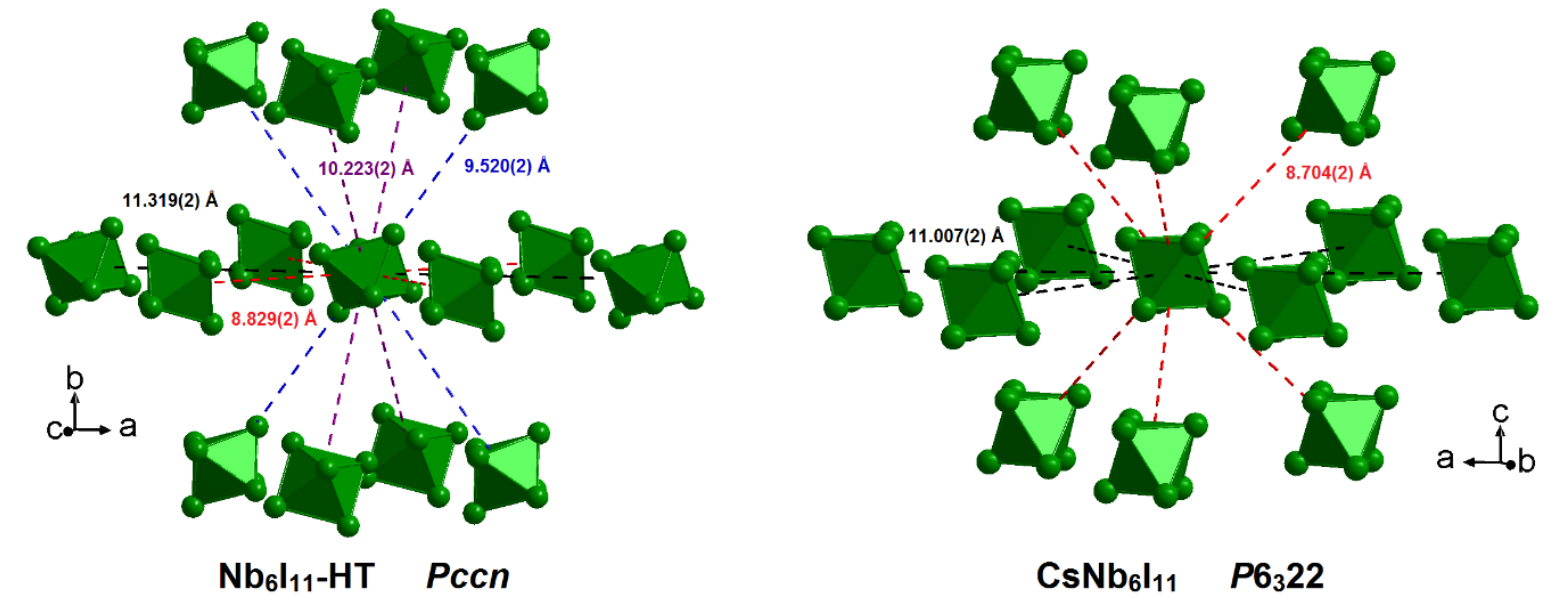

$\mathrm{CsNb}_{6} \mathrm{I}_{11} \quad P 6_{3} 22$

Fig. 7 Representation of the intercluster $\mathrm{Nb}_{6} \cdots \mathrm{Nb}_{6}$ distances in the high temperature form of $\left.\mathrm{Nb}_{6}\right|_{11}$ (left part) and in $\mathrm{CsNb}_{6} \mathrm{l}_{11}$ (right part). Distances are calculated from crystal data reported at room temperature in [29] and [9], respectively. Cesium and iodine atoms were omitted for clarity 


\section{Cluster Frameworks of Structural Formula $\left[\mathrm{M}_{6} \mathrm{X}_{10}^{\mathrm{i}} \mathrm{X}^{\mathrm{i}-\mathrm{a}}{ }_{2 / 2} \mathrm{X}^{\mathrm{a}-\mathrm{i}}{ }_{2 / 2} \mathrm{X}^{\mathrm{a}-\mathrm{a}}{ }_{4 / 2}\right]$}

The preparation of $\mathrm{Ta}_{6} \mathrm{Br}_{14}$ and $\mathrm{Ta}_{6} \mathrm{I}_{14}$ [58], as well as the crystal structures of $\mathrm{Nb}_{6} \mathrm{Cl}_{14}$ [30] and $\mathrm{Ta}_{6} \mathrm{I}_{14}$ [44] were reported almost at the same time in 1965. These compounds crystallize in the orthorhombic symmetry normalized space group Cmca (No. 64) with lattice parameters $a=13.494(5) \AA, b=12.252(5)$ $\AA$ and $c=11.019$ (5) $\AA$ for $\mathrm{Nb}_{6} \mathrm{Cl}_{14}$ [30] and $a=15.000$ (5) $\AA, b=14.445(5) \AA$ and $c=12.505$ (5) $\AA$ for $\mathrm{Ta}_{6} \mathrm{l}_{14}$ [44] (Table 2). $\mathrm{Nb}_{6} \mathrm{Cl}_{14}$ and $\mathrm{Ta}_{6} \mathrm{l}_{14}$ were at first published in the non-normalized space group Bbam, leading to the redetermination of the crystal structure of $\mathrm{Ta}_{6} \mathrm{l}_{14}$ by Artelt and Mayer in 1993 [45]. While the preparation of $\mathrm{Ta}_{6} \mathrm{Br}_{14}$ was described in 1965 [58], its crystal structure was reported only in 1995, confirming that this compound is isostructural with $\mathrm{Nb}_{6} \mathrm{Cl}_{14}$ and $\mathrm{Ta}_{6} \mathrm{I}_{14}$ [43]. Attempts to prepare the isostructural tantalum chloride compound in the same conditions than those used for $\mathrm{Ta}_{6} \mathrm{Br}_{14}$ and $\mathrm{Ta}_{6} \mathrm{l}_{14}$, led to the formation of $\mathrm{Ta}_{6} \mathrm{Cl}_{15}$ [58]. One paper reports about the preparation of $\mathrm{Ta}_{6} \mathrm{Cl}_{14}$ from electrochemical reduction of $\mathrm{Ta}(\mathrm{V})$ in $\mathrm{NaCl}^{-\mathrm{AlCl}_{3}}$ melts [59], however the chemical composition and crystal structure of the dark green powder product were never confirmed. No publication reports about the existence of the isostructural niobium bromide and iodine compounds. Surprisingly, a temperature independent paramagnetic behavior was reported for $\mathrm{Nb}_{6} \mathrm{Cl}_{14}$ and $\mathrm{Ta}_{6} \mathrm{I}_{14}$, though these materials are characterized by an even VEC of $16[30,44]$.

In this type of structure, metal atoms are located on two independent crystallographic sites, one of general position $16 \mathrm{~g}$ and one $8 f$, whereas halogen atoms are located on five independent $8 d$, $8 e, 8 f, 16 g$ and $16 g$ crystallographic sites. The structure is built up on four edge-bridged $\left[\mathrm{M}_{6} \mathrm{X}_{12}^{\mathrm{i}}\right]^{2+}$ cluster cores per unit cell. Each cluster is linked to eight neighboring congeners through four apicalapical $X^{a-a}$, two apical-inner $X^{a-i}$, and two inner-apical $X^{i-a}$ bridges (Fig. 8), forming a three-dimensional cluster framework and leading to the structural formula $\left[\mathrm{M}_{6} \mathrm{X}_{10}^{\mathrm{i}} \mathrm{X}^{\mathrm{i}-\mathrm{a}}{ }_{2 / 2} \mathrm{X}^{\mathrm{a}-\mathrm{i}}{ }_{2 / 2} \mathrm{X}^{\mathrm{a}-\mathrm{a}}{ }_{4 / 2}\right]$. The structure can be viewed as a lozenge arrangement of clusters in the $(a, c)$ plane linked by the apical-apical $X^{a-a}$ bridges and stacked along the $b$-axis through the apical-inner $X^{a-i}$ and inner-apical $X^{i-a}$ bridges (Fig. 9). $\ln \mathrm{Nb}_{6} \mathrm{Cl}_{14}$, the apical-inner $X^{a-i}$ and inner-apical $X^{i-a}$ bridges lead to four short intercluster distances of 8.239(3) $\AA$ in the $(b, c)$ plane and the apical-apical $X^{a-a}$ bridges to four slightly longer intercluster distances of $8.711(3) \AA$ in the $(a, c)$ plane (Fig. 9). The environment is completed by four surrounded clusters in the $(a, b)$ plane not directly linked to the central cluster at intercluster distances of 9.113(3) $\AA$ (Fig. 9). Consequently, in $\mathrm{Nb}_{6} \mathrm{Cl}_{14}$ each $\mathrm{Nb}_{6}$ cluster is surrounded by twelve $\mathrm{Nb}_{6}$ clusters at relatively close intercluster distances forming a pseudo closed packed three-dimensional cluster framework. Similar cluster framework is encountered in $\mathrm{Ta}_{6} \mathrm{Br}_{14}$ and $\mathrm{Ta}_{6} \mathrm{I}_{14}$ compounds with longer intercluster distances in relation with the ionic radius of halogen ligands (Table 5 and Fig. 10). However, the evolution of the intercluster distances as a function of the halogen ionic radius shows some dependence with the type of cluster bridges. Indeed, while the intercluster distances related to surrounding clusters not directly linked (in black in Fig. 10) or linked through apical-inner $X^{a-i}$ and inner-apical $X^{i-a}$ bridges (in red in Fig. 10) evolve similarly with the halogen ionic radius, those related to apical-apical $X^{a-a}$ bridges (in blue in Fig. 10) are not influenced to the same degree with the increase halogen ionic radius. This evolution should be directly related to the ionicity of the $M-X$ bonds, which decrease from $X=C l$ to $X=I$, at the expense of a covalent character more and more pronounced. 


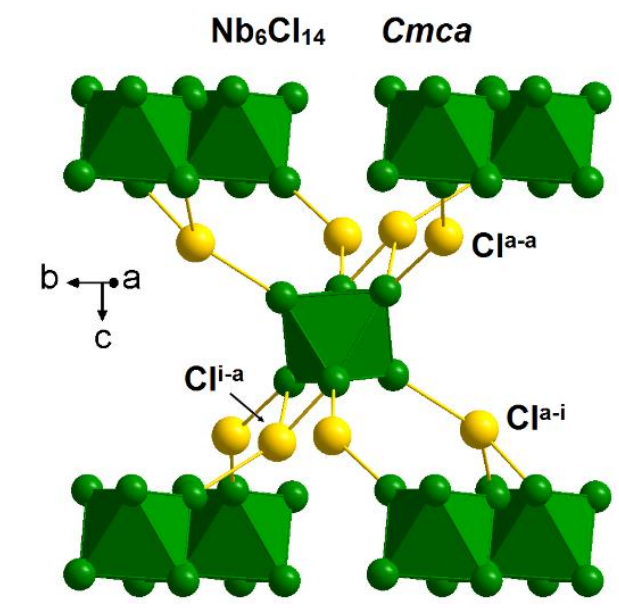

Fig. 8 Crystal structure representation of $\mathrm{Nb}_{6} \mathrm{Cl}_{14}$ (space group $\mathrm{Cmca}$ ) highlighting the three dimensional cluster framework through apical-apical $\mathrm{Cl}^{\mathrm{a}-\mathrm{a}}$, apical-inner $\mathrm{Cl}^{\mathrm{a}-\mathrm{i}}$ and inner-apical $\mathrm{Cl}^{i-a}$ bridges
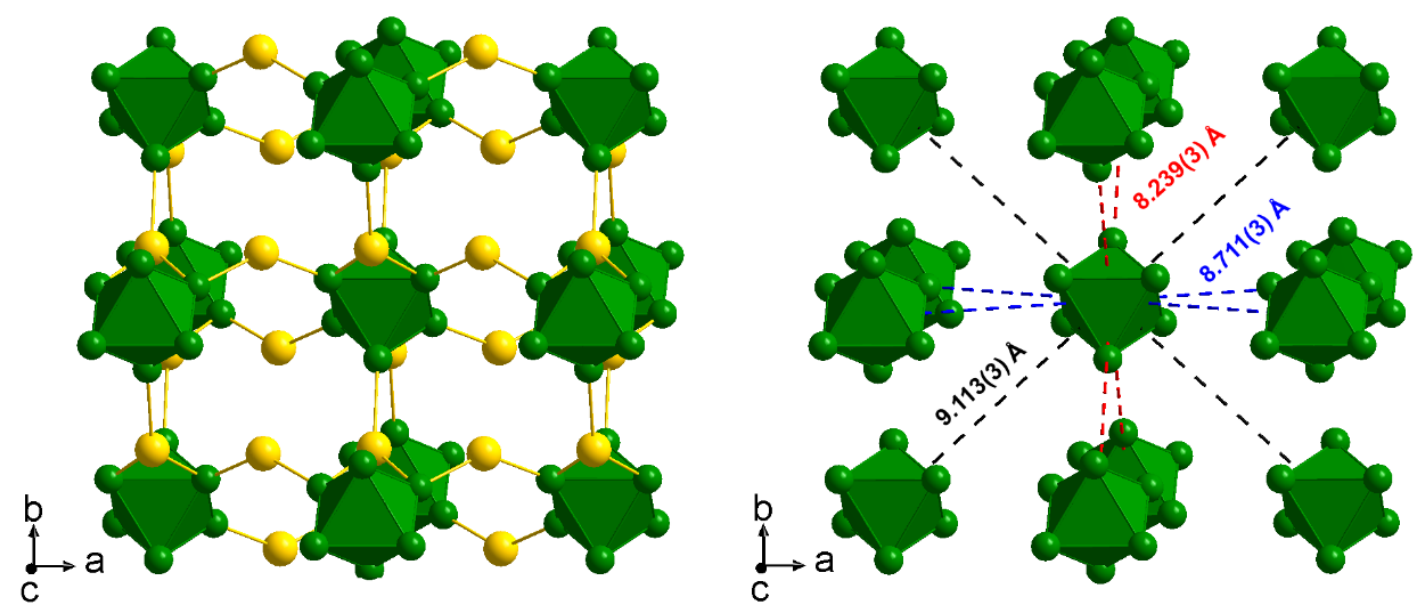

Fig. 9 Representation of the three-dimensional cluster framework (left part) and intercluster $\mathrm{Nb}_{6} \cdots \mathrm{Nb}_{6}$ distances in $\mathrm{Nb}_{6} \mathrm{Cl}_{14}$ (right part). Distances are calculated from crystal data reported in [30]

Table $5 \mathrm{M}_{6} \cdots \mathrm{M}_{6}$ intercluster distances $(\AA)$ in $\mathrm{Nb}_{6} \mathrm{Cl}_{14}$-type structure compounds

\begin{tabular}{lllll}
\hline Bridging type & $\mathrm{Nb}_{6} \mathrm{Cl}_{14}{ }^{\mathrm{a}}$ & $\mathrm{Ta}_{6} \mathrm{Br}_{14}{ }^{\mathrm{b}}$ & $\mathrm{Ta}_{6} \mathrm{l}_{14}{ }^{\mathrm{c}}$ & $\mathrm{Ta}_{6} \mathrm{l}_{14}{ }^{\mathrm{d}}$ \\
\hline Direct $\left(\mathrm{X}^{\mathrm{a}-\mathrm{i}} \times 2, \mathrm{X}^{\mathrm{i}-\mathrm{a}} \times 2\right)$ & $8.239(3)$ & $8.768(6)$ & $9.553(3)$ & $9.573(3)$ \\
Direct $\left(\mathrm{X}^{\mathrm{a}-\mathrm{a}} \times 4\right)$ & $8.711(3)$ & $9.105(6)$ & $9.764(3)$ & $9.781(3)$ \\
Indirect $(\times 4)$ & $9.113(3)$ & $9.640(2)$ & $10.412(3)$ & $10.438(2)$ \\
\hline
\end{tabular}

Distances calculated from crystal data reported in: ${ }^{a}$ Ref. [30]. ${ }^{b}$ Ref. [43].$~{ }^{c}$ Ref. [44]. ${ }^{d}$ Ref. [45] 


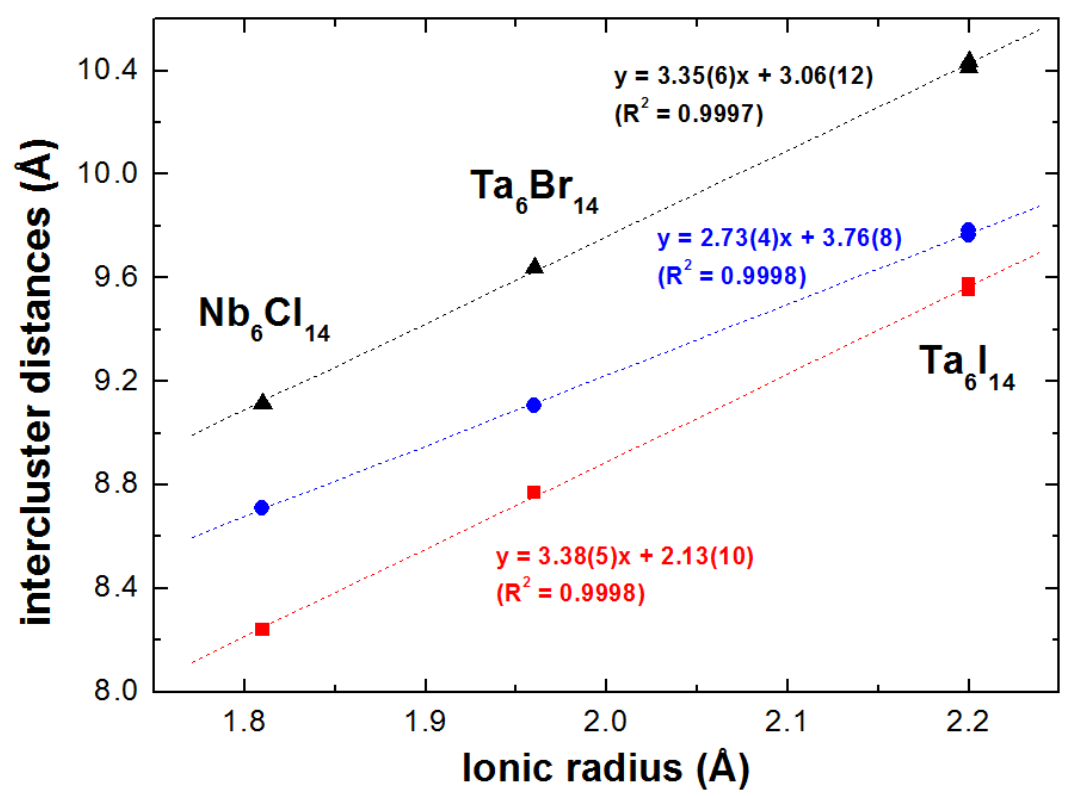

Fig. 10 Evolution of the intercluster distances vs. halogen ionic radius in $\mathrm{Nb}_{6} \mathrm{Cl}_{14}$-type structure compounds. Black triangles correspond to intercluster distances between clusters not directly linked, blue circles correspond to those related to apical-apical $X^{a-a}$ bridges and red squares correspond to those related to apical-inner $X^{a-i}$ and inner-apical $X^{i-a}$ bridges

\section{Cluster Frameworks of Structural Formula $\left[\mathrm{M}_{6} \mathrm{X}_{12}^{\mathrm{i}} \mathrm{X}^{\mathrm{a}-\mathrm{a}-\mathrm{a}}{ }_{6 / 3}\right]$}

The $\mathrm{Nb}_{6} \mathrm{Cl}_{12-x} \mathrm{I}_{2+x}(x \leq 2)$ compounds, obtained from the reaction of $\mathrm{Nb}_{3} \mathrm{Cl}_{8}$ and $\mathrm{Nb}_{3} \mathrm{I}_{8}$ cluster compounds in welded niobium tubes, crystallize in the cubic symmetry space group $\mathrm{Pa} \overline{3}$ (No. 205) with lattice parameters $a$ ranging from $12.578(1) \AA$ for $\mathrm{Nb}_{6} \mathrm{Cl}_{12} \mathrm{l}_{2}$, to 12.754 (1) $\AA$ for $\mathrm{Nb}_{6} \mathrm{Cl}_{10} \mathrm{I}_{4}$ [31]. Crystal structure resolution, performed for two chemical compositions, i.e., $\mathrm{Nb}_{6} \mathrm{Cl}_{12} \mathrm{l}_{2}$ and $\mathrm{Nb}_{6} \mathrm{Cl}_{10.8} \mathrm{l}_{3.2}$ (Table 2), reveals that in $\mathrm{Nb}_{6} \mathrm{Cl}_{12} \mathrm{I}_{2}$, niobium atoms are located on one crystallographic site of general position $24 d$, chlorine atoms on two independent $24 d$ sites and iodine atoms on a $8 c$ crystallographic site. Excess of iodine atoms (i.e., $x$ value) in the $\mathrm{Nb}_{6} \mathrm{Cl}_{12-x} \mathrm{I}_{2+x}(0<x \leq 2)$ series are located on one of the $24 d$ site occupied by chlorine atoms, the second one being fully occupied by chlorine atoms. $\mathrm{Nb}_{6} \mathrm{Cl}_{12-x} \mathrm{I}_{2+x}$ compounds contain four edge-bridged octahedral niobium clusters per unit cell, connected three by three by iodine atoms in apical position through apical-apical-apical bridges (Fig. 11). This leads to a face centered cubic three-dimensional arrangement of structural formula $\left[\left.\mathrm{Nb}_{6} \mathrm{X}_{12}{ }_{12}\right|^{\mathrm{a}-\mathrm{a}-\mathrm{a}} 6 / 3\right]$ (Fig. 12) closely related to that encountered in $\mathrm{Nb}_{6} \mathrm{Cl}_{14}$-type structure (Fig. 9) compounds via a rotation of the $\left[\mathrm{Nb}_{6} \mathrm{X}_{12}{ }_{12}\right]^{2+}$ cluster cores [31]. Consequently, in $\mathrm{Nb}_{6} \mathrm{Cl}_{12} \mathrm{l}_{2}$, each $\mathrm{Nb}_{6}$ cluster is surrounded by twelve $\mathrm{Nb}_{6}$ clusters at intercluster distances of 8.894(1) $\AA$ (Fig. 12). This value, slightly longer than the intercluster distance average encountered in $\mathrm{Nb}_{6} \mathrm{Cl}_{14}$ (i.e., $8.688 \AA$ ), is due to the presence of two iodine atoms instead of chlorine atoms. 


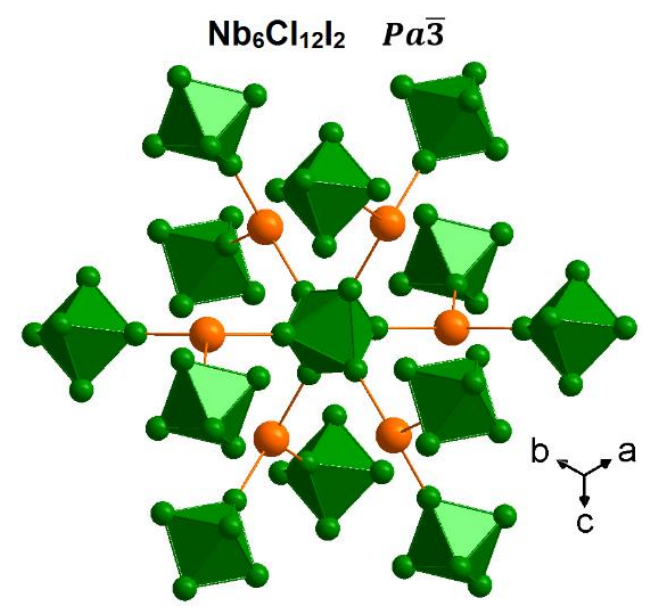

Fig. 11 Crystal structure representation of $\mathrm{Nb}_{6} \mathrm{Cl}_{12} \mathrm{I}_{2}$ (space group $\mathrm{Pa} \overline{3}$ ) highlighting the threedimensional cluster framework through apical-apical ${ }^{a-a-a}$ bridges
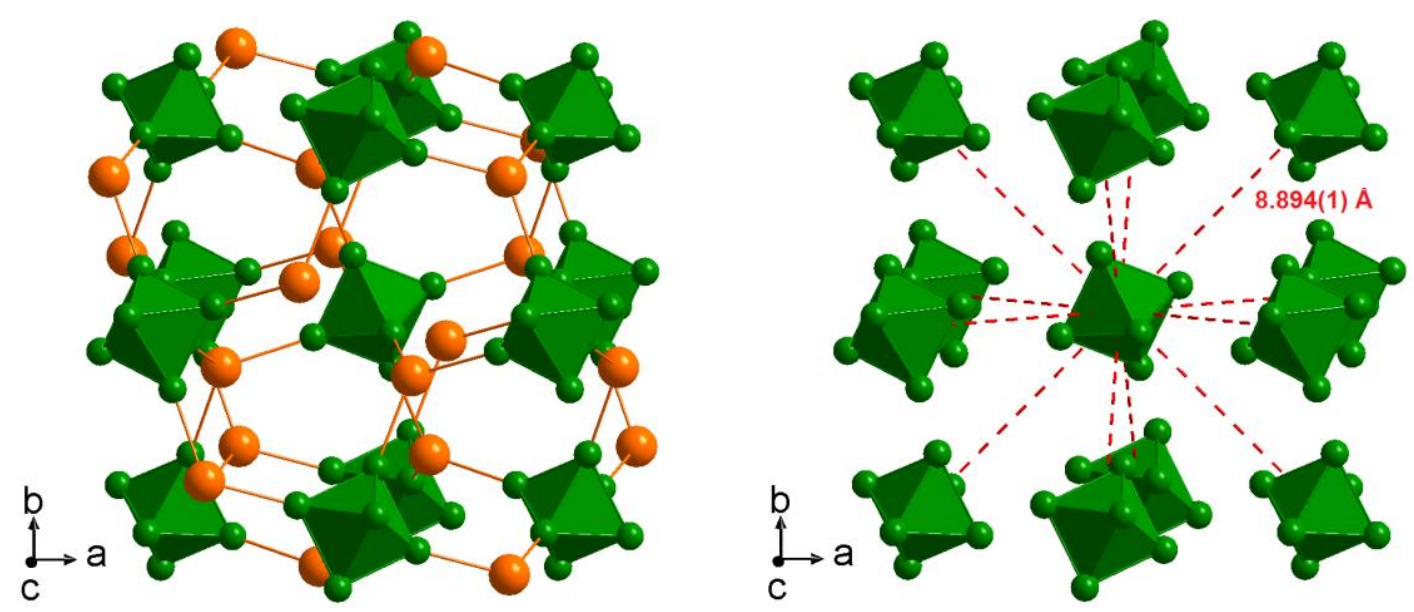

Fig. 12 Representation of the three-dimensional cluster framework (left) and intercluster $\mathrm{Nb}_{6} \cdots \mathrm{Nb}_{6}$ distances in $\mathrm{Nb}_{6} \mathrm{Cl}_{12} \mathrm{I}_{2}$ (right). Distances are calculated from crystal data reported in [31]

\section{Cluster Frameworks of Structural Formula $\left[\mathrm{M}_{6} \mathrm{X}_{12}^{\mathrm{i}} \mathrm{X}^{\mathrm{a}-\mathrm{a}}{ }_{6 / 2}\right]$}

Among inorganic niobium and tantalum octahedral cluster halide compounds with three-dimensional frameworks, those characterized by the structural formula $\left[\mathrm{M}_{6} \mathrm{X}_{12} \mathrm{X}^{\mathrm{a}-\mathrm{a}} 6 / 2\right]$ form the largest and richest family in term of crystal chemistry and structure types (Fig. 13). This is mainly due to (i) the nature of the apical-apical $\mathrm{M}-\mathrm{X}^{\mathrm{a}-\mathrm{a}}-\mathrm{M}$ bridges, which can be linear, non-linear (i.e., bent) or both linear and nonlinear (Fig. 13), and (ii) the ability of the cluster frameworks to incorporate cations and/or $\left(\mathrm{MX}_{6}\right)^{\mathrm{n}-}$ complexes (Fig. 13). This latter point directly influences the VEC of the cluster units which can be stabilized at 14 electrons with incorporation of anion complexes or 16 electrons with incorporation of counter-cations into 15-VEC $M_{6} \mathrm{X}_{15}$ cluster frameworks (Fig. 13). In this section, the crystal structures of cluster compounds of structural formula $\left[\mathrm{M}_{6} \mathrm{X}_{12}{ }_{12} \mathrm{X}^{\mathrm{a}-{ }_{6}}{ }_{6 / 2}\right.$ ], firstly those related to $\mathrm{Nb}_{6} \mathrm{~F}_{15}$ (linear $\mathrm{M}-\mathrm{X}^{\mathrm{a}-\mathrm{a}}-\mathrm{M}$ bridges), secondly those related to $\mathrm{Ta}_{6} \mathrm{Cl}_{15}$ (bent $\mathrm{M}-\mathrm{X}^{\mathrm{a}-\mathrm{a}}-\mathrm{M}$ bridges in cubic structure), thirdly those related to $\mathrm{Nb}_{6} \mathrm{Br}_{8} \mathrm{~F}_{7}$ (bent $\mathrm{M}-\mathrm{X}^{\mathrm{a}-\mathrm{a}}-\mathrm{M}$ bridges in trigonal structure), and finally those related to $\mathrm{InNb}_{6} \mathrm{Cl}_{15}$ (both linear and bent $\mathrm{M}-\mathrm{X}^{\mathrm{a}-\mathrm{a}}-\mathrm{M}$ bridges) will be described. 
$\left[\mathrm{M}_{6} \mathrm{X}_{12}^{\mathrm{i}} \mathrm{X}^{\mathrm{a}-\mathrm{a}}{ }_{6 / 2}\right]$ cluster frameworks

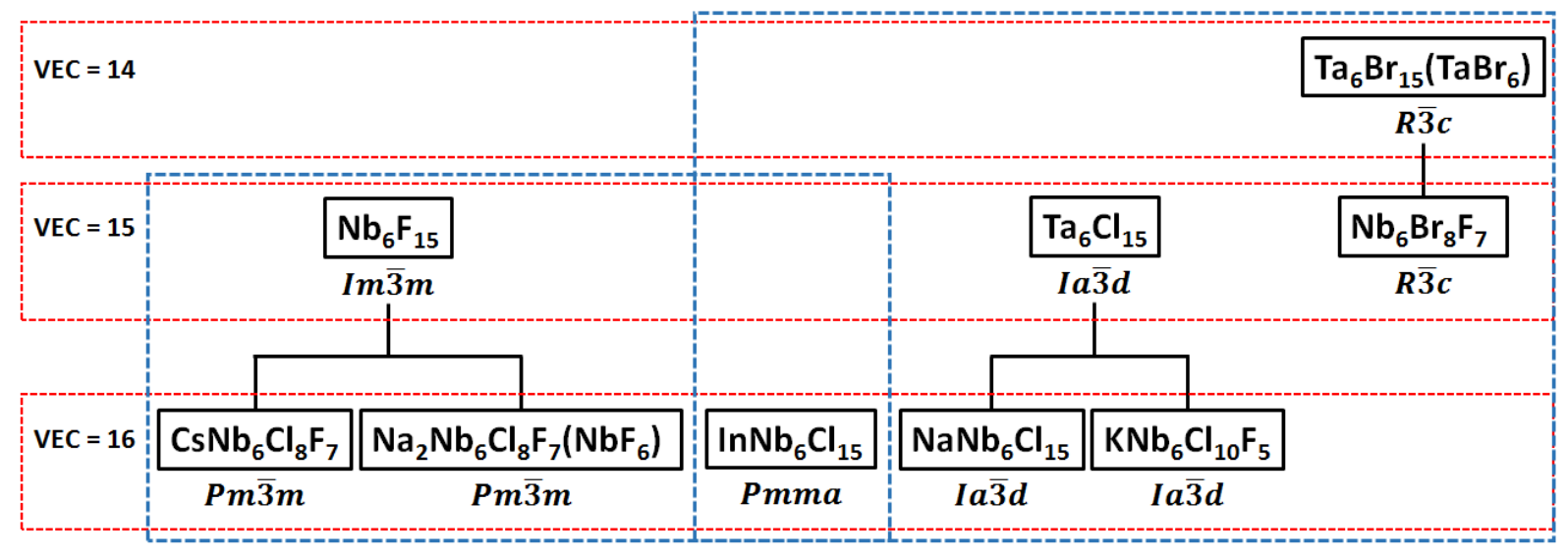

Linear $\mathrm{M}-\mathrm{X}^{\mathrm{a}-\mathrm{a}}-\mathrm{M}$ bridges

Non-linear $\mathrm{M}-\mathrm{X}^{\mathrm{a}-\mathrm{a}}-\mathrm{M}$ bridges

Fig. 13 Classification of the inorganic niobium and tantalum octahedral cluster halide types of structures with three-dimensional frameworks of structural formula $\left[\mathrm{M}_{6} \mathrm{X}_{12}^{\mathrm{i}} \mathrm{X}^{\mathrm{a}-\mathrm{a}}{ }_{6 / 2}\right]$

\subsection{Cluster Compounds with Linear $M-X^{a-a}-M$ Bridges}

\subsection{1 $\mathrm{Nb}_{6} \mathrm{~F}_{15}$-Type}

The crystal structure of $\mathrm{Nb}_{6} \mathrm{~F}_{15}$ was reported in 1965 by Schäfer et al. [32]. This compound crystallizes in the cubic symmetry (space group $\operatorname{Im} \overline{3} m$, No. 229) with lattice parameter $a=8.19 \AA$. Niobium atoms are located on one $12 e$ crystallographic site, fluorine atoms in inner position on one $24 \mathrm{~h}$ site and fluorine atoms in apical position on the $6 b$ site [32]. Its crystal structure is formed by the interpenetration of two primitive cubic cluster networks (Fig. 14), related one to the other by a $[1 / 2,1 / 2$, $1 / 2$ ] translation. Each primitive network forms a three-dimensional framework through linear apicalapical $\mathrm{F}^{\mathrm{a}-\mathrm{a}}$ bridges (Fig. 14) and is linked to the second network through $\mathrm{F}^{\mathrm{i}} \ldots \mathrm{F}^{\mathrm{i}}$ and $\mathrm{F}^{\mathrm{i}} \ldots \mathrm{F}^{\mathrm{a}}$ halogen bonds of inter-halogen distances of $2.880 \AA$ [46], slightly longer than the sum of the van der Waals radius of fluorine (i.e., $2.70 \AA$ ). This leads to a highly compact crystal structure, where each cluster $\mathrm{Nb}_{6} \mathrm{~F}_{15}$ occupied a volume of $275 \AA^{3}$ at room temperature. This volume per cluster unit is by far the smallest one among the cluster compounds discussed in this review (Table 2).
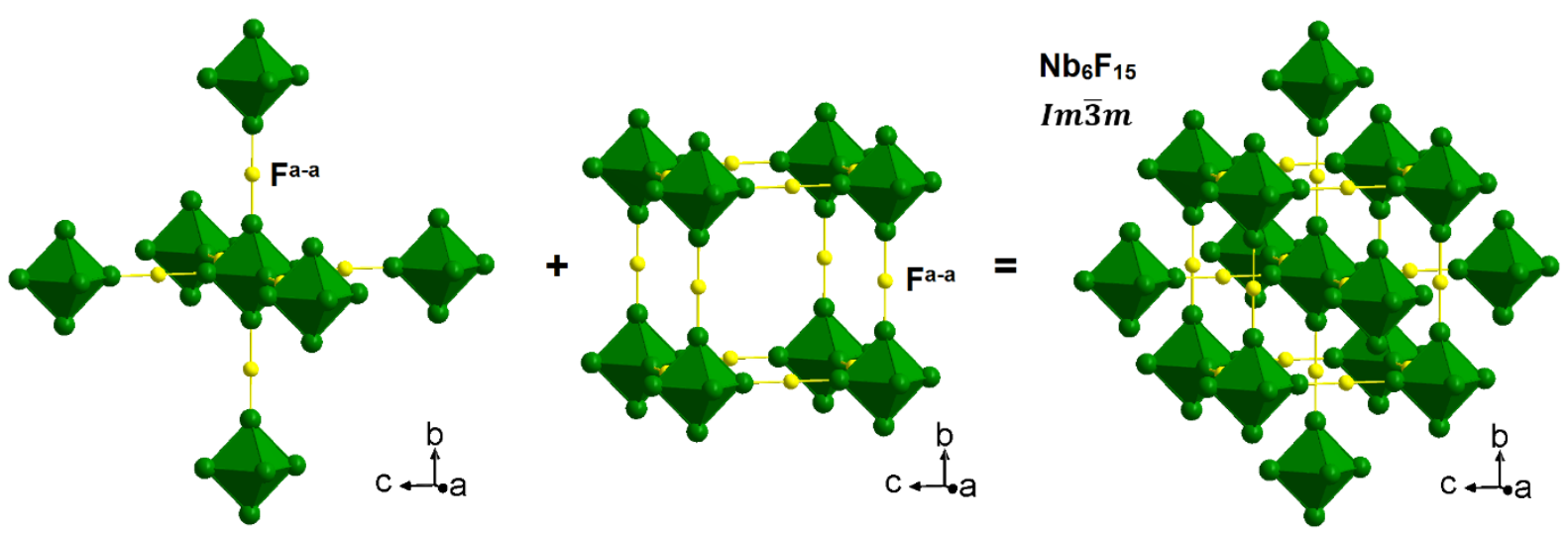

Fig. 14 Crystal structure representation of $\mathrm{Nb}_{6} \mathrm{~F}_{15}$ (space group $\operatorname{Im} \overline{3} m$ ) highlighting the two interpenetrated primitive cluster networks. Inner ligands are omitted for clarity 
The crystal structure of $\mathrm{Nb}_{6} \mathrm{~F}_{15}$ is characterized by halogen bridging between cluster units leading to the structural formula $\left[\mathrm{Nb}_{6} \mathrm{~F}_{12}^{\mathrm{i}} \mathrm{F}^{\mathrm{a}-\mathrm{a}} 6 / 2\right]$ and a $\mathrm{VEC}$ of 15 , which could cause Curie-Weiss behavior via superexchange interactions [60]. This behavior, related to one unpaired electron per $\left[\mathrm{Nb}_{6} \mathrm{~F}_{12}{ }_{12}^{3+}\right.$ cluster core, was confirmed by magnetic susceptibility, ${ }^{19} \mathrm{~F}$ nuclear magnetic resonance and electron magnetic resonance measurements [46, 60-62]. Below $6 \mathrm{~K}, \mathrm{Nb}_{6} \mathrm{~F}_{15}$ exhibits an antiferromagnetic ordering $[46,61,62]$. From a spin exchange interactions analysis using electronic structure theoretical calculations of extended Hückel type, it was suggested that this antiferromagnetic arrangement is associated to an antiferromagnetic coupling between the two interpenetrating ferromagnetic simple cubic cluster networks [63]. Neutron powder diffraction measurements did not confirm this magnetic structure, but rather revealed a decrease of the low-angle background upon cooling [62]. This result is consistent with the emergence of magnetic ordering, which leads to the removal of the paramagnetic scattering contribution to the background, and is a clear signature of the unpaired electron delocalization on the $\left[\mathrm{Nb}_{6} \mathrm{~F}_{12}^{\mathrm{i}}\right]^{3+}$ cluster core [62].

\subsection{2 $\mathrm{CsNb}_{6} \mathrm{Cl}_{8} \mathrm{~F}_{7}-\mathrm{Type}$}

$\mathrm{CsNb}_{6} \mathrm{Cl}_{8} \mathrm{~F}_{7}$, reported in 2001 by Cordier et al., crystallizes in the cubic symmetry space group $P m \overline{3} m$ (No. 221) with unit cell parameter $a=8.2743$ (3) $\AA$ [20]. In this structure, niobium atoms are located on one crystallographic site (6e), chlorine and fluorine atoms are randomly distributed on one site (12i) corresponding to the ligands in inner position, fluorine atoms also fully occupied one site ( $3 d$ ) corresponding to the ligands in apical position, and cesium atoms are distributed on six independent sites $(6 f, 12 j, 24 I, 24 I, 24 m$, and $48 n)$ all partially occupied. This leads to the refined structural formula $\mathrm{Cs}_{1.3(1)}\left[\mathrm{Nb}_{6} \mathrm{Cl}_{8}{ }_{8} \mathrm{~F}_{4} \mathrm{~F}^{\mathrm{a}-\mathrm{a}}{ }_{6 / 2}\right]$, where a VEC of 16 is assumed. Its crystal structure can be described as a simple cubic stacking of $\left[\mathrm{Nb}_{6} \mathrm{Cl}_{8}{ }_{8} \mathrm{~F}_{4} \mathrm{~F}_{3}{ }_{3}\right]$ cluster units linked to six adjacent other ones by linear $\mathrm{F}^{\text {a-a }}$ bridges, leading to the $\left[\mathrm{Nb}_{6} \mathrm{Cl}_{8}{ }_{8} \mathrm{~F}_{4}{ }_{4} \mathrm{~F}^{\mathrm{a}-\mathrm{a}}{ }_{6 / 2}\right]$ structural formula (Fig. 15). This primitive three-dimensional cluster framework can be viewed as a $\mathrm{Nb}_{6} \mathrm{~F}_{15}$ derivative [20] as highlighted by only one $\mathrm{Nb}-\mathrm{Nb}$ distance (i.e., perfectly octahedral cluster), linear $\mathrm{F}^{\mathrm{a}-\mathrm{a}}$ bridges and equivalent $\mathrm{Nb}-\mathrm{F}^{\mathrm{a}-\mathrm{a}}$ interatomic distances $(2.114 \AA$ for $\mathrm{CsNb}_{6} \mathrm{Cl}_{8} \mathrm{~F}_{7}$ compared to $2.113 \AA$ for $\mathrm{Nb}_{6} \mathrm{~F}_{15}$, Table 3).

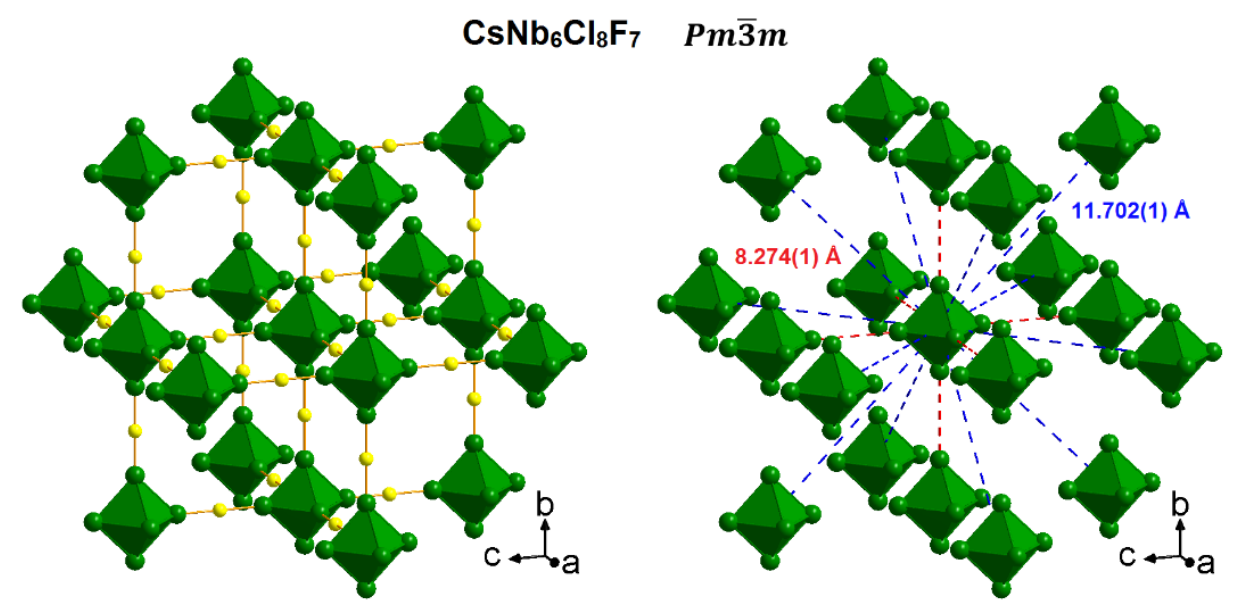

Fig. 15 Representation of the three-dimensional cluster framework (left) and intercluster $\mathrm{Nb}_{6} \cdots \mathrm{Nb}_{6}$ distances (right) in $\mathrm{CsNb}_{6} \mathrm{Cl}_{8} \mathrm{~F}_{7}$. Inner ligands are omitted for clarity. Distances are calculated from crystal data reported in [20] 


\subsection{3 $\mathrm{Na}_{2} \mathrm{Nb}_{6} \mathrm{Cl}_{8} \mathrm{~F}_{7}\left(\mathrm{NbF}_{6}\right)$-Type}

$\mathrm{Na}_{2} \mathrm{Nb}_{6} \mathrm{Cl}_{8} \mathrm{~F}_{7}\left(\mathrm{NbF}_{6}\right)$ was the first niobium cluster chlorofluoride reported in the literature in 1999 by Cordier and Simon [19]. It crystallizes in the cubic symmetry space group $P m \overline{3} m$ (No. 221) with unit cell parameter $a=8.2005$ (9) $\AA$. In this compound, niobium atoms related to the cluster occupy one $6 e$ crystallographic site, chlorine and fluorine atoms corresponding to ligands in inner position are randomly distributed on one $12 i$ site, while the $3 d$ site related to the ligands in apical position is fully occupied by fluorine atoms. Niobium and fluorine atoms related to $\left(\mathrm{NbF}_{6}\right)^{\mathrm{n}-}$ complexes (see below) occupied the $1 b$ and one $6 f$ crystallographic sites, respectively. Finally, sodium cations are statistically distributed on one $12 h$ crystallographic site with a site occupancy factor (SOF) of 0.156(8). This leads, within the standard deviations, to the structural formula $\mathrm{Na}_{2}\left[\mathrm{Nb}_{6} \mathrm{Cl}_{8}^{\mathrm{i}_{8}} \mathrm{~F}_{4}^{\mathrm{i}} \mathrm{F}^{\mathrm{a}-\mathrm{a}}{ }_{6 / 2}\right]\left(\mathrm{NbF}_{6}\right)$ [19].

The crystal structure of $\mathrm{Na}_{2} \mathrm{Nb}_{6} \mathrm{Cl}_{8} \mathrm{~F}_{7}\left(\mathrm{NbF}_{6}\right)$ is related to that of $\mathrm{Nb}_{6} \mathrm{~F}_{15}$, for which only one cluster network (identical to that encountered in $\mathrm{CsNb}_{6} \mathrm{Cl}_{8} \mathrm{~F}_{7}$, Fig. 15 ) is preserved while the second is replaced by $\left(\mathrm{NbF}_{6}\right)^{\mathrm{n}-}$ complexes (Fig. 16). Two sodium cations statistically distributed on the faces of the cubic unit cell provide the cohesion of the crystal structure (Fig. 16) and counter-balance the charge of the $\left(\mathrm{NbF}_{6}\right)^{\text {n- }}$ complex located at the center of the cubic unit cell and eventually that of the cluster [19]. Indeed, the VEC of the cluster should be either 15, if the two sodium cations counter-balance the charge of the $\left(\mathrm{NbF}_{6}\right)^{2-}$ complex, or 16 if one sodium cation counter-balances the charge of the $\left(\mathrm{NbF}_{6}\right)^{-}$ complex, the second one counter-balancing the charge of the cluster [19].

A second compound was found to be isotypic with $\mathrm{Na}_{2} \mathrm{Nb}_{6} \mathrm{Cl}_{8} \mathrm{~F}_{7}\left(\mathrm{NbF}_{6}\right)$, namely, $\mathrm{Na}_{2} \mathrm{Nb}_{6} \mathrm{Br}_{4} \mathrm{~F}_{11}\left(\mathrm{NbF}_{6}\right)$ [34]. However, in this case, the atomic coordinates of bromine and fluorine atoms on the inner position were refined independently, while those of chlorine and fluorine were constrained to be the same in $\mathrm{Na}_{2} \mathrm{Nb}_{6} \mathrm{Cl}_{8} \mathrm{~F}_{7}\left(\mathrm{NbF}_{6}\right)$.
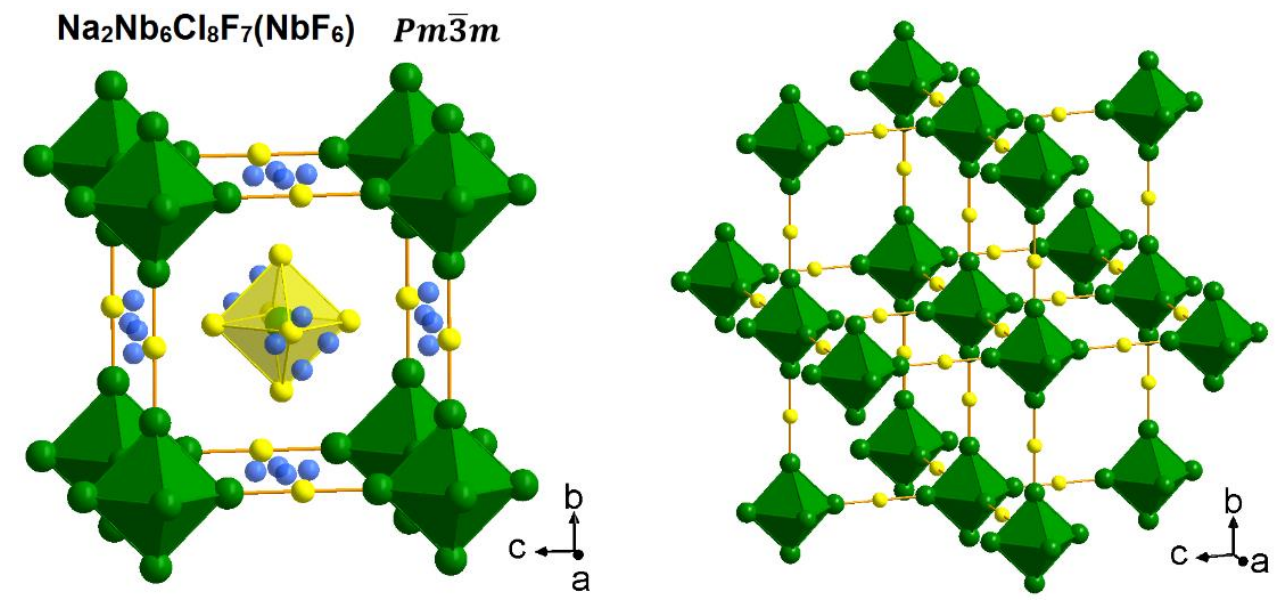

Fig. 16 Representation of the unit cell of $\mathrm{Na}_{2} \mathrm{Nb}_{6} \mathrm{Cl}_{8} \mathrm{~F}_{7}\left(\mathrm{NbF}_{6}\right)$ (left) and of its three-dimensional cluster framework (right). Inner ligands are omitted for clarity

\subsubsection{Comparison of $\mathrm{Nb}_{6} \mathrm{~F}_{15}, \mathrm{CsNb}_{6} \mathrm{Cl}_{8} \mathrm{~F}_{7}$ and $\mathrm{Na}_{2} \mathrm{Nb}_{6} \mathrm{Cl}_{8} \mathrm{~F}_{7}\left(\mathrm{NbF}_{6}\right)$ Cluster Frameworks}

In $\mathrm{Nb}_{6} \mathrm{~F}_{15}$, the interpenetration of two primitive cubic cluster networks leads to eight very short intercluster distances of $7.09 \AA$ (Table 6). The cluster units separated from these intercluster distances

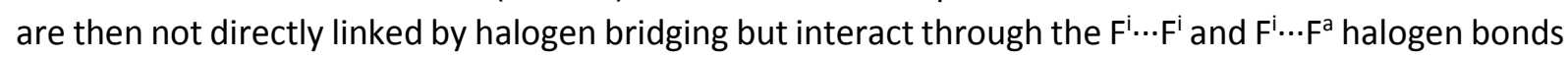
existing between the two networks. Direct linear apical-apical $F^{a-a}$ bridges induce six short intercluster distances of $8.19 \AA$ A. Finally, the cluster environment is completed by twelve clusters of the same network at intercluster distances of $11.58 \AA$, which are not directly linked to the central cluster unit. 
As previously mentioned, the crystal structures of $\mathrm{CsNb}_{6} \mathrm{Cl}_{8} \mathrm{~F}_{7}$ and $\mathrm{Na}_{2} \mathrm{Nb}_{6} \mathrm{Cl}_{8} \mathrm{~F}_{7}\left(\mathrm{NbF}_{6}\right)$ are related to that of $\mathrm{Nb}_{6} \mathrm{~F}_{15}$. However, in the former compounds only one cluster network is preserved, the second being replaced either by cesium cations or $\left(\mathrm{NbF}_{6}\right)$ anionic complexes. This leads to the absence of the eight very short intercluster distances related to the interpenetration of the two primitive cubic cluster networks. Hence, the cluster environment in $\mathrm{CsNb}_{6} \mathrm{Cl}_{8} \mathrm{~F}_{7}$ and $\mathrm{Na}_{2} \mathrm{Nb}_{6} \mathrm{Cl}_{8} \mathrm{~F}_{7}\left(\mathrm{NbF}_{6}\right)-$ type structure compounds is formed by six cluster units directly linked through $\mathrm{X}^{\mathrm{a}-\mathrm{a}}$ bridges and twelve cluster units not directly linked to the central cluster (see Fig. 15 for example and Table 6). The intercluster distances in $\mathrm{CsNb}_{6} \mathrm{Cl}_{8} \mathrm{~F}_{7}$ are slightly longer compared to those in $\mathrm{Nb}_{6} \mathrm{~F}_{15}$ (Table 6). On the contrary, they are equivalent in the $\mathrm{Na}_{2} \mathrm{Nb}_{6} \mathrm{Cl}_{8} \mathrm{~F}_{7}\left(\mathrm{NbF}_{6}\right)$-type structure compounds (Table 6), despite the fact that partial replacement of fluorine inner ligands either by chlorine (i.e., $\mathrm{Na}_{2} \mathrm{Nb}_{6} \mathrm{Cl}_{8} \mathrm{~F}_{7}\left(\mathrm{NbF}_{6}\right)$ ) or by bromine (i.e., $\mathrm{Na}_{2} \mathrm{Nb}_{6} \mathrm{Br}_{4} \mathrm{~F}_{11}\left(\mathrm{NbF}_{6}\right)$ ) leads to longer $\mathrm{M}-\mathrm{X}^{\mathrm{i}}$ interatomic distances (Table 3). This suggests that the size of the cluster core and the electronic effect induced by the repulsion between cluster units and complexes, are compensated by halogen matrix effects between sodium cations and cluster units/complexes.

Table $6 \mathrm{M}_{6} \cdots \mathrm{M}_{6}$ intercluster distances $(\AA)$ in $\mathrm{Nb}_{6} \mathrm{~F}_{15}, \mathrm{CsNb}_{6} \mathrm{Cl}_{8} \mathrm{~F}_{7}$ and $\mathrm{Na}_{2} \mathrm{Nb}_{6} \mathrm{Cl}_{8} \mathrm{~F}_{7}\left(\mathrm{NbF}_{6}\right)$-type structure compounds

\begin{tabular}{llllll}
\hline Bridging type & $\mathrm{Nb}_{6} \mathrm{~F}_{15}{ }^{\mathrm{a}}$ & $\mathrm{Nb}_{6} \mathrm{~F}_{15}{ }^{\mathrm{b}}$ & $\mathrm{CsNb}_{6} \mathrm{Cl}_{8} \mathrm{~F}_{7}{ }^{\mathrm{c}}$ & $\mathrm{Na}_{2} \mathrm{Nb}_{6} \mathrm{Cl}_{8} \mathrm{~F}_{7}\left(\mathrm{NbF}_{6}\right)^{\mathrm{d}}$ & $\mathrm{Na}_{2} \mathrm{Nb}_{6} \mathrm{Br}_{4} \mathrm{~F}_{11}\left(\mathrm{NbF}_{6}\right)^{\mathrm{e}}$ \\
\hline Indirect $(\times 8)$ & $7.093(1)$ & $7.091(1)$ & - & - & - \\
Direct $(\times 6)$ & $8.190(1)$ & $8.188(1)$ & $8.274(1)$ & $8.201(1)$ & $8.177(1)$ \\
Indirect $(\times 12)$ & $11.582(1)$ & $11.579(1)$ & $11.702(1)$ & $11.597(1)$ & $11.563(1)$ \\
\hline
\end{tabular}

Distances calculated from crystal data reported in: ${ }^{a}$ Ref. [32]. ${ }^{b}$ Ref. [46]. ${ }^{c}$ Ref. [20]. ${ }^{d}$ Ref. [19]. ${ }^{\text {e }}$ Ref. [34]

\subsection{Cluster Compounds with Bent $M-X^{a-a}-M$ Bridges in Cubic Structure}

\subsection{1 $\mathrm{Ta}_{6} \mathrm{Cl}_{15}$-Type}

$\mathrm{Ta}_{6} \mathrm{Cl}_{15}$ and $\mathrm{Ta}_{6} \mathrm{Br}_{15}$ have been reported in 1968 by Bauer and von Schnering to crystallize in the cubic symmetry (space group $I a \overline{3} d$, No. 230) with lattice parameters $a=20.286(1) \AA$ and $21.290(1) \AA$, respectively [33]. The crystal structure resolution, performed on single crystal of $\mathrm{Ta}_{6} \mathrm{Cl}_{15}$, indicated that niobium atoms are located on one crystallographic site of general position $96 h$, halogen atoms in inner position are located on two independent $96 \mathrm{~h}$ sites and halogen atoms in apical position on one $48 \mathrm{~g}$ site [33]. As in $\mathrm{Nb}_{6} \mathrm{~F}_{15}$, the crystal structure of $\mathrm{Ta}_{6} \mathrm{Cl}_{15}$ is characterized by clusters sharing apical ligands in the three directions (Fig. 17), leading to the same kind of structural formula $\left[\mathrm{Ta}_{6} \mathrm{Cl}_{12}^{1} \mathrm{Cl}^{\mathrm{a}-\mathrm{a}}{ }_{6 / 2}\right]$ but with a different three-dimensional cluster framework arrangement (Fig. 18). Indeed, in $\mathrm{Nb}_{6} \mathrm{~F}_{15}$ the $\mathrm{M}-\mathrm{X}^{\mathrm{a}-\mathrm{a}}-\mathrm{M}$ bridges are linear giving two identical independent interpenetrated cluster networks while in $\mathrm{Ta}_{6} \mathrm{Cl}_{15}$ the bridges are bent giving a unique network. 


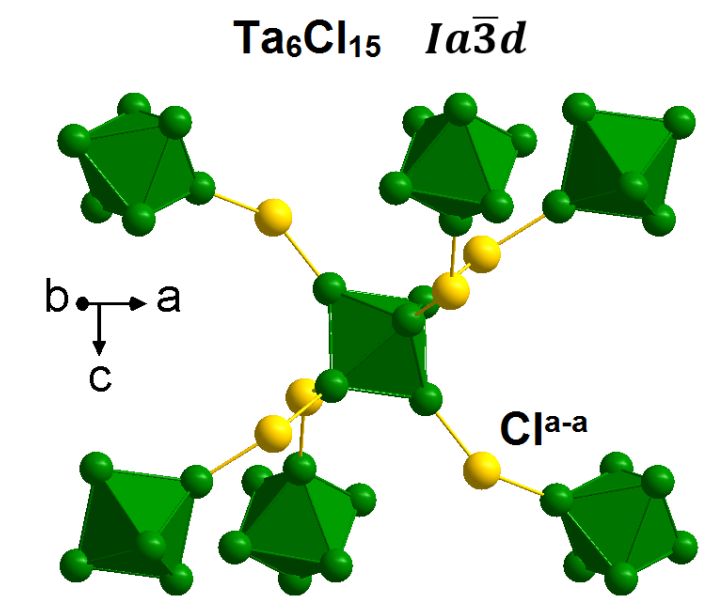

Fig. 17 Crystal structure representation of $\mathrm{Ta}_{6} \mathrm{Cl}_{15}$ (space group $I a \overline{3} d$ ) highlighting the threedimensional cluster framework through apical-apical $\mathrm{Cl}^{\text {a-a }}$ bridges. Inner ligands are omitted for clarity
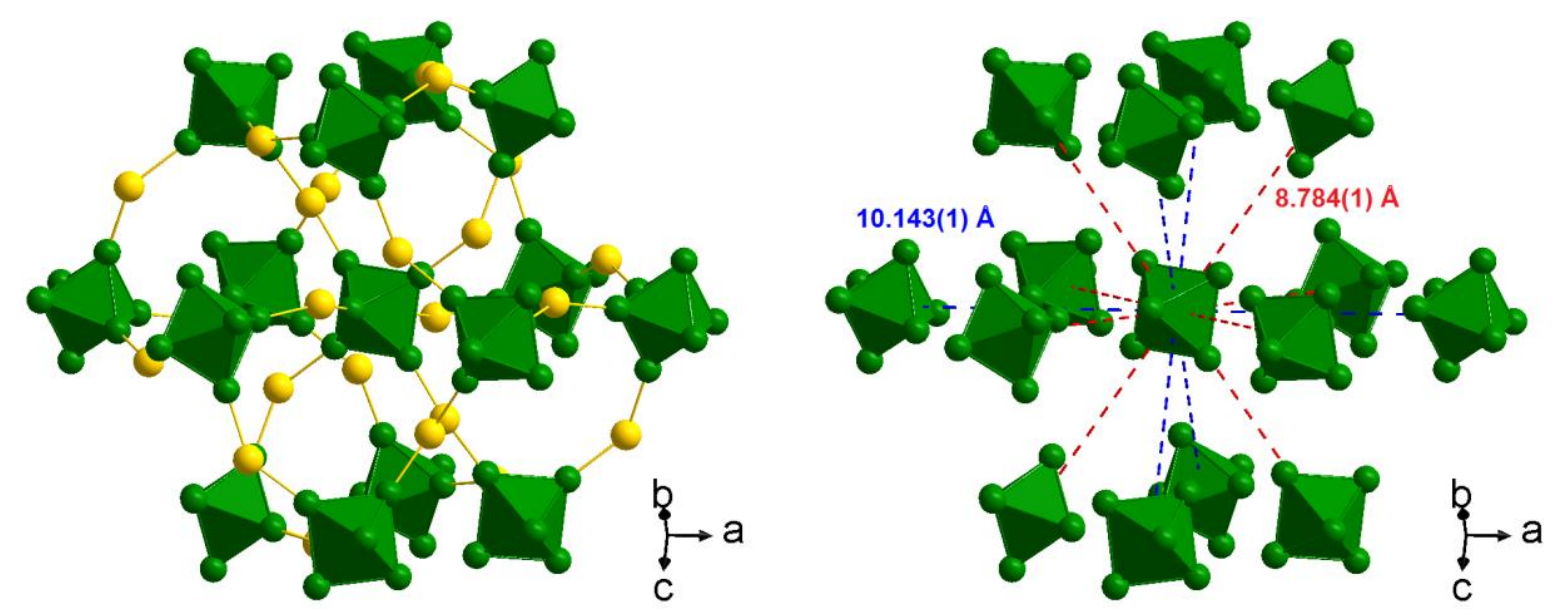

Fig. 18 Representation of the three-dimensional cluster framework (left) and intercluster $\mathrm{Ta}_{6} \cdots \mathrm{Ta}_{6}$ distances in $\mathrm{Ta}_{6} \mathrm{Cl}_{15}$ (right). Inner ligands are omitted for clarity. Distances are calculated from crystal data reported in [33]

Ta $6 l_{15}$ was also reported in 1968 to crystallize in a cubic unit cell with $a=11.02 \AA$ and then was supposed to be isotypic to $\mathrm{Nb}_{6} \mathrm{~F}_{15}$ [64]. While the crystal structure of $\mathrm{Ta}_{6} \mathrm{Br}_{15}$ was confirmed in 1999 by von Schnering et al. [47], that of $\mathrm{Ta}_{6} \mathrm{I}_{15}$ is yet unsolved but is probably isotypic to $\mathrm{Ta}_{6} \mathrm{Cl}_{15}$.

Isostructural niobium chloride compound derivatives can be stabilized by the replacement of a small amount of chlorine by fluorine [48]. The crystal structure of two $\mathrm{Nb}_{6} \mathrm{Cl}_{15-\mathrm{x}} \mathrm{F}_{\mathrm{x}}$ chlorofluoride compounds ( $x=2.2$ and 4.4) were studied by single-crystal X-ray diffraction [48]. Their structure is based on $\left[\mathrm{Nb}_{6} \mathrm{X}_{12} \mathrm{X}_{3}{ }_{3}\right]$ cluster units in which fluorine atoms are randomly distributed on the inner positions but also on the apical positions for $x=4.4$ [48].

As for $\mathrm{Nb}_{6} \mathrm{~F}_{15}, \mathrm{Ta}_{6} \mathrm{Cl}_{15}$ and $\mathrm{Ta}_{6} \mathrm{Br}_{15}$ exhibit a Curie-Weiss behavior in agreement with the VEC of 15 of the $\left[\mathrm{Ta}_{6} \mathrm{X}_{12}\right]^{3+}$ cluster cores $[33,60]$. A magnetic behavior is also expected for $\mathrm{Nb}_{6} \mathrm{Cl}_{15-\mathrm{x}} \mathrm{F}_{\mathrm{x}}$ compounds in relation with their VEC of 15 [48], but it was never confirmed experimentally. 


\subsection{2 $\mathrm{NaNb}_{6} \mathrm{Cl}_{15}$-Type}

The crystal structure of $\mathrm{NaNb}_{6} \mathrm{Cl}_{15}$ was reported in 1995 by Sägebarth et al. [16]. This compound and its isotypic compound, $\mathrm{LiNb}_{6} \mathrm{Cl}_{15}$, crystallize in the cubic symmetry space group $I a \overline{3} d$ (No. 230) with lattice parameter $a=20.417$ (2) $\AA$ at $293 \mathrm{~K}$ for $\mathrm{NaNb}_{6} \mathrm{Cl}_{15}[16]$ and $a=20.555(2) \AA$ at $100 \mathrm{~K}$ for $\mathrm{LiNb}_{6} \mathrm{Cl}_{15}$ [49]. The crystal structure of these compounds is characterized by a three-dimensional cluster framework through bent apical-apical $\mathrm{Cl}^{\text {a-a }}$ bridges, identical to that encountered in $\mathrm{Ta}_{6} \mathrm{Cl}_{15}$ (Figs. 17 and 18), with however, alkaline cations statistically distributed on an interstitial position partially occupied. Hence, niobium atoms are located on one crystallographic site of general position $96 h$, chlorine atoms in inner position are located on two independent $96 \mathrm{~h}$ sites, chlorine atoms in apical position are located on one $48 \mathrm{~g}$ site, and sodium/lithium atoms are located on one $48 \mathrm{f}$ site with a SOF of $\approx 1 / 3[16,49]$. Based on bond distances, the alkaline environment can be described as distorted tetrahedral for lithium cations and distorted trigonal-prismatic bicapped for sodium cations [49]. In this type of structure, alkaline atoms are inside linear channels formed by the body-centered $\left[\mathrm{Nb}_{6} \mathrm{Cl}_{12}{ }_{2} \mathrm{Cl}^{\mathrm{a}-\mathrm{a}}{ }_{6 / 2}\right]$ cluster arrangement. These channels are parallel to the [100], [010] and [001] directions and are stacked in fashion that they do not intersect with each other [49].

The stabilization of the $\mathrm{Ta}_{6} \mathrm{Cl}_{15}$ three-dimensional cluster framework with $\left[\mathrm{Nb}_{6} \mathrm{Cl}_{12}{ }^{1}\right]^{2+}$ cluster core through incorporation of sodium is observed only for the stoichiometric composition $\mathrm{NaNb}_{6} \mathrm{Cl}_{15}$, as no range of homogeneity on the sodium site was detected [16]. It indicates that the $\mathrm{NaNb}_{6} \mathrm{Cl}_{15}$ crystal structure is stable only for compound having a VEC of 16 , value confirmed by magnetic measurements [16].

$\mathrm{NaNb}_{6} \mathrm{Cl}_{15}$ evidences a second order structural transition around $150 \mathrm{~K}$ from the cubic structure with cell parameter $a=20.364(2) \AA$ at $160 \mathrm{~K}$, to a tetragonal structure with cell parameters $a=$ $20.372(6) \AA$ and $c=20.282(2) \AA$ at $80 \mathrm{~K}$ [16]. The space group of the LT form was reported to probably be $I 4_{1} /$ acd [16] but was never confirmed. No structural transition was reported for $\mathrm{LiNb}_{6} \mathrm{Cl}_{15}$. Infrared reflectivity measurements performed on $\mathrm{NaNb}_{6} \mathrm{Cl}_{15}$ showed a vanishing of the narrow bands between 50 and $150 \mathrm{~cm}^{-1}$ with the increase of the temperature from 100 to $200 \mathrm{~K}$ [16]. This is explained by a local order of sodium atoms in the low temperature crystal structure, while these atoms become mobile above the temperature of the structural transition, suggesting that $\mathrm{NaNb}_{6} \mathrm{Cl}_{15}$ is an ionic conductor [16]. This was confirmed by ${ }^{7} \mathrm{Li}$-NMR measurements [49]. These analyses also evidenced a fast lithium mobility above $170 \mathrm{~K}$ in this material [49]. Finally, a study reported on the reversible intercalation of lithium in $\mathrm{Ta}_{6} \mathrm{Cl}_{15}$, leading to the compound $\mathrm{LiTa}_{6} \mathrm{Cl}_{15}$, which is mentioned to be structurally and electronically related to $\mathrm{LiNb}_{6} \mathrm{Cl}_{15}$ [65].

\subsection{3 $\mathrm{KNb}_{6} \mathrm{Cl}_{10} \mathrm{~F}_{5}$-Type}

As for $\mathrm{Nb}_{6} \mathrm{Cl}_{15-\mathrm{x}} \mathrm{F}_{\mathrm{x}}$ [48] and $\mathrm{CsNb}_{6} \mathrm{Cl}_{8} \mathrm{~F}_{7}[20], \mathrm{KNb}_{6} \mathrm{Cl}_{10} \mathrm{~F}_{5}$ was obtained during investigations of fluorine for chlorine substitution in order to increase the interactions between $\mathrm{Nb}_{6}$ clusters by reducing the steric hindrance of ligands [20]. This latter compound was reported to crystallize in the cubic symmetry space group $\operatorname{Ia} \overline{3} d$ (No. 230) with lattice parameter $a=19.589(1) \AA$ at $293 \mathrm{~K}$ and a refined formula $\mathrm{K}_{1.2(2)} \mathrm{Nb}_{6} \mathrm{Cl}_{10} \mathrm{~F}_{5}$ assumed to be stoichiometric within the standard deviations [20]. Its crystal structure, derived of the $\mathrm{Ta}_{6} \mathrm{Cl}_{15}$-type of structure, is based on cluster units sharing apical ligands, leading to a three-dimensional cluster framework $\left[\mathrm{Nb}_{6} \mathrm{X}_{12}^{\mathrm{i}} \mathrm{X}^{\mathrm{a}-\mathrm{a}}{ }_{6 / 2}\right]$ with bent bridges. Crystallographic sites corresponding to the ligands positions (two independent $96 \mathrm{~h}$ sites and one $48 \mathrm{~g}$ site) are randomly occupied by chlorine and fluorine atoms. The potassium cations are statistically distributed on two crystallographic sites: $24 d$ and $96 h$ with SOF of $0.452(24)$ and $0.08(2)$, respectively [20]. Despite a complex crystal structure and structural formula, this compound is characterized by a VEC of 16 . 


\subsubsection{Comparison of $\mathrm{Ta}_{6} \mathrm{Cl}_{15}, \mathrm{NaNb}_{6} \mathrm{Cl}_{15}$ and $\mathrm{KNb}_{6} \mathrm{Cl}_{10} \mathrm{~F}_{5}$ Cluster Frameworks}

In $\mathrm{Ta}_{6} \mathrm{Cl}_{15}$-type structure each cluster unit is surrounded by eight clusters at short intercluster distances, ranging from 8.647(1) $\AA$ for $\mathrm{Nb}_{6} \mathrm{Cl}_{10.6} \mathrm{~F}_{4.4}$ to 9.227(1) $\AA$ for $\mathrm{Ta}_{6} \mathrm{Br}_{15}$ (Table 7). Six of these eight cluster units are directly linked to the central cluster through apical-apical $\mathrm{M}-\mathrm{X}^{\mathrm{a}-\mathrm{a}}-\mathrm{M}$ cluster bridges, while the two remaining cluster units are not directly linked but are located above and below the central cluster on the three-fold axis (Fig. 18). The cluster environment is completed by six cluster units, not directly linked to the central cluster (Fig. 18), at longer intercluster distances ranging from 9.985(1) $\AA$ for $\mathrm{Nb}_{6} \mathrm{Cl}_{10.6} \mathrm{~F}_{4.4}$ to 10.655 (1) ̊̊ for $\mathrm{Ta}_{6} \mathrm{Br}_{15}$ (Table 7).

Table $7 \mathrm{M}_{6} \cdots \mathrm{M}_{6}$ intercluster distances $(\AA)$ in $\mathrm{Ta}_{6} \mathrm{Cl}_{15}$-type structure compounds

\begin{tabular}{llllll}
\hline Bridging type & $\mathrm{Nb}_{6} \mathrm{Cl}_{10.6} \mathrm{~F}_{4.4}{ }^{\mathrm{a}}$ & $\mathrm{Nb}_{6} \mathrm{Cl}_{12.8} \mathrm{~F}_{2.2}{ }^{\mathrm{a}}$ & $\mathrm{Ta}_{6} \mathrm{Cl}_{15}{ }^{\mathrm{b}}$ & $\mathrm{Ta}_{6} \mathrm{Cl}_{15}{ }^{\mathrm{c}}$ & $\mathrm{Ta}_{6} \mathrm{Br}_{15}{ }^{\mathrm{c}}$ \\
\hline Direct $(\times 6)$ & $8.647(1)$ & $8.703(1)$ & $8.784(1)$ & $8.801(1)$ & $9.227(1)$ \\
Indirect $(\times 2)$ & $8.647(1)$ & $8.703(1)$ & $8.784(1)$ & $8.801(1)$ & $9.227(1)$ \\
Indirect $(\times 6)$ & $9.985(1)$ & $10.050(1)$ & $10.143(1)$ & $10.163(1)$ & $10.655(1)$ \\
\hline \multicolumn{5}{l}{ Distances calculated from crystal data reported in: ${ }^{\text {a Ref. [48]. }}{ }^{\mathrm{b}}$ Ref. [33]. ${ }^{\mathrm{c}}$ Ref. [47] }
\end{tabular}

The intercluster distances in $\mathrm{Ta}_{6} \mathrm{Cl}_{15}$-type structure compounds evidence a quadratic evolution with the average halogen ionic radius as shown in Fig. 19. This quadratic evolution is directly related to the average $M-M, M-X^{i}$ and $M-X^{a}$ interatomic distances which are slightly shorter and longer when chlorine ligands are partially substituted by fluorine or totally by bromine, respectively (Table 3 ). This reflects the electronic effect on cluster framework compactness. Moreover, from the quadratic equations, it could be estimated that the minimum intercluster distances should be obtained for an average ionic radius of $1.65 / 1.66 \AA$, which corresponds to a chemical composition of $\mathrm{Nb}_{6} \mathrm{Cl}_{10} \mathrm{~F}_{5}$. This chemical composition, close to that reached experimentally with $\mathrm{Nb}_{6} \mathrm{Cl}_{10.6} \mathrm{~F}_{4.4}$, can be considered as a lower limit to the $\mathrm{Ta}_{6} \mathrm{Cl}_{15}$-type of structure stability, explaining the different type of structure for $\mathrm{Nb}_{6} \mathrm{~F}_{15}$.

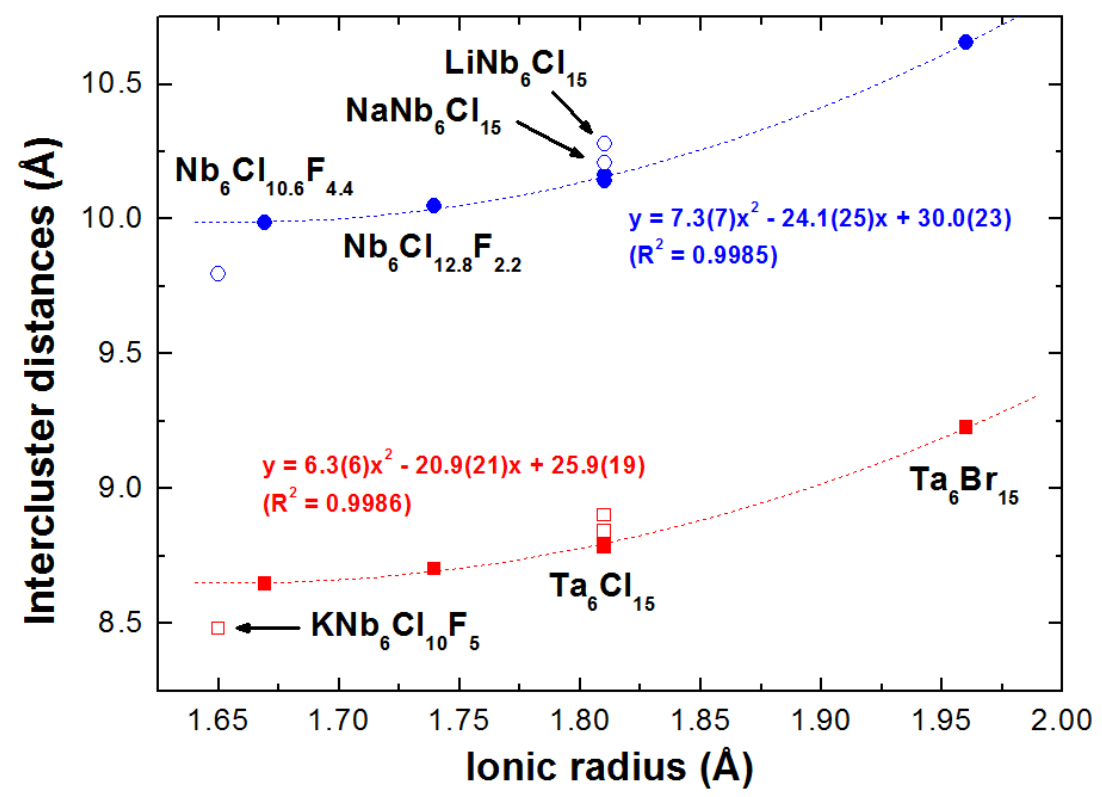

Fig. 19 Evolution of the intercluster distances vs. the average halogen ionic radius in $\mathrm{Ta}_{6} \mathrm{Cl}_{15}$-type, $\mathrm{NaNb}_{6} \mathrm{Cl}_{15}$-type and $\mathrm{KNb}_{6} \mathrm{Cl}_{10} \mathrm{~F}_{5}$ compounds 
Due to their identical three-dimensional cluster frameworks, the cluster unit environments in $\mathrm{NaNb}_{6} \mathrm{Cl}_{15}$ and $\mathrm{KNb}_{6} \mathrm{Cl}_{10} \mathrm{~F}_{5}$ are related to that encountered in $\mathrm{Ta}_{6} \mathrm{Cl}_{15}$, with eight clusters at short intercluster distances (six directly linked through apical-apical $\mathrm{M}-\mathrm{X}^{\mathrm{a}-\mathrm{a}}-\mathrm{M}$ cluster bridges and two not directly linked) and six clusters at longer intercluster distances (Table 8). Similarly to $\mathrm{Ta}_{6} \mathrm{Cl}_{15}$-type structure compounds, an electronic effect is observed on the cluster framework compactness. However, this electronic effect is also influenced by halogen matrix effect through electrostatic interactions occurring between the cluster units and the counter-cations. It leads to intercluster distances slightly longer in ternary cluster chlorides $\mathrm{NaNb}_{6} \mathrm{Cl}_{15}$ and $\mathrm{LiNb}_{6} \mathrm{Cl}_{15}$ (Table 8) than those observed in binary ones (Table 7), and shorter in the pseudo ternary cluster chlorofluoride $\mathrm{KNb}_{6} \mathrm{Cl}_{10} \mathrm{~F}_{5}$ (Table 8) compared to those expected for the corresponding pseudo binary chlorofluoride cluster compound (Fig. 19).

Table $8 \mathrm{M}_{6} \cdots \mathrm{M}_{6}$ intercluster distances $(\AA)$ in $\mathrm{NaNb}_{6} \mathrm{Cl}_{15}$-type and $\mathrm{KNb}_{6} \mathrm{Cl}_{10} \mathrm{~F}_{5}$ compounds

\begin{tabular}{llll}
\hline Bridging type & $\mathrm{NaNb}_{6} \mathrm{Cl}_{15}{ }^{\mathrm{a}}$ & $\mathrm{LiNb}_{6} \mathrm{Cl}_{15}{ }^{\mathrm{b}}$ & $\mathrm{KNb}_{6} \mathrm{Cl}_{10} \mathrm{~F}_{5}{ }^{\mathrm{c}}$ \\
\hline Direct $(\times 6)$ & $8.841(1)$ & $8.901(1)$ & $8.482(1)$ \\
Indirect $(\times 2)$ & $8.841(1)$ & $8.901(1)$ & $8.482(1)$ \\
Indirect $(\times 6)$ & $10.209(1)$ & $10.278(1)$ & $9.795(1)$ \\
\hline
\end{tabular}

Distances calculated from crystal data reported in: ${ }^{a}$ Ref. [16]. ${ }^{b}$ Ref. [49]. ${ }^{c}$ Ref. [20]

\subsection{Cluster Compounds with Bent $M-X^{a-a}-M$ Bridges in Trigonal Structure}

\subsection{1 $\quad \mathrm{Nb}_{6} \mathrm{Br}_{8} \mathrm{~F}_{7}-\mathrm{Type}$}

$\mathrm{Nb}_{6} \mathrm{Br}_{8} \mathrm{~F}_{7}$, reported in 2001 by Cordier et al., crystallizes in the trigonal symmetry space group $R \overline{3} c$ (No. 167) with unit cell parameters $a=9.6373(6) \AA$ and $c=35.415(2) \AA$ [34]. Niobium atoms are located on one $36 f$ crystallographic site. Halogen atoms corresponding to inner ligands are located on two independent $36 \mathrm{f}$ sites, one fully occupied by fluorine atoms and the second statistically occupied by bromine and fluorine atoms with SOF of $0.887(4)$ and $0.113(4)$, respectively. Halogen atoms corresponding to apical ligands are located on one 18e site fully occupied by bromine atoms [34]. The crystal structure of $\mathrm{Nb}_{6} \mathrm{Br}_{8} \mathrm{~F}_{7}$ is based on a three-dimensional cluster framework through bent apicalapical $\mathrm{Br}^{\mathrm{a}-\mathrm{a}}$ bridges (Fig. 20), leading to the structural formula $\left[\mathrm{Nb}_{6} \mathrm{Br}_{5}{ }_{5} \mathrm{~F}_{7} \mathrm{Br}^{\mathrm{a}-\mathrm{a}} 6 / 2\right]$. The non-linearity of the bridges leads to a new kind of cluster arrangement among the $\mathrm{M}_{6} \mathrm{X}_{15}$ compounds of VEC 15 , and is explained by the destabilization of a hypothetical cubic structure due to the presence of a large interstitial void, which is partially filled by bromide apical ligands in the rhombohedral structure [34].
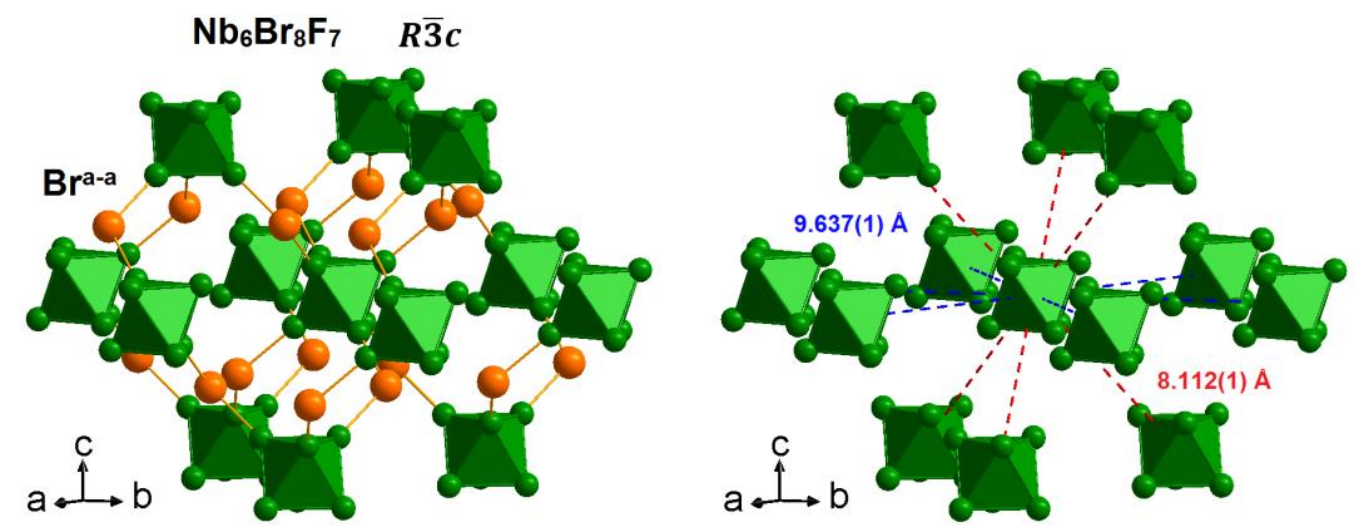

Fig 20 Representation of the three-dimensional cluster framework (left) and intercluster $\mathrm{Nb}_{6} \cdots \mathrm{Nb}_{6}$ distances (right) in $\mathrm{Nb}_{6} \mathrm{Br}_{8} \mathrm{~F}_{7}$. Inner ligands are omitted for clarity. Distances are calculated from crystal data reported in [34] 


\subsection{2 $\operatorname{Ta}_{6} \mathrm{Br}_{15}\left(\mathrm{TaBr}_{6}\right)$-Type}

$\mathrm{Ta}_{6} \mathrm{Br}_{15}\left(\mathrm{TaBr}_{6}\right)_{0.86}$, formerly known as the elusive " $\mathrm{TaBr}_{3}$ ", was reported in 2010 by Habermehl et al. [35]. This cluster compound crystallizes in the trigonal symmetry space group $R \overline{3} c$ (No. 167) with unit cell parameters $a=12.9860(11) \AA$ and $c=33.285$ (4) $\AA$ [35]. Tantalum atoms arising from the cluster are located on one $36 f$ crystallographic site, bromine atoms corresponding to inner ligands are located on two independent $36 f$ sites, and bromine atoms corresponding to apical ligands are located on one 18 e site. Tantalum and bromine atoms arising from the $\mathrm{TaBr}_{6}$ complex occupied the $6 a$ site and one $36 f$ site, respectively, both with SOF of 0.861 (13) [35]. Tantalum in the $\left(\mathrm{TaBr}_{6}\right)$ complex is assumed to be pentavalent, suggesting that $\mathrm{Ta}_{6} \mathrm{Br}_{15}\left(\mathrm{TaBr}_{6}\right)_{0.86}$ should be a salt formed by the association of $\left(\mathrm{TaBr}_{6}\right)^{0.86-}$ complexes and $\left[\mathrm{Ta}_{6} \mathrm{Br}_{15}\right]^{0.86+}$ cluster units [35]. Hence, for a full occupation of the interstitial sites by $\mathrm{TaBr}_{6}$ complexes, a VEC of 14 is expected for the $\left[\mathrm{Ta}_{6} \mathrm{Br}_{12}^{\mathrm{i}}\right]^{4+}$ cluster core [35].

The crystal structure of $\operatorname{Ta}_{6} \mathrm{Br}_{15}\left(\mathrm{TaBr}_{6}\right)_{0.86}$ is strongly related to that of $\mathrm{Nb}_{6} \mathrm{Br}_{8} \mathrm{~F}_{7}$ through identical three-dimensional cluster framework based on bent apical-apical $\mathrm{Br}^{\mathrm{a}-\mathrm{a}}$ bridges, in which interstitial cuboctahedral sites are partially filled by $\left(\mathrm{TaBr}_{6}\right)$ complexes (Fig. 21). These complexes form a three-dimensional network similar to that of the cluster units. Hence, the crystal structure of $\mathrm{Ta}_{6} \mathrm{Br}_{15}\left(\mathrm{TaBr}_{6}\right)_{0.86}$ is formed by the interpenetration of clusters and complexes networks, related one to each other by a $[2 / 3,1 / 3,1 / 12]$ translation (Fig. 21).
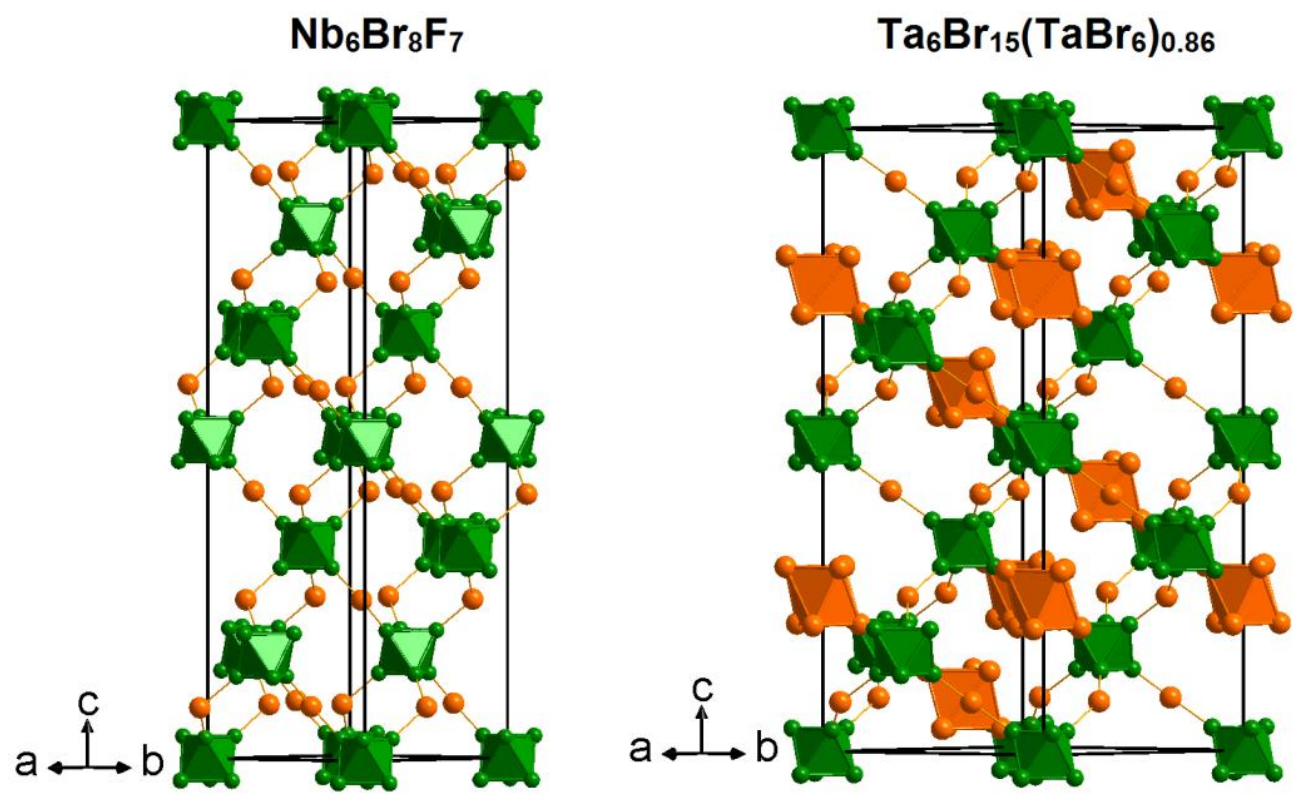

Fig. 21 Representation of the unit cell of $\mathrm{Nb}_{6} \mathrm{Br}_{8} \mathrm{~F}_{7}$ (left) and $\mathrm{Ta}_{6} \mathrm{Br}_{15}\left(\mathrm{TaBr}_{6}\right)_{0.86}$ (right) highlighting the similarity of three-dimensional cluster frameworks. Inner ligands are omitted for clarity

\subsubsection{Comparison of $\mathrm{Nb}_{6} \mathrm{Br}_{8} \mathrm{~F}_{7}$ and $\mathrm{Ta}_{6} \mathrm{Br}_{15}\left(\mathrm{TaBr}_{6}\right)_{0.86}$ Cluster Frameworks}

As previously mentioned, the crystal structures of $\mathrm{Nb}_{6} \mathrm{Br}_{8} \mathrm{~F}_{7}$ and $\mathrm{Ta}_{6} \mathrm{Br}_{15}\left(\mathrm{TaBr}_{6}\right)_{0.86}$ evidence similar three-dimensional cluster networks characterized by bent apical-apical $\mathrm{M}-\mathrm{Br}^{\mathrm{a}-\mathrm{a}}-\mathrm{M}$ bridges (Fig. 21). The shorter intercluster distances are found between cluster linked by apical-apical $\mathrm{Br}^{\mathrm{a}-\mathrm{a}}$ bridges along the $c$-axis, while the longer intercluster distances (corresponding to $a$ parameter) are located in the $(a, b)$ plane between clusters not directly linked by apical-apical bridges (Fig. 20, Fig. 22 and Table 9). The crystal structure of $\mathrm{Ta}_{6} \mathrm{Br}_{15}\left(\mathrm{TaBr}_{6}\right)_{0.86}$ is also characterized by a second network made of $\mathrm{TaBr}_{6}$ 
complexes, interpenetrated with that of the clusters via a $[2 / 3,1 / 3,1 / 12]$ translation (Fig. 21). This leads to an increase of the intercluster $\mathrm{Ta}_{6} \cdots \mathrm{Ta}_{6}$ distances (Table 9) in relation with higher $\mathrm{Ta}-\mathrm{Br}^{\mathrm{a}-\mathrm{a}}-\mathrm{Ta}$ angles $\left(141.3^{\circ}\right)$ compared to the $\mathrm{Nb}-\mathrm{Br}^{\mathrm{a}-\mathrm{a}}-\mathrm{Br}$ angles $\left(117.2^{\circ}\right)$ encountered in $\mathrm{Nb}_{6} \mathrm{Br}_{8} \mathrm{~F}_{7}$. This increase of intercluster distances is more important between clusters located in the $(a, b)$ plane and forming an hexagonal plane (+35\%), compared to clusters directly linked to the central cluster and located above and below this hexagonal plane $(+15 \%)$. While, the increase of intercluster distances in the $(a, b)$ plane is directly related to the $a$ parameter expansion (from $\mathrm{Nb}_{6} \mathrm{Br}_{8} \mathrm{~F}_{7}$ to $\mathrm{Ta}_{6} \mathrm{Br}_{15}\left(\mathrm{TaBr}_{6}\right)_{0.86}$ ) via interpenetration of the two networks, that along the $c$-axis is in apparent contradiction with the $c$ parameter contraction of $6 \%$ (Table 2). This reveals a large anisotropy of the electronic and halogen matrix effects between $\left(\mathrm{TaBr}_{6}\right)^{\mathrm{n}-}$ complexes and $\left[\mathrm{Ta}_{6} \mathrm{Br}_{15}\right]^{n+}$ cluster units in $\mathrm{Ta}_{6} \mathrm{Br}_{15}\left(\mathrm{TaBr}_{6}\right)_{0.86}$. The former is predominant in the $(a, b)$ plane and the latter along the $c$-axis.

Table $9 \mathrm{M}_{6} \cdots \mathrm{M}_{6}$ intercluster distances $(\AA)$ in $\mathrm{Nb}_{6} \mathrm{Br}_{8} \mathrm{~F}_{7}$ and $\mathrm{Ta}_{6} \mathrm{Br}_{15}\left(\mathrm{TaBr}_{6}\right)_{0.86}$ compounds

\begin{tabular}{lll}
\hline Bridging type & $\mathrm{Nb}_{6} \mathrm{Br}_{8} \mathrm{~F}_{7}{ }^{\mathrm{a}}$ & $\mathrm{Ta}_{6} \mathrm{Br}_{15}\left(\mathrm{TaBr}_{6}\right)_{0.86}{ }^{\mathrm{b}}$ \\
\hline Direct $(\times 6)$ & $8.112(1)$ & $9.327(1)$ \\
Indirect $(\times 6)$ & $9.637(1)$ & $12.986(2)$ \\
\hline
\end{tabular}

Distances calculated from crystal data reported in: ${ }^{a}$ Ref. [34]. ${ }^{b}$ Ref. [35]
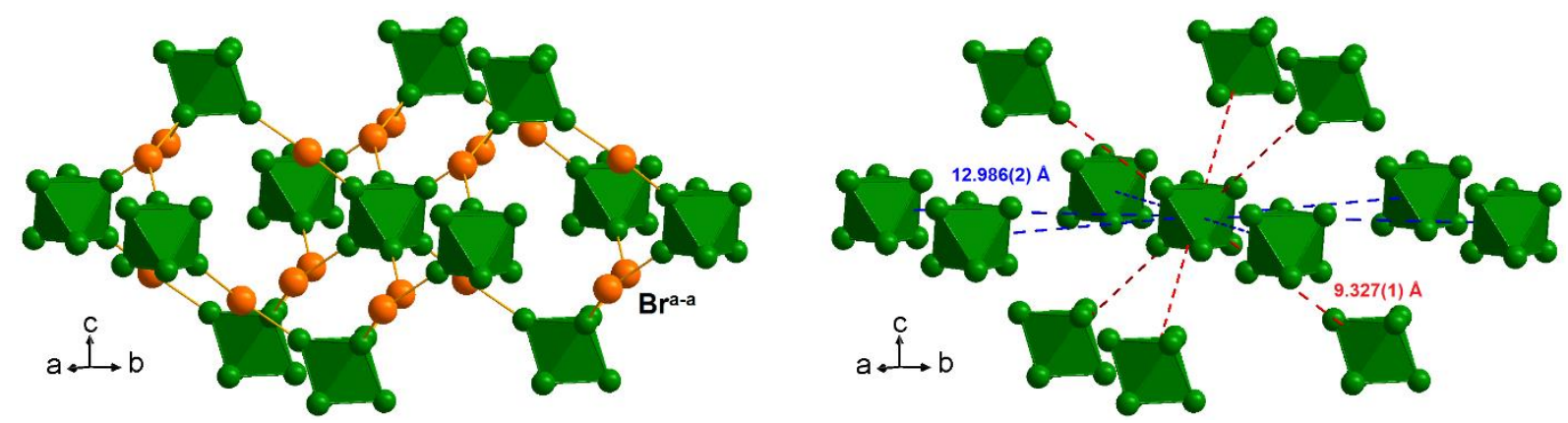

Fig. 22 Representation of the three-dimensional cluster framework (left) and intercluster $\mathrm{Ta}_{6} \cdots \mathrm{Ta}_{6}$ distances (right) in $\mathrm{Ta}_{6} \mathrm{Br}_{15}\left(\mathrm{TaBr}_{6}\right)_{0.86}$. Inner ligands are omitted for clarity. Distances are calculated from crystal data reported in [35]

\subsection{Cluster Compounds with Both Linear and Bent $M-X^{a-a}-M$ Bridges}

The crystal structure of $\mathrm{InNb}_{6} \mathrm{Cl}_{15}$ was first reported by Womelsdorf et al. in 1997 to crystallize in the orthorhombic symmetry space group Pmma (No. 51) with unit cell parameters $a=17.866(1) \AA, b=$ 13.4552(8) $\AA$, and $c=9.2934(8) \AA$ [18]. Its crystal structure is based on two kinds of $\mathrm{Nb}_{6} \mathrm{Cl}_{15}$ cluster units (named cluster $A$ and cluster $B$ ) sharing apical ligands. Clusters $A$ form zigzag chains along the $a$-axis through bent apical-apical $\mathrm{Cl}^{\mathrm{a}-\mathrm{a}}$ bridges and clusters $\mathrm{B}$ form linear chains along the $c$-axis through linear apical-apical $\mathrm{Cl}^{\mathrm{a}-\mathrm{a}}$ bridges (Fig. 23). These chains, perpendicular to each other, are connected along the $b$-axis through bent apical-apical $\mathrm{Cl}^{\mathrm{a}-\mathrm{a}}$ bridges. This leads to a three-dimensional cluster framework of structural formula $\left[\mathrm{Nb}_{6} \mathrm{Cl}_{12} \mathrm{Cl}^{-a-a}{ }_{6 / 2}\right]$, which can be viewed as the interpenetration of two cluster networks formed by clusters $A$ and $B$, respectively, linked to each other by bent apical-apical $\mathrm{Cl}^{\mathrm{a}-\mathrm{a}}$ bridges along the $b$-axis. Indium atoms are located in tetrahedral cavities formed by two clusters $A$ and two clusters $B$. The coordination polyhedron of indium atoms is then formed by eight inner chlorine ligands at distances between 3.229(2) and 3.400(2) $\AA$ and two apical chlorine ligands at distances of 3.301(1) and 3.430(1) $\AA$, forming a distorted bicapped cubic geometry (Fig. 24). Monovalent indium cations counterbalance the charge of the $\left[\mathrm{Nb}_{6} \mathrm{Cl}_{15}\right]^{-}$cluster units, which are characterized by a VEC of 16. Niobium atoms are located on five independent crystallographic sites $(4 j$ and $8 /$ for cluster $A ; 2 e$, 
$2 e$ and $8 /$ for cluster $B$ ), chlorine atoms on inner positions are on eight independent sites $(4 h, 4 j, 8 /$ and $8 /$ for cluster $A ; 4 i, 4 k, 8 /$ and $8 /$ for cluster $B)$, chlorine atoms on apical positions are on three independent sites ( $2 f$ for cluster $\mathrm{A} ; 2 e$ for cluster $\mathrm{B} ; 8 /$ for chlorine atoms common to cluster $\mathrm{A}$ and $\mathrm{B}$ ), and indium atoms are on one $4 k$ site [18].

The crystal structure of isotypic $\mathrm{K}_{0.77} \mathrm{Nb}_{6} \mathrm{Cl}_{15}, \mathrm{RbNb}_{6} \mathrm{Cl}_{15}$ and $\mathrm{CsNb}_{6} \mathrm{Cl}_{15}$ compounds were also studied by single-crystal X-ray diffraction [50], while that of $\mathrm{TINb}_{6} \mathrm{Cl}_{15}$ was assigned from powder X-ray diffraction data [18]. However, in contrast to the crystal structure of $\operatorname{InNb}_{6} \mathrm{Cl}_{15}$ where the cationic $4 k$ site is totally filled, that in $\mathrm{K}_{0.77} \mathrm{Nb}_{6} \mathrm{Cl}_{15}$ is partially filled with a SOF of $0.768(5)$, while alkaline atoms in $\mathrm{RbNb}_{6} \mathrm{Cl}_{15}$ and $\mathrm{CsNb}_{6} \mathrm{Cl}_{15}$ are highly disordered with a statistically distribution on five and four crystallographic sites, respectively.

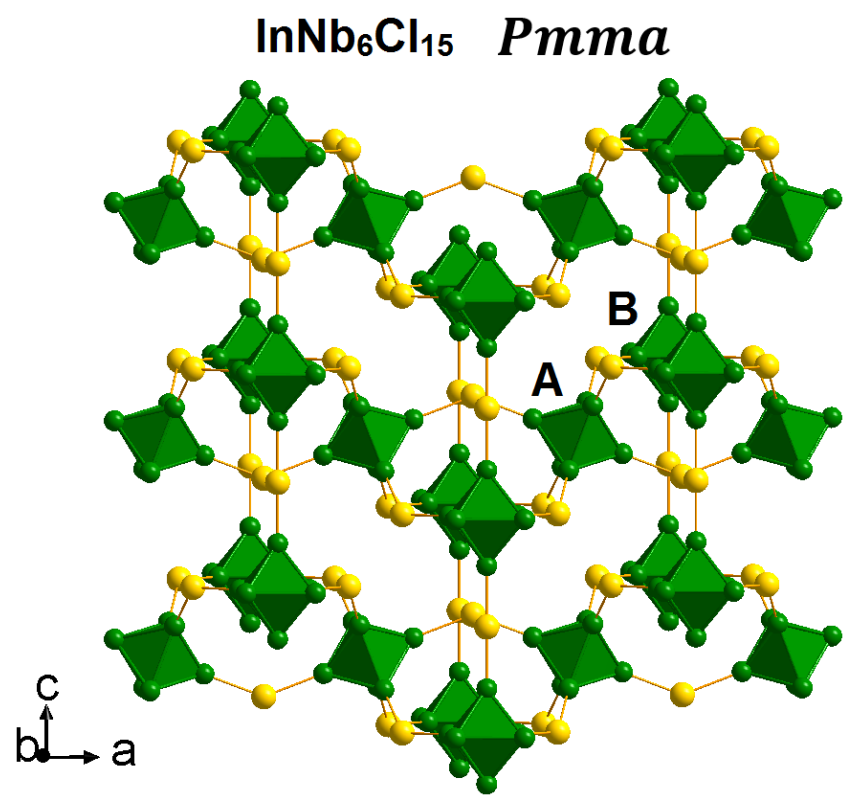

Fig. 23 Representation of the three-dimensional cluster framework encountered in $\mathrm{InNb}_{6} \mathrm{Cl}_{15}$. Inner ligands and Indium atoms are omitted for clarity

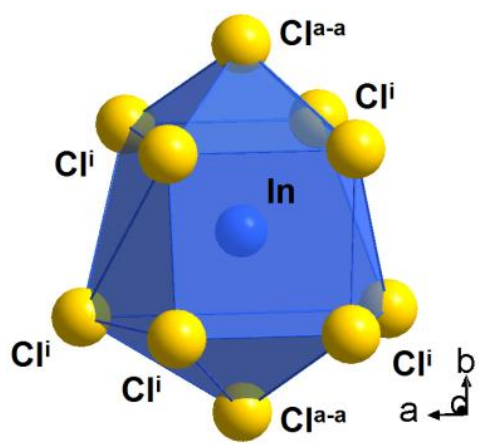

Fig. 24 Representation of the indium environment in $\operatorname{lnNb}_{6} \mathrm{Cl}_{15}$

In $\mathrm{InNb}_{6} \mathrm{Cl}_{15}$-type structure compounds, the average $\mathrm{Nb}-\mathrm{Nb}$ and $\mathrm{Nb}$ - $\mathrm{Cl}$ interatomic distances are equivalent for clusters $\mathrm{A}$ and $\mathrm{B}$ (Table 3 ), even if the cluster core is more distorted in the latter than in the former. On the contrary, the average $\mathrm{Nb}-\mathrm{Cl}^{-\mathrm{a}}$ interatomic distances are non-equivalent with a systematic higher value for cluster A compared to cluster B (Table 3 ). This is related to longer $\mathrm{Nb}-\mathrm{Cl}^{\mathrm{a}-\mathrm{a}}$ interatomic distances in the zigzag chains than those encountered in the linear chains. 

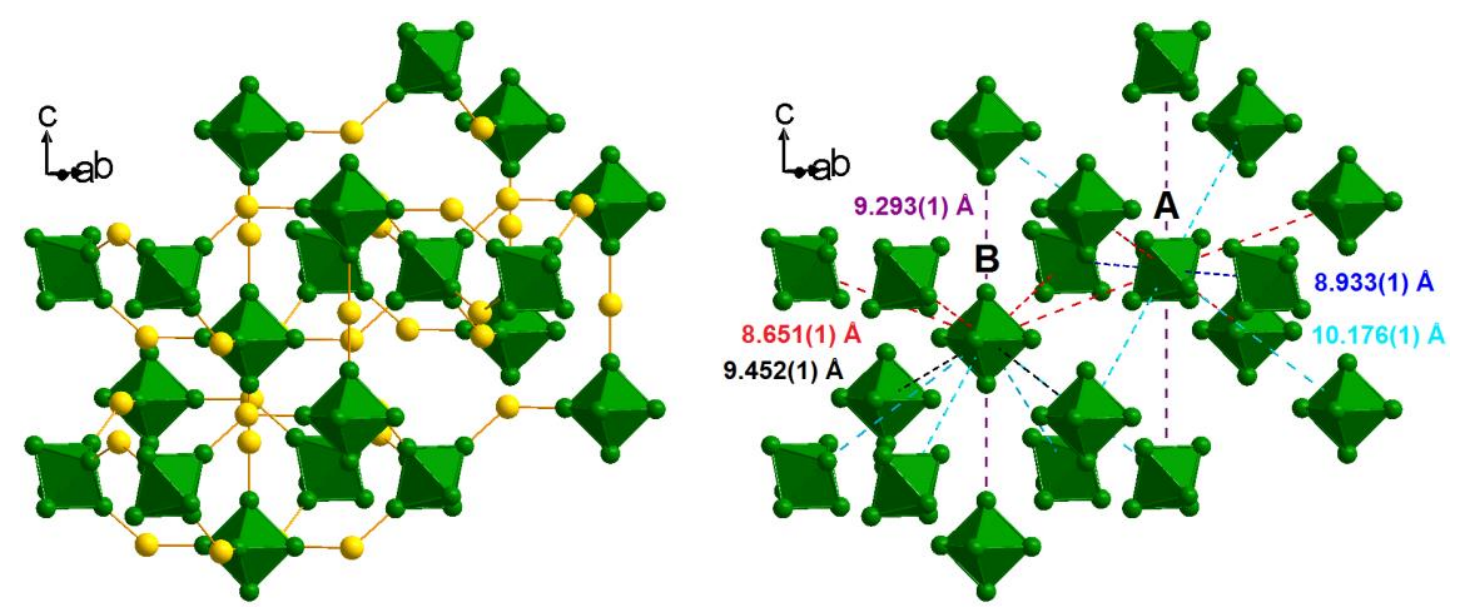

Fig. 25 Representation of the three-dimensional cluster framework (left) and intercluster $\mathrm{Nb}_{6} \cdots \mathrm{Nb}_{6}$ distances (right) in $\mathrm{InNb}_{6} \mathrm{Cl}_{15}$. Inner ligands and indium atoms are omitted for clarity. Distances are calculated from crystal data reported in [18]

In $\mathrm{InNb}_{6} \mathrm{Cl}_{15}$ short intercluster distances of 8.651(1), 8.933(1) and 9.293(1) $\AA$ are encountered between cluster $\mathrm{A}$ and cluster $\mathrm{B}$ along the $b$-axis through bent apical-apical $\mathrm{Nb}-\mathrm{Cl}$-a-a $\mathrm{Nb}$ bridges $\left(132.2^{\circ}\right)$, between clusters $\mathrm{A}$ along the $a$-axis through bent apical-apical bridges $\left(138.3^{\circ}\right)$ and between clusters $B$ along the $c$-axis through linear apical-apical bridges $\left(180^{\circ}\right)$, respectively (Figure 25$)$. Due to the interpenetration of the two cluster networks, short intercluster distances of 9.293(1) $\AA$ are also observed along the $c$-axis between clusters $A$, even if these clusters are not directly linked by apicalapical Nb-Cl-a-Nb bridges (Figure 25). Finally, the cluster environments of both clusters $B$ and $A$ are completed by surrounded clusters B at intercluster distances of $9.452(1)$ and $10.176(1) \AA$, respectively (Figure 25). The intercluster distances are influenced by the nature of the cation but do not modify the aforementioned description (Table 10). However, due to cation disordering or partial occupation of the cation site, it is not possible to determine the influence of the cation size on the intercluster distances and on the halogen matrix effect in the $\operatorname{lnNb}_{6} \mathrm{Cl}_{15}$-type structure compounds.

Table $10 \mathrm{Nb}_{6} \cdots \mathrm{Nb}_{6}$ intercluster distances $(\AA ̊)$ in $\mathrm{InNb}_{6} \mathrm{Cl}_{15}$-type structure compounds

\begin{tabular}{lllll}
\hline Bridging type & $\mathrm{InNb}_{6} \mathrm{Cl}_{15}{ }^{\mathrm{a}}$ & $\mathrm{K}_{0.77} \mathrm{Nb}_{6} \mathrm{Cl}_{15}{ }^{\mathrm{b}}$ & $\mathrm{RbNb}_{6} \mathrm{Cl}_{15}{ }^{\mathrm{b}}$ & $\mathrm{CsNb}_{6} \mathrm{Cl}_{15}{ }^{\mathrm{b}}$ \\
\hline Direct A-B $(\times 4)$ & $8.651(1)$ & $8.634(1)$ & $8.666(1)$ & $8.708(1)$ \\
Direct A-A $(\times 2)$ & $8.933(1)$ & $8.901(1)$ & $8.917(1)$ & $8.947(1)$ \\
Direct B-B $(\times 2)$ & $9.293(1)$ & $9.255(1)$ & $9.214(1)$ & $9.244(2)$ \\
Indirect A-A (×2) & $9.293(1)$ & $9.255(1)$ & $9.214(1)$ & $9.244(2)$ \\
Indirect B-B (×2) & $9.452(1)$ & $9.396(1)$ & $9.351(1)$ & $9.350(1)$ \\
Indirect A-B (×4) & $10.176(1)$ & $10.119(1)$ & $10.051(1)$ & $10.046(1)$ \\
\hline
\end{tabular}

Distances calculated from crystal data reported in: ${ }^{a}$ Ref. [18]. ${ }^{b}$ Ref. [50]

\section{Interatomic Distances in Inorganic $\mathrm{Nb}_{6}$ and $\mathrm{Ta}_{6}$ Cluster Halide Compounds with Three-dimensional Frameworks}

\subsection{Cluster Units Based on Face-capped $M_{6} X^{i}{ }_{8} X^{a}{ }_{6}$ Building Blocks}

First, among cluster units based on face-capped $\mathrm{M}_{6} \mathrm{X}_{8} \mathrm{X}^{\mathrm{a}}{ }_{6}$ building blocks, those arising from $\mathrm{Mo}_{5-\mathrm{x}} \mathrm{Nb}_{1+\mathrm{x}} \mathrm{l}_{11}$ compounds must be considered separately from the others. Indeed, these cluster units are generally characterized by a VEC of 24 , leading to very short M-M $\left(\overline{d_{M-M}}=2.695 \AA\right)$ and $\mathrm{M}-\mathrm{X}^{\mathrm{i}}\left(\overline{d_{M-I^{l}}}\right.$ $=2.785 \AA$ ) interatomic distances compared to those encountered in cluster units characterized by a 
VEC of 19 or 20 (Table 3). On the opposite, the M-Xa-a interatomic distances are similar to those found in the other iodides (Table 3 ), indicating that VEC value influences only the $\left[\mathrm{M}_{6} \mathrm{X}_{8}^{\mathrm{i}}\right]$ cluster core.

Second, the structural transition from the $\mathrm{HT}$ to $\mathrm{LT}$ forms occurring in $\mathrm{Nb}_{6} \mathrm{I}_{11}$ and derivative compounds with VEC of 19 (excluding $\left.\mathrm{Nb}_{6}\right|_{8.7} \mathrm{Br}_{2.3}$ due to strong disorder on apical positions, especially $\mathrm{Br}^{\mathrm{a}}$, leading to $\mathrm{Nb}-\mathrm{Br}^{\mathrm{a}}$ distances ranging from $2.567 \AA$ to $4.431 \AA$ ) do not influence drastically the interatomic distances: $\overline{d_{M-M}}=2.846 \AA, \overline{d_{M-X^{\imath}}}=2.864 \AA$ and $\overline{d_{M-X^{a-a}}}=2.919 \AA$ for the HT form compounds, and $\overline{d_{M-M}}=2.850 \AA \overline{d_{M-X^{\imath}}}=2.861 \AA$ and $\overline{d_{M-X^{a-a}}}=2.920 \AA$ for the LT form compounds (Table 3).

Finally, as already mentioned, hydrogen/deuterium atom insertion into $\mathrm{Nb}_{6} \mathrm{l}_{11}$ leads to a weak increase of the $\mathrm{Nb}-\mathrm{Nb}$ distances regardless of the structural form and a narrower distribution of them (Table 3).

\subsection{Cluster Units Based on Edge-bridged $\mathrm{M}_{6} \mathrm{X}_{12}^{i} \mathrm{X}_{6}^{a}$ Building Blocks}

In cluster units based on edge-bridged $\mathrm{M}_{6} \mathrm{X}_{12}^{\mathrm{i}} \mathrm{X}^{\mathrm{a}}{ }_{6}$ building blocks, it should be noted that the M-M interatomic distances are mainly influenced by the halogen matrix effect. This effect is particularly important when fluorine atoms occupy (partially or totally) the inner positions, leading to the shortest $\mathrm{M}-\mathrm{M}$ distances, as exemplified by average $\mathrm{M}-\mathrm{M}$ distances of $2.794-2.803 \AA$ in $\mathrm{Nb}_{6} \mathrm{~F}_{15}$ or $2.815 \AA$ in $\mathrm{Na}_{2} \mathrm{Nb}_{6} \mathrm{Br}_{4} \mathrm{~F}_{11}\left(\mathrm{NbF}_{6}\right)$, while in $\mathrm{Ta}_{6} \mathrm{Cl}_{15}$ and $\mathrm{Ta}_{6} \mathrm{Br}_{15}$ the average $\mathrm{M}-\mathrm{M}$ distances are 2.918-2.925 $\AA$ and $2.957 \AA$, respectively (Table 3).

In this family of compounds, the halogen matrix effect on $M-X^{i}$ and $M-X^{a-a}$ interatomic distances is also predominant. This is highlighted by the linear evolutions of the average $M-X^{i}$ (Fig. 26) and $M-X^{a-a}$ (Fig. 27) interatomic distances with the average $X^{i}$ and $X^{a}$ ionic radius, respectively. This leads to short $M-X^{i}$ and $M-X^{a-a}$ distances of 2.049-2.059 $\AA$ and 2.113-2.118 $\AA$, respectively, in $N_{6} F_{15}$ to long $M-X^{i}$ and

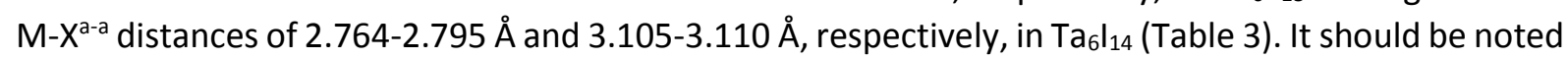
that the number of clusters (i.e., 2 or 3 ) shared by iodine atoms in apical position presents a weak influence on the $M-X^{a-a} / M-X^{a-a-a}$ distances (Fig. 27).

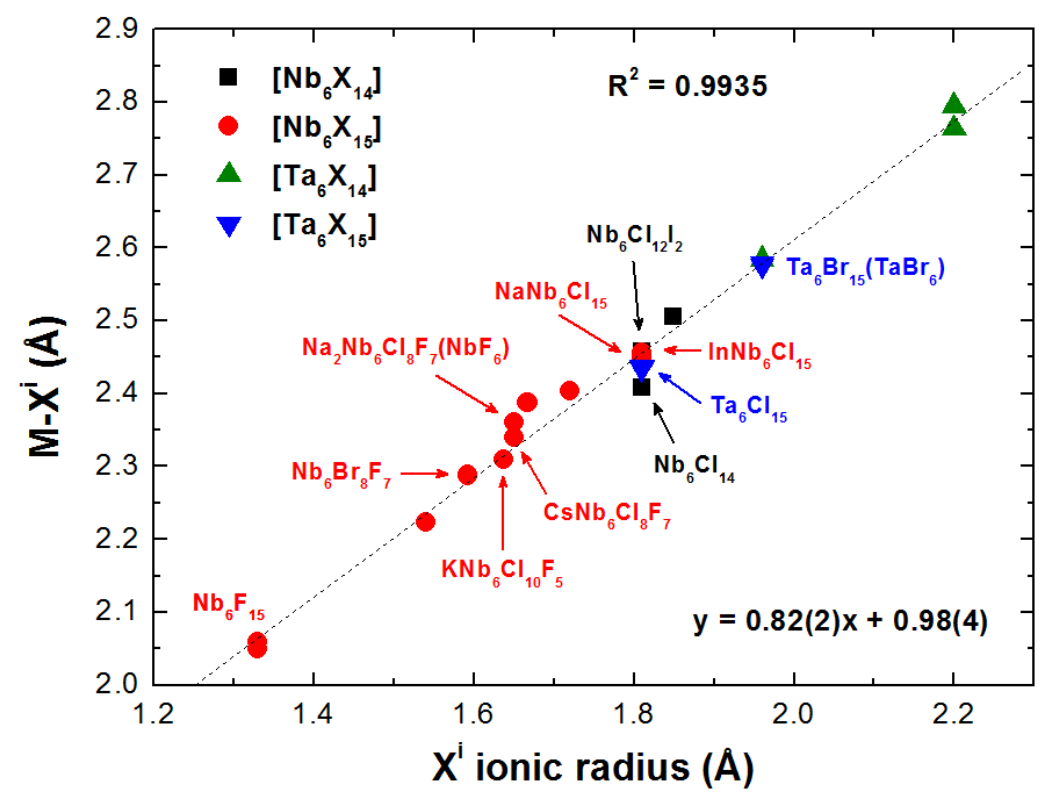

Fig. 26 Evolution of the average $M-X^{i}$ interatomic distances vs. the average $X^{i}$ ionic radius in cluster units based on edge-bridged $\mathrm{M}_{6} \mathrm{X}^{\mathrm{i}}{ }_{22} \mathrm{X}_{6}^{\mathrm{a}}$ building blocks 


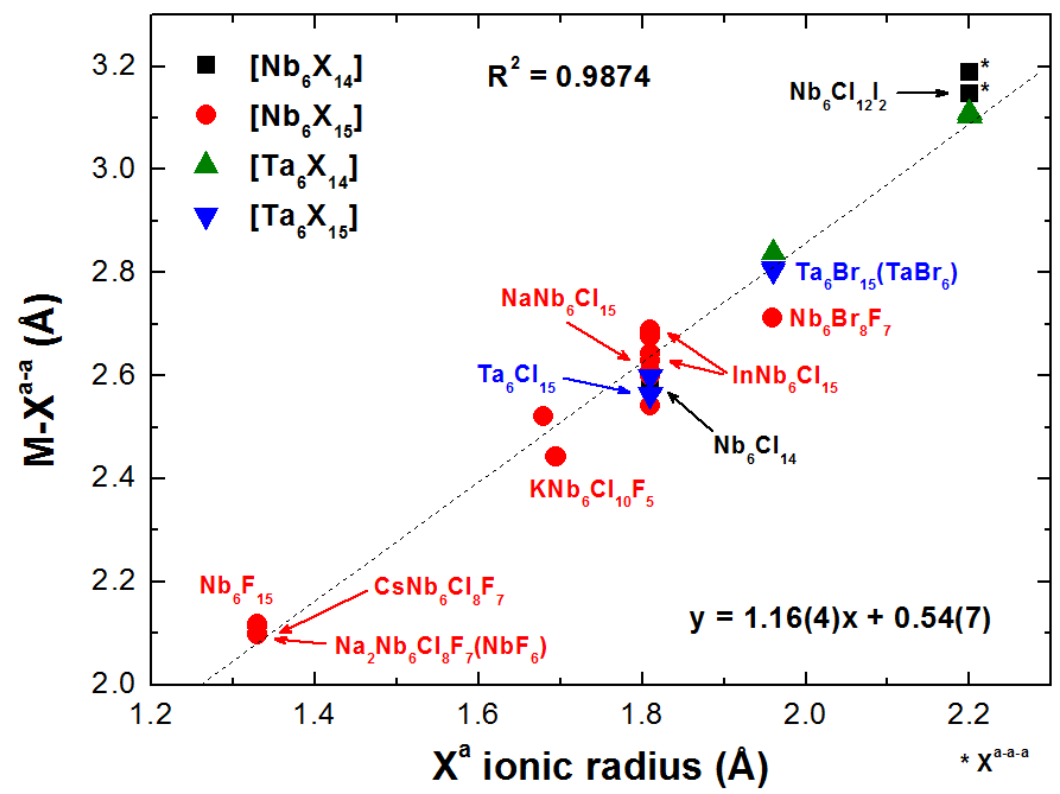

Fig. 27 Evolution of the average $M-X^{a-a}$ interatomic distances vs. the average $X^{a}$ ionic radius in cluster units based on edge-bridged $M_{6} X_{12} X^{a}{ }_{6}$ building blocks

Due to the linear evolution of the average $M-X^{i}$ and $M-X^{a-a}$ distances with the average $X^{i}$ and $X^{a}$ ionic radius, a linear evolution between average $M-X^{i}$ and $M-X^{a-a}$ distances is also observed when both $X^{i}$ and $X^{a}$ correspond to the same halogen atoms (Fig. 28). On the contrary, for a different nature of inner and apical ligands, a deviation to this linear tendency is expected as exemplified with $\mathrm{Nb}_{6} \mathrm{Br}_{8} \mathrm{~F}_{7}$ for which inner and apical positions are occupied by fluorine/bromine and bromine atoms, respectively, or $\mathrm{CsNb}_{6} \mathrm{Cl}_{8} \mathrm{~F}_{7}$ for which inner and apical positions are occupied by fluorine/chlorine and fluorine atoms, respectively (Fig. 28).

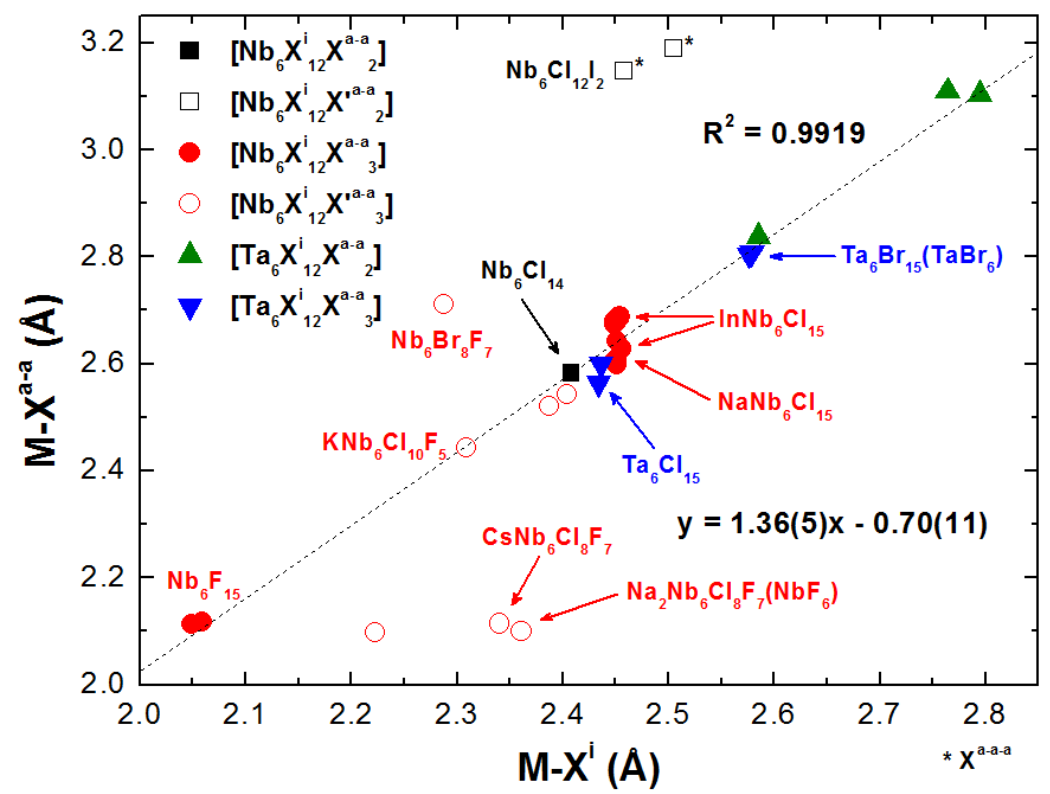

Fig. 28 Evolution of the average $M-X^{a-a}$ interatomic distances vs. the average $M-X^{i}$ interatomic distances in cluster units based on edge-bridged $\mathrm{M}_{6} \mathrm{X}_{12} \mathrm{X}_{6}{ }_{6}$ building blocks 


\section{Structural Relationships Between Crystal Structures Based on Hexagonal, Cubic and Trigonal Symmetry}

In Fig. 29 are represented the different cluster arrangements along three-fold axes encountered in crystal structures of three-dimensional cluster frameworks with hexagonal (i.e., along the [001] direction), cubic (i.e., along the [111] direction) and trigonal (i.e., along the [001] direction) symmetries. One common structural feature encountered in these types of structures represented in Fig. 29, is that niobium/tantalum atoms are located on only one crystallographic site, which is not the case for the other structure-types discussed in this review. A second common structural feature is related to the fact that the clusters are located on three-fold axes. This leads at least to six identical M-M interatomic distances, which are related to the cluster faces perpendicular to the three-fold axes. This is also true for $\mathrm{CsNb}_{6} \mathrm{l}_{11}$ even if the crystal structure is non-centrosymmetric (Table 1 ).

These crystal structures can be described by the stacking of hexagonal layers of clusters, which are separated from another by layers of apical ligands (Fig. 29). Due to the existence of only one threefold axis direction in hexagonal and trigonal symmetry structures (i.e., along the [001] direction), the clusters arising from one layer are all oriented in the same direction. This is also the case for $\mathrm{Nb}_{6} \mathrm{~F}_{15}$, $\mathrm{CsNb}_{6} \mathrm{Cl}_{8} \mathrm{~F}_{7}$ and $\mathrm{Na}_{2} \mathrm{Nb}_{6} \mathrm{Cl}_{8} \mathrm{~F}_{7}\left(\mathrm{NbF}_{6}\right)$-type structure compounds due to the fact that the centroid of the clusters is at the intersection of the three-fold axes along the [111], [111], [1111], and [11 $\overline{1}]$ directions (Fig. 29). On the contrary, in the other cubic symmetry structure types (i.e., $\mathrm{Nb}_{6} \mathrm{Cl}_{12} \mathrm{I}_{2}, \mathrm{Ta}_{6} \mathrm{Cl}_{15}, \mathrm{NaNb}_{6} \mathrm{Cl}_{15}$ and $\mathrm{KNb}_{6} \mathrm{Cl}_{10} \mathrm{~F}_{5}$ ), the clusters are located on only one three-fold axis, leading to four different orientations of the clusters in the same layer (Fig. 29).

The crystal structure of $\mathrm{CsNb}_{6} \mathrm{I}_{11}$ is characterized by the stacking along the $c$-axis of two cluster layers, denoted A and B in Fig. 29, leading to a pseudo hexagonal close-packed arrangement of cluster units. The cluster layers are separated from another by bent apical-apical bridges. The clusters arising from layer $A$ are related to clusters of layer $B$ by a rotation of $180^{\circ}$ induces by the six-fold screw axis $\sigma_{3}$.

The crystal structure of $\mathrm{Nb}_{6} \mathrm{~F}_{15}$ is characterized by the interpenetration of two cluster frameworks, each forming a pseudo cubic close-packed arrangement "A-B-C" of cluster units oriented in the same direction (Fig. 29), and related one to the other by a $[1 / 2,1 / 2,1 / 2]$ translation (Fig. 14). The cluster layers arising from the same framework are separated by linear apical-apical bridges. The crystal structure of $\mathrm{CsNb}_{6} \mathrm{Cl}_{8} \mathrm{~F}_{7}$ and $\mathrm{Na}_{2} \mathrm{Nb}_{6} \mathrm{Cl}_{8} \mathrm{~F}_{7}\left(\mathrm{NbF}_{6}\right)$ are characterized by only one pseudo cubic closepacked arrangement "A-B-C" of cluster units, the second being replaced by cesium cations and $\left(\mathrm{NbF}_{6}\right)$ complexes, respectively. As in $\mathrm{Nb}_{6} \mathrm{~F}_{15}$, the cluster layers arising from this arrangement are separated to the others by linear apical-apical bridges. For the sake of clarity, the crystal structure representation of these compounds, shown in Fig. 29, highlights only the cluster layer stacking common to the three types of structures, the blue spheres representing either the centroid of the clusters arising from the second framework or the centroid of the cesium cations distribution/( $\left.\mathrm{NbF}_{6}\right)$ complexes. As in $\mathrm{CsNb}_{6} \mathrm{Cl}_{8} \mathrm{~F}_{7}$ and $\mathrm{Na}_{2} \mathrm{Nb}_{6} \mathrm{Cl}_{8} \mathrm{~F}_{7}\left(\mathrm{NbF}_{6}\right)$, the crystal structure of $\mathrm{Nb}_{6} \mathrm{Cl}_{12} \mathrm{I}_{2}$ is also characterized by a pseudo cubic close-packed arrangement "A-B-C" of cluster units (Fig. 29). However in the latter structure, the clusters are oriented in four different directions, and the cluster layers are separated one to the others by bent apical-apical-apical bridges.

The crystal structures of $\mathrm{Nb}_{6} \mathrm{Br}_{8} \mathrm{~F}_{7}$ and $\mathrm{Ta}_{6} \mathrm{Br}_{15}\left(\mathrm{TaBr}_{6}\right)$ are characterized by a cluster layer

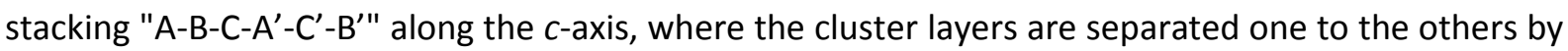
bent apical-apical bridges similar to those encountered in $\mathrm{CsNb}_{6} \mathrm{I}_{11}$ (Fig. 29). The crystal structures of $\mathrm{Ta}_{6} \mathrm{Cl}_{15}, \mathrm{NaNb}_{6} \mathrm{Cl}_{15}$ and $\mathrm{KNb}_{6} \mathrm{Cl}_{10} \mathrm{~F}_{5}$ are also characterized by a cluster layer stacking "A-B-C-A'-C'-B'" but with a higher degree of interpenetration (Fig. 29). These structures can be viewed as pseudo cubic 
derivatives close-packed arrangement of cluster units. However, in $\mathrm{Ta}_{6} \mathrm{Cl}_{15}, \mathrm{NaNb}_{6} \mathrm{Cl}_{15}$ and $\mathrm{KNb}_{6} \mathrm{Cl}_{10} \mathrm{~F}_{5}$, the cubic symmetry induces four different orientations of the clusters in the same layer, while in $\mathrm{Nb}_{6} \mathrm{Br}_{8} \mathrm{~F}_{7}$ and $\mathrm{Ta}_{6} \mathrm{Br}_{15}\left(\mathrm{TaBr}_{6}\right)$ the clusters show the same orientation inside the layers. Moreover, in $\mathrm{Ta}_{6} \mathrm{Cl}_{15}, \mathrm{NaNb}_{6} \mathrm{Cl}_{15}$ and $\mathrm{KNb}_{6} \mathrm{Cl}_{10} \mathrm{~F}_{5}$ structures, bent apical-apical bridges are located between but also inside the cluster layers, leading to an enlargement and a shortening of the structure perpendicularly and in parallel to the stacking direction, respectively, compared to trigonal structures (Fig. 29).

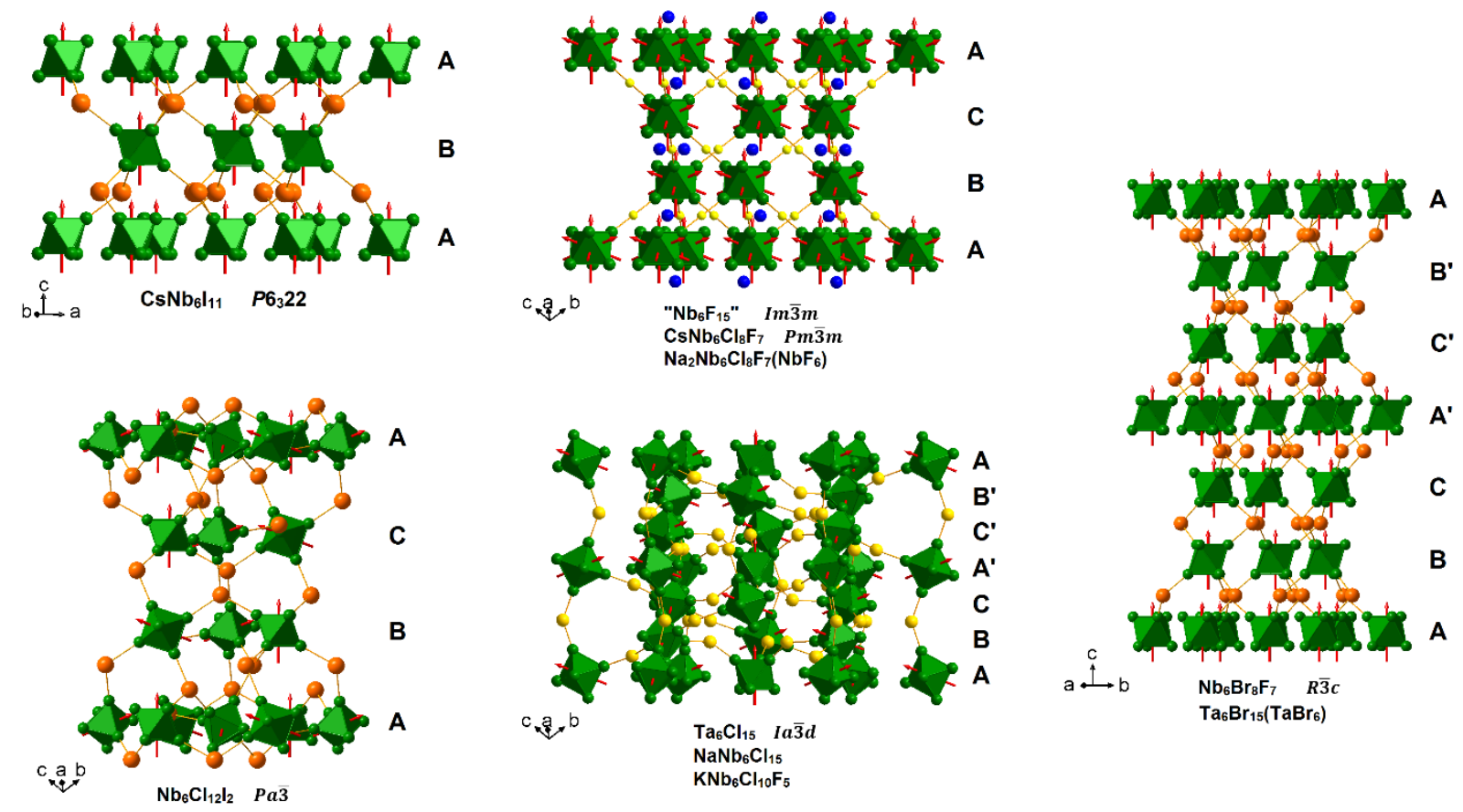

Fig. 29 Cluster arrangements along three-fold axes encountered in crystal structures of threedimensional cluster frameworks with hexagonal (i.e., along the [001] direction), cubic (i.e., along the [111] direction) and trigonal (i.e., along the [001] direction) symmetries. Three-fold axes are represented by red arrows. Blue spheres represent either the centroid of the clusters arising from the second cluster framework in $\mathrm{Nb}_{6} \mathrm{~F}_{15}$ or the centroid of the cesium cations distribution/ $\left(\mathrm{NbF}_{6}\right)$ complexes in $\mathrm{CsNb}_{6} \mathrm{Cl}_{8} \mathrm{~F}_{7} / \mathrm{Na}_{2} \mathrm{Nb}_{6} \mathrm{Cl}_{8} \mathrm{~F}_{7}\left(\mathrm{NbF}_{6}\right)$

\section{Electronic Structure of Niobium and Tantalum Octahedral Cluster Halide}

\section{Compounds}

Face-capped and edge-bridged octahedral clusters, with the general formula $\mathrm{M}_{6} \mathrm{X}_{8} \mathrm{X}_{6}{ }_{6}$ and $\mathrm{M}_{6} \mathrm{X}_{12} \mathrm{X}_{6}{ }_{6}$, respectively (Fig. 1), are among the oldest prototypes of inorganic cluster chemistry [66]. Over the years, these octahedral clusters have been the subject of considerable theoretical studies carried out at different levels of theory (mostly extended Hückel (EH) and density functional theory (DFT)) [67-84]. Results converge overall to a bonding picture where the $M-M$ bonding is based essentially on the interaction of metal $d$ orbitals, a situation notably different from the bonding picture for most transition-metal carbonyl clusters $[74,85]$. The bonding in both types of cluster has been described initially in terms of localized two-center or three-center bonds in $M_{6} X_{8}^{i} X_{6}{ }_{6}$ and $M_{6} X_{12}{ }_{12} X_{6}^{a}$, respectively [68]. In this description, five hybrid orbitals at each metal atom are directed toward the five ligands, which are arranged in a square-pyramidal fashion (Fig. 1). The remaining four hybrid orbitals per vertex, point along the edges for $M_{6} X_{12}^{i} X_{6}{ }_{6}$ and into the faces for $M_{6} X_{8}^{i} X_{6}^{a}$. Later on, a delocalized molecular orbital model has been developed providing additional insights into the structural and electronic properties of these clusters $[67,69,70,75]$. Qualitative molecular orbital diagrams of face- 
capped and edge-bridged octahedral clusters $\mathrm{M}_{6} \mathrm{X}_{8} \mathrm{X}_{6}{ }_{6}$ and $\mathrm{M}_{6} \mathrm{X}_{12}{ }_{12} \mathrm{X}_{6}{ }_{6}$ are shown in Fig. 30 to illustrate similarities and differences in their electronic structures [79]. In summary, the electronic structure of face-capped $\mathrm{M}_{6} \mathrm{X}_{8} \mathrm{X}_{6}^{\mathrm{a}}{ }_{6}$ clusters shows $12 \mathrm{M}-\mathrm{M}$ bonding molecular orbitals (MOs) energetically separated from antibonding ones. That of edge-bridged $\mathrm{M}_{6} \mathrm{X}_{12}^{\mathrm{i}} \mathrm{X}_{6}{ }_{6}$ clusters exhibits only $8 \mathrm{M}-\mathrm{M}$ bonding MOs. Consequently, full occupation of these M-M bonding MOs leads to stable VEC of 24 and 16 metal electrons for face-capped $\mathrm{M}_{6} \mathrm{X}_{8} \mathrm{X}_{6}{ }_{6}$ and edge-bridged $\mathrm{M}_{6} \mathrm{X}_{12} \mathrm{X}_{6}{ }_{6}$ clusters, respectively (Fig. 30). These two different "magic" numbers differ due to the different number and structural distribution of the $X^{i}$ ligands. Indeed, when the ligands are face-capped, the metal electrons occupy the regions along the $\mathrm{M}-\mathrm{M}$ bonds to avoid electron-electron repulsion. Similarly, when the ligands are edge-bridged, the metal electrons occupy the regions of metal triangle faces [79]. All theoretical calculations indicate that the highest occupied molecular orbitals (HOMO), $e_{g}$ for $\mathrm{M}_{6} \mathrm{X}_{8}^{\mathrm{i}} \mathrm{X}_{6}^{\mathrm{a}}{ }_{6}$ and $a_{24}$ for $\mathrm{M}_{6} \mathrm{X}_{12} \mathrm{X}_{6}^{\mathrm{a}}$, are somewhat energetically separated from the other occupied bonding MOs (Fig. 30). This is due to their peculiar nodal properties. In the former, the $e_{g}$ orbitals are weakly $\mathrm{M}-\mathrm{M}$ bonding, being of local $\delta$ symmetry with respect to an axis extending from $M$ to the neighbor $X^{a}$ atom as shown in Fig. 31 [73]. In the latter, the $a_{2 u}$ orbital is also of $\delta$ symmetry and consequently weakly M-M bonding (Fig. 31), and moreover is $\mathrm{M}-\mathrm{X}^{\mathrm{i}}$ antibonding [81]. This peculiar situation confers exceptional 'redox' properties to these face-capped and edge-bridged octahedral clusters and related properties (paramagnetism, conductivity, superconductivity, optics, etc.), explaining the sustained interest in these compounds. A great advantage of the delocalized bonding picture described above is that it can equally well describe $\mathrm{M}_{6} \mathrm{X}_{12}^{\mathrm{i}} \mathrm{X}_{6}{ }_{6}$ and $\mathrm{M}_{6} \mathrm{X}_{8} \mathrm{X}^{\mathrm{a}}{ }_{6}$ clusters with variable VEC. For example, $\mathrm{KLuNb}_{6} \mathrm{Cl}_{18}$ has a VEC of 16 filling all the $\mathrm{M}-\mathrm{M}$ bonding MOs of an edge-bridged octahedron, and the $\mathrm{Nb}-\mathrm{Nb}$ bond lengths are 2.91-2.92 $\AA$ [12]. The existence of the structurally related $\mathrm{LuNb}_{6} \mathrm{Cl}_{18}$ compound (VEC of 15) can be associated with the partial depopulation of the $a_{2 u} \mathrm{MO}$. The $\mathrm{Nb}-\mathrm{Nb}$ bond lengths are 2.95-2.96 $\AA$, confirming the weakly bonding nature of the $\mathrm{HOMO}$, and the compound is paramagnetic [12], confirming that the HOMO is singly degenerate.

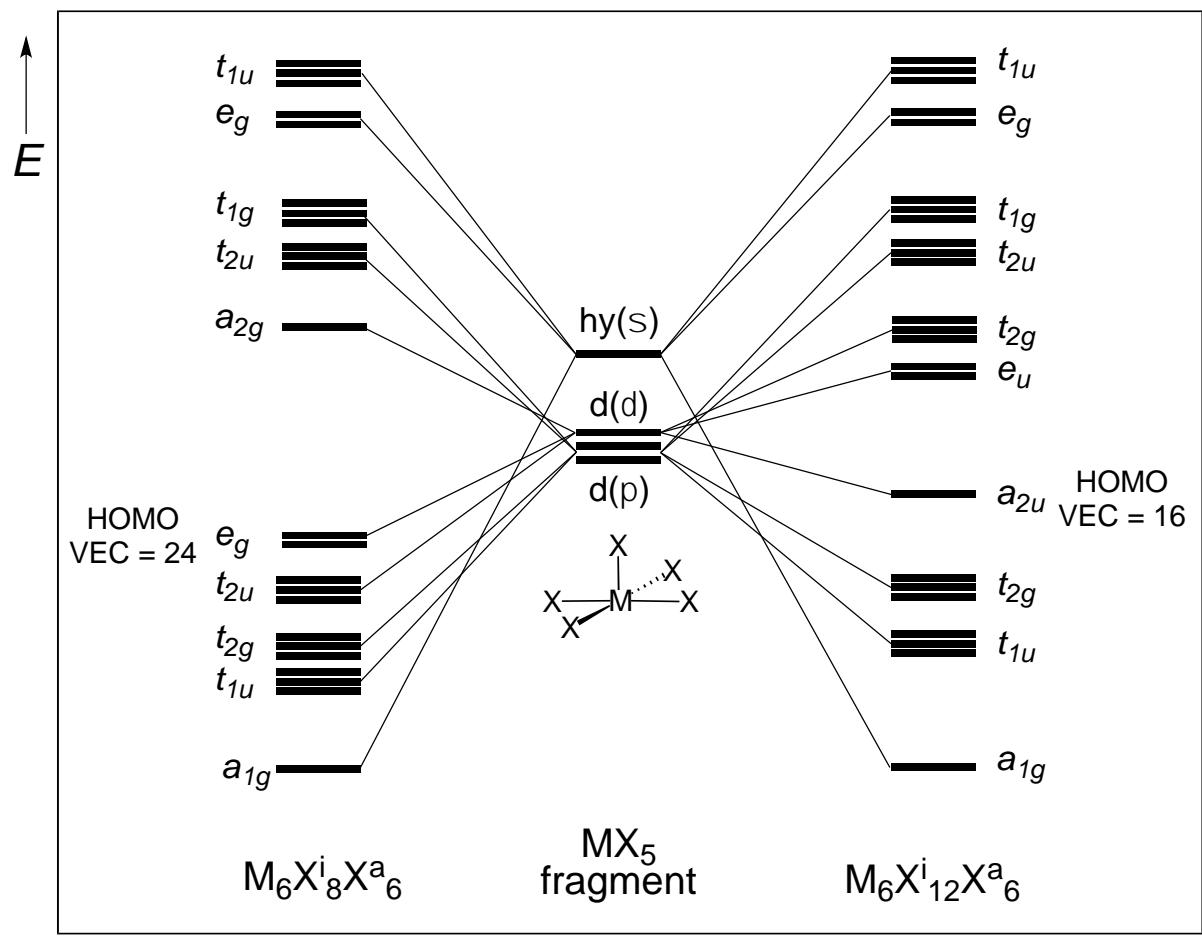

Fig. 30 Qualitative molecular orbital interaction diagrams for face-capped $M_{6} X_{8}{ }_{8} X_{6}{ }_{6}$ (left) and edgebridged $\mathrm{M}_{6} \mathrm{X}_{12} \mathrm{X}_{6}{ }_{6}$ (right) octahedral clusters 

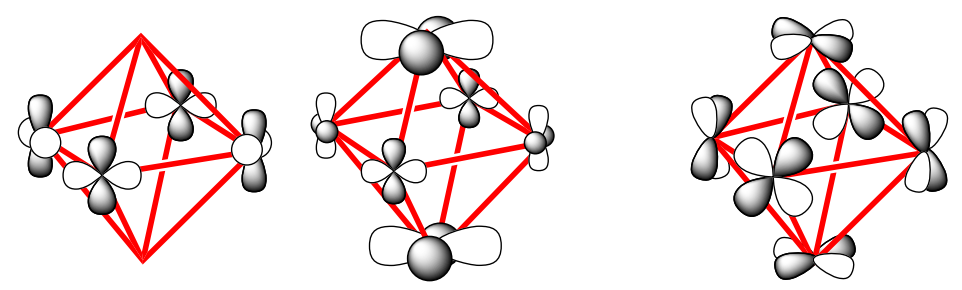

Fig. 31 Qualitative sketch of the $e_{g}$ and $a_{2 u}$ HOMOs of 24-electron face-capped $\mathrm{M}_{6} \mathrm{X}_{8} \mathrm{X}_{6}{ }_{6}$ (left) and 16electron edge-bridged $\mathrm{M}_{6} \mathrm{X}_{12}^{\mathrm{i}} \mathrm{X}_{6}{ }_{6}$ (right) clusters, respectively

\subsection{Variable VEC of $\mathrm{Nb}_{6} \mathrm{l}_{11}$ and Derivatives}

As just said, because of the weakly M-M bonding character of the $e_{g}$ orbital in face-capped octahedral $M_{6} X_{8}^{i} X^{a}{ }_{6}$ clusters, the VEC can rather easily be lowered from 24 to 20 . This is the case of the "Chevrel phases" $\mathrm{PbMo}_{6} \mathrm{~S}_{8}$ for instance [86], amply discussed in Chapter 1 of this volume, which contain 22electron $\left[\mathrm{Mo}_{6} \mathrm{~S}_{8}\right]^{2-}$ motifs, rendering this compound superconductor [87]. Being largely encountered for group 6 and 7 transition elements, face-capped octahedral $M_{6} X_{8}^{i} X^{a}{ }_{6}$ are observed with group 5 metals only for electron-deficient $\mathrm{Nb}_{6} \mathrm{l}_{11}$ and derivatives (Tables 1-3). With 20 electrons per motif $\left[\left.\mathrm{Nb}_{6} \mathrm{l}_{8}{ }_{8}\right|_{3}{ }_{3}\right]^{-}$in $\mathrm{CsNb}_{6} \mathrm{I}_{11}[9]$ the $e_{g}$ orbital is fully depopulated. More puzzling is the drastically electron deficient 19-electron $\left[\left.\mathrm{Nb}_{6}\right|_{8}{ }_{8}{ }^{a}{ }_{3}\right]$ unit in the paramagnetic $\left.\mathrm{Nb}_{6}\right|_{11}$ compound $[28,54]$. Indeed, the low value of VEC = 19 is the reason for a reversible incorporation of a hydrogen atom into the cluster center.

\subsection{Electronic Structure of Edge-bridged $M_{6} X_{12}^{i} X^{a}{ }_{6}$ Clusters}

Examination of Tables 1-3 indicates that the same relatively regular octahedral architectural unit is observed in all edge-bridged inorganic niobium and tantalum octahedral cluster halide compounds, regardless of the VEC which can vary from 14 to 16 . There is, however, some significant lengthening of the $M-M$ distances and some shortening of the $M-X^{a}$ and $M-X^{i}$ bond lengths, respectively, with the diminution of the electron count from 16 to 15 or 14 . This is the case for instance for the structurally related 16-electron $\mathrm{KLuNb}_{6} \mathrm{Cl}_{18}$ and 15-electron $\mathrm{LuNb}_{6} \mathrm{Cl}_{18}$ compounds just mentioned above due to the partial depopulation of the $a_{2 u} \mathrm{HOMO}$ in the latter [12].

It is clear that the conceptual ease of describing the structure of inorganic niobium and tantalum octahedral cluster halide compounds with the isolated "molecular" method of construction outlined above obscures the effect of intercluster contacts. As shown above, clusters can pack in different ways generating a plethora of zero-to-three-dimensional solid-state structures (Table 1). We may wonder if the various features of intercluster connection and/or the variability in positioning and stoichiometry with regard to the intercalated counter-ions can influence the VEC of the $M_{6} X_{12}^{i} X_{6}{ }_{6}$ motifs. It seems not much looking at Table 1 where most of $M_{6} X_{12}^{i} X^{a}{ }_{6}$ clusters possess a VEC $=16$, regardless of the dimensionality of the solid-state compounds. Indeed, because of the rather large separations between the $\mathrm{M}_{6} \mathrm{X}_{12}^{\mathrm{i}} \mathrm{X}_{6}^{\mathrm{a}}$ motifs encountered in this kind of compound, it would be difficult to imagine that the energy bands in the solid-state structures, which can be thought of as consisting of a broadening version of the cluster MOs depicted in Fig. 30, would be so perturbed as to modify the electronic properties expected from the 'isolated' clusters. This suspicion has not been directly confirmed for inorganic niobium and tantalum octahedral cluster halide compounds since no periodic theoretical calculations have been performed so far to the best of our knowledge. On the other hand, this has been confirmed using periodic EH-tight binding [88] and DFT [89] calculations for related octahedral niobium cluster-based solid-state oxyhalides such as $\mathrm{RbNb}_{6} \mathrm{Cl}_{12} \mathrm{O}_{2}$ which contains 15- 
electron $\left[\mathrm{Nb}_{6} \mathrm{Cl}_{10}^{\mathrm{i}} \mathrm{O}_{1}{ }_{1} \mathrm{Cl}_{2}{ }_{2} \mathrm{O}^{\mathrm{a}}{ }_{1}\right]^{-}$units and related compounds [36]. The electronic density of states (DOS) in these species shows narrow peaks that indicate weak intercluster three-dimensional interactions in the compound.

\section{Summary}

In this review we have surveyed the development of crystal and bonding chemistry of face-capped and edge-bridged inorganic niobium and tantalum octahedral cluster halide compounds, over a long period, from its origin to most recent work, with a particular emphasis on those showing threedimensional cluster frameworks. Structure and bonding are intimately linked to the valence electron concentration, i.e., the number of electrons that held the octahedral architecture. Apart from $\left.\mathrm{Nb}_{6}\right|_{11}$ and derivatives, which show electron-deficient face-capped $\mathrm{M}_{6} \mathrm{X}_{8}{ }_{8} \mathrm{X}_{6}{ }_{6}$ units, compounds containing edge-bridged $\mathrm{M}_{6} \mathrm{X}_{12}^{\mathrm{i}} \mathrm{X}_{6}^{\mathrm{a}}$ motifs are the most largely encountered. Closed-shell compounds with a valence electron concentration of 16 are predominant, although a few 15-electron open-shell magnetic compounds or even 14-electron closed-shell species have also been reported.

Particularly interesting from a structural point of view is the fashion in which these face-capped and edge-bridged clusters "pack" in crystals. The astonishing diversity of structural types, which are observed, is mainly due to the flexibility of the halogen ligands to coordinate in various manners to metal atoms. This is highlighted with the fact that fluorine ligands in apical positions favor the formation of linear bridges between building blocks whereas they are bent for other halogens, or the predominant halogen matrix effect on $\mathrm{M}-\mathrm{X}^{\mathrm{i}}$ and $\mathrm{M}-\mathrm{X}^{\mathrm{a}-\mathrm{a}}$ interatomic distances. Moreover, considering the ionic nature of the $\mathrm{M}-\mathrm{X}^{\mathrm{a}}$ bonds compared to the $\mathrm{M}-\mathrm{X}^{\mathrm{i}}$ ones, it turns out that all these structures can be described by the stacking of layers of $\left\{\mathrm{M}_{6} \mathrm{X}_{12}^{\mathrm{i}}\right\}^{\mathrm{n+}}$ or $\left\{\mathrm{M}_{6} \mathrm{X}_{8}^{\mathrm{i}}\right\}^{\mathrm{nt}}$ cluster cores separated by layers of apical ligands $\left\{X^{a}\right\}$. The nature of the clusters orientation arising from one layer, influences the degree of ordering/disordering of the apical ligands in their corresponding layers. This is exemplified with hexagonal, trigonal, and cubic structures, where the localization of the cluster units on a three-fold axis leads to one or four different orientations of the clusters in the same layer, inducing in the former case a higher degree of ordering of the apical ligands compared to the latter case. Finally, a rigorous structural analysis of these compounds reveals no close relationship between the valence electron concentration and the variability of the intercluster connections and/or the nature of the counter-ions. Indeed, the main bonding features of these compounds can be understood from the delocalized bonding picture of isolated 'molecular-like' $\mathrm{M}_{6} \mathrm{X}_{8}{ }_{8} \mathrm{X}_{6}{ }_{6}$ or $\mathrm{M}_{6} \mathrm{X}^{\mathrm{i}}{ }_{12} \mathrm{X}^{\mathrm{a}}{ }_{6}$ clusters.

\section{References}

1. Cordier S, Hernandez O, Thépot J-Y, Shames Al, Perrin C (2003) Inorg Chem 42:1101-1106

2. Simon A, von Schnering HG (1966) J Less-Common Met 11:31-46

3. Ben Yaich H, Jegaden J-C, Potel M, Sergent M, Rastogi AK, Tournier R (1984) J Less-Common Met 102:9-22

4. Habermehl K, Kleinke H, Meyer G (2010) Z Anorg Allg Chem 636:50-53

5. Cordier S, Gulo F, Roisnel T, Gautier R, Le Guennic B, Halet J-F, Perrin C (2003) Inorg Chem 42:83208327

6. Schäfer H, Schnering HG (1964) Angew Chem 76:833-868

7. Vajenine GV, Simon A (1999) Inorg Chem 38:3463-3473

8. Simon A, von Schnering HG, Schäfer H (1968) Z Anorg Allg Chem 361:235-248

9. Imoto H, Corbett JD (1980) Inorg Chem 19:1241-1245

10. Ihmaïne S, Perrin C, Sergent M (1986) C R Acad Sc Paris 303:1293-1298 
11. Ihmaïne S, Perrin C, Sergent M (1987) Acta Cryst C 43:813-816

12. Ihmaïne S, Perrin C, Peña O, Sergent M (1988) J Less-Common Met 137:323-332

13. Ihmaïne S, Perrin C, Sergent M (1989) Acta Cryst C 45:705-707

14. Cordier S, Perrin C, Sergent M (1993) Z Anorg Allg Chem 619:621-627

15. Lachgar A, Meyer H-J (1994) J Solid State Chem 110:15-19

16. Sägebarth ME, Simon A, Imoto H, Weppner W, Kliche G (1995) Z Anorg Allg Chem 621:1589-1596

17. Baján B, Meyer H-J (1997) Z Anorg Allg Chem 623:791-795

18. Womelsdorf H, Meyer H-J, Lachgar A (1997) Z Anorg Allg Chem 623:908-912

19. Cordier S, Simon A (1999) Solid State Sci 1:199-209

20. Cordier S, Hernandez O, Perrin C (2001) J Fluo Chem 107:205-214

21. Cordier S, Hernandez O, Perrin C (2002) J Solid State Chem 163:319-324

22. Cordier S, Perrin C (2004) J Solid State Chem 177:1017-1022

23. Lemoine P, Wilmet M, Malaman B, Paofai S, Dumait N, Cordier S (2018) J Solid State Chem 257:72-79

24. Nguyen TKN, Renaud A, Wilmet M, Dumait N, Paofai S, Dierre B, Chen W, Ohashi N, Cordier S, Grasset F, Uchikoshi T (2017) J Mater Chem C 5:10477-10484

25. Renaud A, Wilmet M, Truong TG, Seze M, Lemoine P, Dumait N, Chen W, Saito N, Ohsawa T, Uchikoshi T, Ohashi N, Cordier S, Grasset F (2017) J Mater Chem C 5:8160-8168

26. Chen W, Wilmet M, Truong TG, Dumait N, Cordier S, Matsui Y, Hara T, Takei T, Saito N, Nguyen TKN, Ohsawa T, Ohashi N, Uchikoshi T, Grasset F (2018) Heliyon 4:e00654

27. Prokopuk N, Shriver DF (1998) Chem Mater 10:10-12

28. Simon A, von Schnering HG, Schäfer H (1967) Z Anorg Allg Chem 355:295-310

29. Imoto $H$, Simon $A$ (1982) Inorg Chem 21:308-319

30. Simon A, Schnering HG, Wöhrle H, Schäfer H (1965) Z Anorg Allg Chem 339:155-170

31. Sägebarth M, Simon A (1990) Z Anorg Allg Chem 587:119-128

32. Schäfer H, Schnering HG, Niehues KJ, Nieder-Vahrenholz HG (1965) J Less-Common Met 9:95-104

33. Bauer D, von Schnering HG (1968) Z Anorg Allg Chem 361:259-276

34. Cordier S, Hernandez O, Perrin C (2001) J Solid State Chem 158:327-333

35. Habermehl K, Mudring A-V, Meyer G (2010) Eur J Inorg Chem 4075-4078

36. Demont A, Prestipino C, Hernandez O, Elkaïm E, Paofai S, Naumov N, Fontaine B, Gautier R, Cordier S (2013) Chem Eur J 19:12711-12719

37. Sperlich E, König J, Weiß DH, Schröder F, Köckerling M (2019) Z Anorg Allg Chem 645:233-241

38. Yoshiasa A, Borrmann H, Simon A (1994) Z Anorg Allg Chem 620:1329-1338

39. Simon A, Stollmaier F, Gregson D, Fuess H (1987) J Chem Soc Dalton Trans 431-434

40. Simon A (1967) Z Anorg Allg Chem 355:311-322

41. Artemkina SB, Naumov NG, Virovets AV, Fedorov VE (2013) Russ J Coord Chem 39:1-5

42. Fitch AN, Barrett SA, Fender BEF, Simon A (1984) J Chem Soc Dalton Trans 501-505

43. Baján B, Meyer H-J (1995) Z Kristallogr 210:607

44. Bauer D, Schnering HG, Schäfer H (1965) J Less-Common Met 8:388-401

45. Artelt HM, Meyer G (1993) Z Kristallogr 206:306-307

46. Knoll R, Sokolovski J, BenHaim Y, Shames AI, Goren SD, Shaked H, Thépot JY, Perrin C, Cordier S (2006) Physica B 381:47-52

47. von Schnering HG, Vu D, Jin SL, Peters K (1999) Z Kristallogr NCS 214:15-16

48. Le Polles L, Cordier S, Perrin C, Sergent M (1999) C R Acad Sci Paris, Ser II c 2:661-667

49. Baján B, Balzer G, Meyer H-J (1997) Z Anorg Allg Chem 623:1723-1728

50. Nägele A, Day C, Lachgar A, Meyer H-J (2001) Z Naturforsch B 56:1238-1240

51. Schäfer H, von Schnering HG, Simon A, Giegling D, Bauer D, Siepmann R, Spreckelmeyer B (1966) J Less-Common Met 10:154-155 
52. Bateman LR, Blount JF, DahI LF (1966) J Am Chem Soc 88:1082-1084

53. Finley JJ, Nohl H, Vogel EE, Imoto H, Camley RE, Zevin V, Andersen OK, Simon A (1981) Phys Rev Lett 46:1472-1475

54. Finley JJ, Camley RE, Vogel EE, Zevin V, Gmelin E (1981) Phys Rev B 24:1323-1332

55. Brown PJ, Ziebeck KRA, Simon A, Sägebarth M (1988) J Chem Soc Dalton Trans 111-115

56. Geyer-Lippmann J, Simon A, Stollmaier F (1984) Z Anorg Allg Chem 516:55-66

57. Fritsche H-G, Dübler F, Müller H (1984) Z Anorg Allg Chem 513:46-56

58. Kuhn PJ, McCarley RE (1965) Inorg Chem 4:1482-1486

59. von Barner JH, McCurry LE, Jørgensen CA, Bjerrum NJ, Mamantov G (1992) Inorg Chem 31:10341039

60. Converse JG, McCarley RE (1970) Inorg Chem 9:1361-1366

61. MacFarlane WA, Schick-Martin D, Egilmez M, Fan I, Song Q, Chow KH, Cordier S, Perrin C, Goren SD (2009) Physica B 404:622-625

62. Knoll R, Shames A, Goren SD, Shaked H, Cordier S, Perrin C, Hernandez O, Roisnel T, André G, Kremer RK, Simon A (2013) Appl Magn Reson 44:143-151

63. Köhler J, Simon A, Whangbo M-H (2009) Z Anorg Allg Chem 635:2396-2398

64. Bauer D, Schäfer H (1968) J Less-Common Met 14:476

65. Kuhn A, Dill S, Meyer H-J (2005) Z Anorg Allg Chem 631:1565-1567

66. Pauling L (1960) The Nature of the Chemical Bond, $3^{\text {rd }}$ Ed., Cornell University Press, Ithaca, New York

67. Cotton FA, Haas RE (1964) Inorg Chem 3:10-17

68. Kettle SFA (1965) Theor Chim Acta 3:211-212

69. Guggenberger L, Sleight AW (1969) Inorg Chem 8:2041-2049

70. Bursten BE, Cotton FA, Stanley GG (1980) Israel J Chem 19:132-142

71. Le Beuze A, Makhyoun MA, Lissillour R, Chermette H (1982) J Chem Phys 76:6060-6066

72. Certain D, Le Beuze A, Lissillour R (1983) J Solid State Comm 46:7-10

73. Hughbanks T, Hoffmann R (1983) J Am Chem Soc 105:1150-1162

74. Woolley RG (1985) Inorg Chem 24:3519-3525

75. Johnston RL, Mingos DMP (1986) Inorg Chem 25:1661-1671

76. Mingos DMP, Johnston RL (1987) Struct Bond 68:29-87

77. Mingos DMP, Lin Z (1989) Z Phys D 12:53-59

78. Hughbanks T (1989) Prog Solid State Chem 19:329-372

79. Lin Z, Williams ID (1996) Polyhedron 15:3277-3287

80. Kaltsoyannis N (1997) J Chem Soc, Dalton Trans 1-11

81. Ogliaro F, Cordier S, Halet J-F, Perrin C, Saillard J-Y, Sergent M (1998) Inorg Chem 37:6199-6207

82. Ramirez-Tagle R, Arratia-Pérez R (2008) Chem Phys Lett 460:438-441

83. Schott $E$, Zarate $X$, Arratia-Pérez R (2012) Polyhedron 36:127-132

84. Kuc A, Heine T, Mineva T (2012) Struct Chem 23:1357-1367

85. Mingos DMP, Wales D (1990) Introduction to Cluster Chemistry, Prentice-Hall, Inc., Englewood Cliffs, New Jersey

86. Chevrel R, Sergent M, Prigent J (1971) J Solid State Chem 3:515-519

87. Matthias BT, Marezio M, Corenzwit E, Cooper AS, Barz HE (1972) Science 175:1465-1466

88. Anokhina EV, Day CS, Meyer H-J, Ströbele M, Kauzlarich SM, Kim H, Whangbo M-H, Lachgar A (2002) J Alloys Compd 338:218-228

89. Fontaine B, Cordier S, Gautier R, Gulo F, Halet J-F, Perić B, Perrin C (2011) New J Chem 35:22452252 